Version d'auteur de l'article paru sous le titre « Euvrer, servir, souffrir. Réflexions sur la sémantique des activités médiévales », dans Michel LAUWERS (dir.), Labeur et production au sein des monastères de l'Occident médiéval, Turnhout, Brepols, 2021, p. 31-79.

CENTRE NATIONAL DE LA RECHERCHE SCIENTIFIQUE

Cultures et Environnements. Préhistoire, Antiquité, Moyen Âge

COLLECTION D'ÉTUDES MÉdIÉVALES DE NICE

VOLUME 17

\title{
LABEUR, PRODUCTION ET ÉCONOMIE MONASTIQUE DANS L'OCCIDENT MÉDIÉVAL
}

DE LA RÈGLE DE SAINT BENOÎT AUX CISTERCIENS
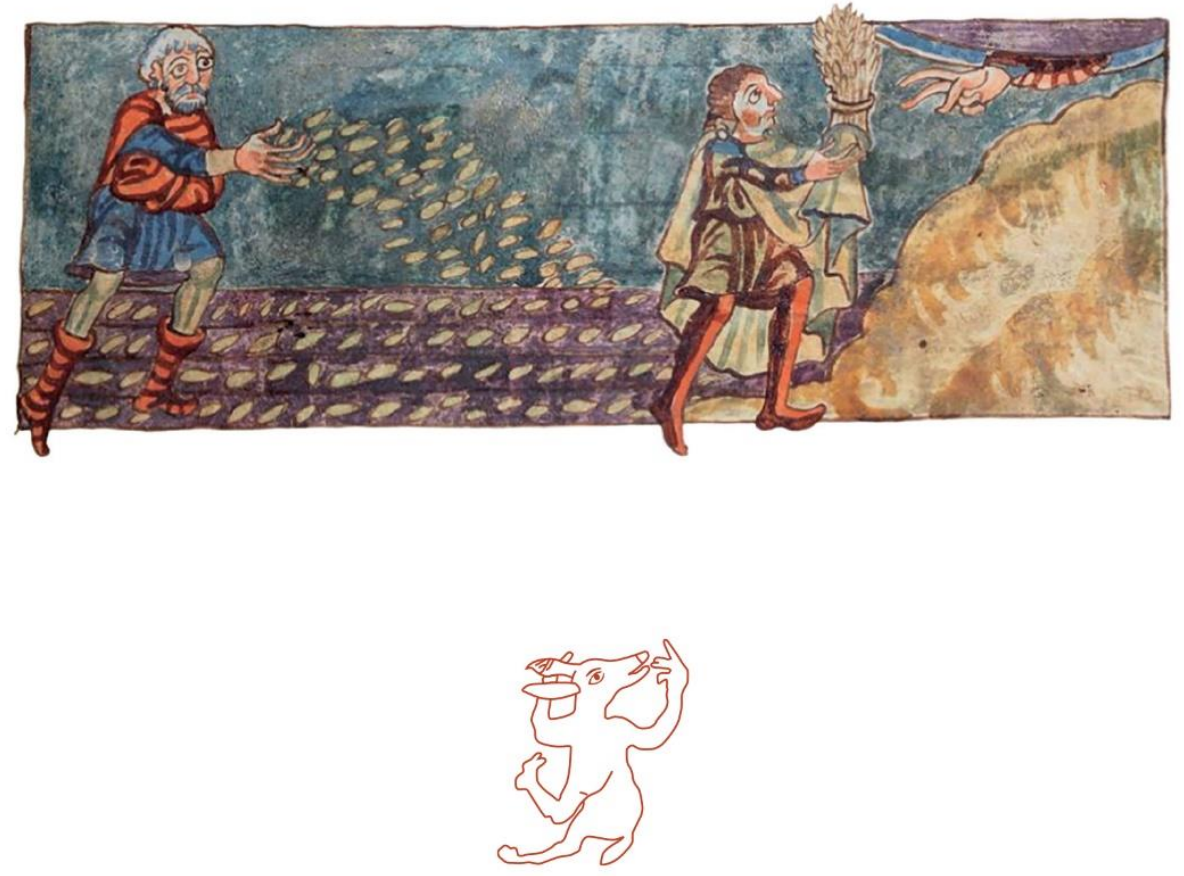

BREPOLS 


\title{
CEUVRER, SERVIR, SOUFFRIR
}

\section{REFLEXIONS SUR LA SEMANTIQUE DES ACTIVITES MEDIEVALES}

\author{
Nicolas Perreaux
}

\begin{abstract}
Depuis le XIX ${ }^{\mathrm{e}}$ siècle au moins, l'attitude des historiens face aux activités médiévales oscille principalement entre deux approches ${ }^{1}$. La première consiste à considérer que le « travail » forme peu ou prou une catégorie universelle, aux fondements sociologiques voire anthropologiques, dont il serait possible de partir afin d'en étudier les implications ${ }^{2}$. La seconde choisit de s'ancrer dans l'anthropologie et l'étude des termes médiévaux propres aux activités humaines, faisant souvent remarquer au passage que le concept de «travail » n'est pas directement présent dans la documentation de la période ${ }^{3}$. Cette seconde approche fut celle de Jacques Le Goff et de Robert Fossier ${ }^{4}$, qui suivirent indirectement l'hypothèse de Karl Marx sur l'émergence contemporaine du travail en général - sans toutefois en tirer pleinement les conséquences $^{5}$. En 1952, Marie-Dominique Chenu notait, lui aussi, avec une contrition sans doute un peu malicieuse, qu'il était « curieux, et bien douloureux, d'observer que, sinon depuis le Moyen Âge, âge de la théologie classique en Occident, du moins depuis le XVI ${ }^{\mathrm{e}}$ siècle, avec Vitoria et Suarez, il y [avait], chez les chrétiens, une théologie de la guerre [...], une théologie des affaires [...], une théologie de l'histoire [...]; mais il n'y [avait] pas de théologie du travail $»^{6}$. Le point de départ de notre enquête est donc le suivant : de l'avis de nombreux historiens, il n'existe pas de terme dans l'Europe médiévale pour désigner globalement ce que nous, contemporains, nommons le travail. Ce dilemme n'est certes pas propre au problème du
\end{abstract}

\footnotetext{
${ }^{1}$ Nous tenons à remercier vivement Paul Bertrand, Rosa-Maria Dessì, Alain Guerreau, Catherine Kikuchi, Ludolf Kuchenbuch, Michel Lauwers, Émilie Mineo, Didier Méhu, Joseph Morsel, Didier Panfili, François Rivière, Alain Rauwel et Nicolas Ruffini, pour leurs conseils éclairés lors de la réalisation puis la rédaction de cette enquête.

${ }^{2}$ Par exemple P. BoISSONNADE, Le travail dans l'Europe chrétienne au Moyen Âge (Ve-XI siècle), Paris, 1921 ; H. STAHLEDER, Arbeit in der mittelalterlichen Gesellschaft, München, 1972 ; A. EGGEBRECHT, J. FLEMMING, G. Meyer, A. Von MÜller, A. OpPolzer, A. PAUlinyi et H. SCHNEIDER, Geschichte der Arbeit. Vom Alten Ägypten bis zur Gegenwart, Köln, 1980.

${ }^{3}$ Cette double lecture pourrait faire écho à celle des sociologues du travail, qui distinguent entre approches « historiciste » et «essentialiste ». Voir D. MEDA, Le Travail, une valeur en voie de disparition, Paris, 1998 ; F. Gollain, Une critique du travail. Entre écologie et socialisme, Paris, 2000, en particulier le chapitre VIII. Sur l'étymologie du terme « travail », voir A. Eskénazi, «L'étymologie de Travail », Romania, 503-504, 2008, p. 296372, ainsi que la contribution de Stéphanie Le Briz dans le présent volume.

${ }^{4}$ «Le silence des documents du haut Moyen Âge sur le travail et les travailleurs est déjà significatif d'une mentalité » (J. LE GoFF, «Travail, techniques et artisans dans les systèmes de valeur du haut Moyen Âge $\left(\mathrm{V}^{\mathrm{e}}-\mathrm{X}^{\mathrm{e}}\right.$ siècle) », dans Pour un autre Moyen Âge. Temps, travail et culture en Occident : 18 essais, Paris, 1977, p. 108130, ici p. 109). J. Le Goff et R. Fossier notent tous deux qu'une lecture sémantique serait essentielle pour comprendre la logique des activités médiévales. Fossier évoque « la richesse du champ [sémantique] à parcourir » (dans R. FossIER, Le travail au Moyen Âge, Paris, 2000, p. 15). Mais tout en récusant l'idée d'un travail abstrait universel, ils n'excluent pas le concept de travail de leurs travaux et fondent une partie de leurs analyses sur ce terme. Ainsi pour Jacques Le Goff, « il est aussi légitime de chercher à savoir ce qui correspondait dans l'esprit de Charlemagne et de ses contemporains à notre appréciation du travail que d'appliquer à l'économie de cette époque la formule de Fisher qu'elle ignorait » (dans J. LE GoFF, « Travail, techniques et artisans », p. 109).

5 «Conçu sous l'angle économique, dans toute sa simplicité, le «travail » est cependant une catégorie aussi moderne que les rapports qui engendrent cette abstraction, pure et simple. », dans K. MARX, Fondement de la critique de l'économie politique, Paris, 1859, I :33. Voir aussi le passage de l'introduction du Grundrisse de 1857, cité dans l'introduction de Michel Lauwers. Réflexions stimulantes dans : E. RENAULT, «Comment Marx se réfère-t-il au travail et à la domination? », Actuel Marx, $\mathrm{n}^{\circ}$ 49, 2011, p. 15-31. Le paradoxe est que les médiévistes qui ont fait remarquer l'impropreiété du concept de «travail » au Moyen Âge sont parmi ceux qui ont le plus travaillé sur la question.

${ }^{6}$ M.-D. CHENU, « Pour une théologie du travail », Esprit, 186, 1952, p. 1-12, ici p. 3.
} 
« travail »: on le retrouve dans l'ensemble de l'historiographie du système de représentations médiévales ${ }^{7}$. Mais il est particulièrement sensible ici $^{8}$, car le concept de «travail » joue un rôle pivot dans notre système contemporain, colorant notre compréhension du monde et des rapports sociaux ${ }^{9}$.

Paradoxalement et en dépit de son omniprésence, il reste difficile de cerner le « travail » contemporain en tant que notion ${ }^{10}$. Les dictionnaires donnent le plus souvent des définitions contradictoires, dont l'applicabilité aux sciences humaines et sociales est incertaine ${ }^{11}$. L'une des plus pénétrantes demeure sans doute celle de Marx. L'auteur propose en particulier l'utilisation de quatre pôles permettant de décrire les rapports de production: «travail abstrait », «travail concret », «valeur d'échange » et «valeur d'usage ${ }^{12}$. Ce qui définit, selon

${ }^{7}$ A. Guerreau, «Vinea », dans M. Goullet et M. PARISSE (dir.), Les historiens et le latin médiéval, Paris, 2001, p. 67-73. Sur la sémantique historique du travail, voir en particulier : J. LEONHARD et W. STEINMETZ (dir.), Semantiken von Arbeit. Diachrone und vergleichende Perspektiven, Köln, 2016, et les références qui suivent.

${ }^{8}$ Différents bilans ont été donnés depuis quelques années, pour la perspective essentialiste : C. DoLAN (dir.), Travail et travailleurs en Europe au Moyen Âge et au début des temps modernes, Toronto, 1991 ; J. LE GoFF, «Travail», dans J. LE GofF et J.-C. SCHMiTT (dir.), Dictionnaire raisonné de l'Occident médiéval, Paris, 1999, p. 1137-1149 ; C. VERNA et P. BERNARDI, «Travail et Moyen Âge : un renouveau historiographique », Cahiers d'histoire : revue d'histoire critique, vol. 83 : Comment les historiens parlent-ils du travail ?, 2001, p. 27-46; P. Bernardi, M. ARnouX et P. Braunstein, «Travailler, produire. Eléments pour une histoire de la consommation », dans J.-C. SCHMITT et O.-G. OEXLE (dir.), Les Tendances actuelles de l'histoire du Moyen Age en France et en Allemagne, Paris, 2002, p. 537-554 ; C. JEHANNO, « Le travail au Moyen Âge, à Paris et ailleurs : retour sur l'histoire d'un modèle », Médiévales, 69, 2015, p. 5-17. Voir aussi : J. EHMER et C. LIS (dir.), The idea of work in Europe from Antiquity to Modern Times, Farnham, 2009 ; M. ARNOUX, Le temps des laboureurs. Travail, ordre social et croissance en Europe (XI ${ }^{e}$ XIV $V^{e}$ siècle), Paris, 2012 ; C. LIS et H. SOLY (dir.), Worthy Efforts: Attitudes to Work and Workers in Pre-Industrial Europe, Leyde, 2012, en particulier le chapitre «Christian Ideologies of Work », p. 99-155 (fondé uniquement sur des traductions) ; P. BECK, P. BERNARDI et L. FELLER (dir.), Rémunérer le travail au Moyen Âge. Pour une histoire sociale du salariat, Paris, 2014 ; L. PANI ERMINI (éd.), Teoria e pratica del lavoro nel monachesimo altomedievale, Spolète, 2015.

${ }^{9}$ Il n'est pas anodin que Ludolf Kuchenbuch, l'un des premiers médiévistes à avoir pensé la fracture conceptuelle entre le Moyen Âge européen et le système capitaliste, se soit particulièrement intéressé à la sémantique du processus de production: L. KUCHENBUCH et B. MiCHAEL, Feudalismus - Materialien zur Theorie und Geschichte, Francfort, 1977. En 2012, celui-ci écrivait encore : «Wenn der Gesellschaft die Arbeit auszugehen droht — in welchen historischen Voraussetzungen und Konstellationen gründet dann überhaupt ihre Vormacht und Allgemeinheit? Das war und ist eine genuin mediävistische Frage. », dans IDEM, Reflexive Mediävistik. Textus - Opus - Feudalismus, Francfort/New York, 2012, p. 25.

${ }^{10}$ Le Trésor de la langue française donne une série d'éléments peu articulés, allant du « travail obstétrical » à l'économie politique. Globalement, l'idée d'une activité contraignante, visant à tirer parti des ressources («éléments naturels ») «et/ou à la production de nouvelles choses, de nouvelles idées », en vue de créer des richesses, paraît prédominer. Cette définition est proche de celle qui émerge aux XVII ${ }^{\mathrm{e}}$ XVIII ${ }^{\mathrm{e}}$ siècles, en lien direct avec celle de « valeur », chez les fondateurs de l'économie politique (Antoine de Montchrestien, Pierre Le Pesant de Boisguilbert, William Petty, Adam Smith, John Locke, etc.). Nous ne contestons pas que certains économistes ont repris des éléments issus de la théologie, mais pensons que cet apport fut radicalement remanié pour correspondre au nouveau cadre de pensée dominant qui émerge alors. Sur cette filiation, dans une perspective différente de la nôtre, voir S. PIRON, L'Occupation du monde, Bruxelles, 2018. À l'inverse, l'idée du « travail obstétrical », de la «femme en travail » (sens lattéral dans la sémantique globale du « travail » contemporain), nous semble directement dérivée du labor médiéval.

${ }^{11}$ En règle général, les articles de dictionnaires consacrés au « travail » ne proposent aucune perspective historique. Une enquête autour du concept de « ressource(s) » avait permis d'observer des résultats similaires : D. HAUSMANN et N. PerreAuX, «Resources. A Historical and Conceptual History », dans I. AMELUNG, H. LEPPIN, C.A. MÜLLER (dir.), Discourses of Weakness and Resource Regimes. Trajectories of a New Research Program, Francfort, 2018, p. 179-208. Ce parallélisme est probablement lié à la nature même et à l'importance des deux concepts dans le processus de production contemporain.

12 Sur l'apport de Marx à l'analyse du travail, nous renvoyons à la synthèse de J. BIDET, « Travail », dans G. BENSUSSAN et G. LABICA (dir.), Dictionnaire critique du marxisme, Paris, 1982, p. 1176-1179. En 2013, Alain Guerreau a donné une conférence (inédite) concernant le processus de production médiéval, à laquelle nous avions pu assister - nous remercions l'auteur de nous avoir confié les supports visuels de cette communication. 
Marx, la spécificité du travail capitaliste, c'est la possibilité de toujours considérer les rapports de production sous l'angle de la «valeur » (c'est-à-dire un «travail-marchandise », lui-même étroitement lié au temps capitaliste et au marché). Or, dans le cas du système médiéval, l'immense partie des cultures, constructions, fonctions et autres créations n'était pas réalisée dans le but de générer cette «valeur d'échange », puisque celles-ci étaient principalement autoconsommées ou destinées à un but précis, et ne pouvaient circuler librement ${ }^{13}$. On peut même penser que l'échange généralisé des productions était antinomique à l'Europe médiévale $^{14}$ : son existence aurait permis des permutations incongrues, dans un système où les transferts étaient encadrés, et la capacité à faire circuler elle-même fortement contrôlée-limitée par la classe dominante. À l'inverse, une part fondamentale des éléments sémantiques intégrés à des termes habituellement désignés comme relevant du «travail » au Moyen Âge renvoyaient à des champs tout autre que celui-ci. Il suffit de rappeler, par exemple, que le syntagme opus Dei désignait la liturgie, en particulier les prières, mais aussi plus ponctuellement la messe ${ }^{15}$. La difficulté à affronter ici est donc double : d'une part, de l'avis de nombreux chercheurs, le concept de travail en général n'existait pas dans les sociétés précapitalistes, a fortiori pour la période qui nous retient ; d'autre part, les définitions courantes du travail contemporain sont protéiformes, pour ne pas dire hétérogènes, tandis que les définitions scientifiques requièrent un haut degré d'abstraction ${ }^{16}$. Plusieurs questions émergent alors : les corollaires de notre « travail » contemporain (e.g. marché, travailleurs, salaire, ressources, outils), dont la présence semble nécessaire à celle du «travail », existaient-ils dans l'Europe médiévale ? Sinon, que signifiaient les termes médiolatins que l'historiographie associe souvent au «travail » (opus, labor, servitium, ars, officium, etc.) ? Entretiennent-ils des rapports structurés entre eux ou avec d'autres champs lexico-sémantiques ? Enfin, quelles méthodes et perspectives pourraient nous aider à mieux comprendre les rapports de production médiévaux, au-delà du lexique que l'on a évoqué ?

L'introduction de Michel Lauwers au présent volume recourt à deux termes, «labeur» et « rapports de production », selon la démarche qu'il avait déjà présentée en 2017 à Spolète ${ }^{17}$. Elle s'inscrit dans la lignée assez rare des travaux consacrés aux représentations des activités dans l'Europe médiévale, dans une perspective de sémantique historique. Différentes enquêtes ont en effet tenté de définir le rapport des médiévaux aux activités vivrières, de construction, mais aussi intellectuelles - dont on pourrait précisément se demander si elles formaient véritablement un tout ${ }^{18}$. L'apport le plus important en la matière reste sans doute celui de Ludolf

\footnotetext{
${ }^{13}$ Voir les travaux de Julien Demade mentionnés plus bas.

${ }^{14}$ A. GuerreaU, «Avant le marché, les marchés : en Europe, XIII - XVIII ${ }^{\mathrm{e}}$ siècle (note critique) », Annales HSS, vol. 56:6, 2001, p. 1129-1175.

${ }^{15}$ Par exemple : Intervallum quod inter opus Dei et horam refectionis contigerit aut orando aut legendo transigunt, dans la règle de Simpert de Murbach, Regularia statuta, dans PL 99, col. 737-746a, ici col. 743d. Voir G. AgAmben, Homo Sacer. II, 5, Opus Dei : archéologie de l'office, Paris, 2012.

16 Voir H.-D. KITTSTEINER, Naturabsicht und Unsichtbare Hand. Zur Kritik des geschichtsphilosophischen Denkens, Francfort, 1980.

${ }^{17}$ M. LAUWERS, «Opus manuum et labor agrorum. À propos de l'organisation socio-spatiale de la production et de l'approvisionnement des monastères dans l'Occident médiéval », dans Monachesimi d'oriente e d'occidente nell'alto medioevo. Atti della LXIV Settimana sull'alto medioevo, Spoleto, 31 marzo-6 aprile 2016, Spoleto, 2017, p. 877-912 ; IDEM, « Le "travail" sans la domination? Notes d'historiographie et de sémantique à propos du labeur des cultivateurs dans l'Occident médiéval », dans A. DIERKENS, N. SCHROEDER et A. WILKIN (dir.), Penser la paysannerie médiévale, un défi impossible? Recueil d'études offert à Jean-Pierre Devroey, Paris, 2017 (Histoire ancienne et médiévale, 148), p. 303-332, ici p. 311-317.

18 J. HAMESSE et C. MURAILle-SAMARAN (dir.), Le travail au Moyen Âge. Une approche interdisciplinaire, Louvain-la-Neuve, 1990 ; G. OVITT, « Manual labor and early medieval monasticism », Viator, 17, 1986, p. 1-18 ; Arbeit im Mittelalter: Vorstellungen und Wirklichkeiten, éd. V. Postel, Berlin, 2006 ; P. MANE, Le travail à la campagne au Moyen âge: étude iconographique, Paris, 2006 ; V. POSTEL, Arbeit und Willensfreiheit im Mittelalter, Stuttgart, 2009 ; C. MEIER, «Labor improbus oder opus nobile? Zur Neubewertung der Arbeit in
} 
Kuchenbuch, qui débuta des enquêtes sur la question dès la fin des années $1980^{19}$. Plus récemment, les travaux de Julien Demade montrent que l'évacuation du concept travail en général pour l'étude des sociétés précapitalistes ne conduit pas à un appauvrissement des perspectives, mais au contraire à un enrichissement ${ }^{20}$. En dépit de ces recherches, on reste frappé par la différence entre l'usage massif du concept de «travail » chez les historiens et la rareté des études lexicales consacrées au processus de production médiéval et aux activités ${ }^{21}$.

Bien que délicate ${ }^{22}$, cette enquête systématique nous semble aujourd'hui possible grâce à la diffusion de vastes corpus documentaires, qui se sont multipliés au cours des dernières années $^{23}$. Nous disposons en effet d'ensembles textuels numérisés aussi riches que la Patrologie Latine (100 millions de mots, désormais $P L$, qui couvre la période allant du $\mathrm{III}^{\mathrm{e}}$ au début du XIII ${ }^{\mathrm{e}}$ siècle, et reste incontournable pour toute étude globale sur le système de représentations médiéval), le Corpus Thomisticum (environ 13 millions de mots, XIII ${ }^{\mathrm{e}}$ siècle) ${ }^{24}$, des textes antiques non-chrétiens ( 6 millions de mots, essentiellement du $\mathrm{II}^{\mathrm{e}}$ siècle avant au $\mathrm{II}^{\mathrm{e}}$ siècle après J.C., pour contre-épreuve) et la Vulgate ( 0,7 million). À cela s'ajoutent des ensembles de documents diplomatiques, que nous avons réunis depuis une dizaine d'années dans une base cohérente intitulée Cartae Europae Medii Aevi (CEMA). Celle-ci contient aujourd'hui 230000 documents (environ 75 millions de mots, avec des textes couvrant essentiellement les $\mathrm{VI}^{\mathrm{e}}-\mathrm{XV}^{\mathrm{e}}$ siècles). Cette masse documentaire induit que les perspectives dégagées, souvent invisibles à l'œil $\mathrm{nu}^{25}$, sont nécessairement globales et invitent à d'autres enquêtes. Cette perspective n'empêche en rien d'autres lectures des documents, à des échelles plus fines, qui restent strictement nécessaires et surtout complémentaires.

philosophisch-theologischen Texten des 12. Jahrhunderts », Frühmittelalterliche Studien, vol. 30, 1996, p. 315342. Toutes ces études ne sont pas entièrement consacrées au lexique, mais contiennent néanmoins des éléments sur cette question. On trouvera des réflexions très intéressantes et neuves dans M. BLANCHARD, De materialibus ad immaterialia. Le rôle de la matière dans l'œuvre de Suger de Saint-Denis, Québec, 2020.

19 Nous renvoyons à son texte dans le présent volume. Outre ses cours donnés à Hagen, intitulés Arbeit im vorindustriellen Europa, voir en particulier : L. KUCHENBUCH, « Mühsal, Werk, Kunst, Lohn. - Zur "Arbeit" im mittelalterlichen Ruhrgebiet», dans F. SEIBT (dir.), Vergessene Zeiten. Mittelalter im Ruhrgebiet. Katalog zur Ausstellung im Ruhrlandmuseum Essen, Essen, 1990, vol. 2, p. 103-110; IDEM, «Dienen als Werken. Eine arbeitssemantische Untersuchung der Regel Benedikts », dans J. LEONHARD et W. STEINMETZ (dir.), Semantiken von Arbeit, cit. n. 7, p. 63-92 ; IDEM, Reflexive Mediävistik: Textus - Opus - Feudalismus, cit. n. 9.

${ }^{20} \mathrm{~J}$. DEMADE, Ponction féodale et société rurale en Allemagne du sud (XI ${ }^{e}-X V I^{e}$ siècles). Essai sur la fonction des transactions monétaires dans les économies non capitalistes, Paris, 2004 (disponible sur HAL SHS) ; IDEM, «Valeur d'usage et valeur d'échange dans le système seigneurial : de la détermination sociale du rapport à la valeur », Genèses (à paraître).

${ }^{21}$ Une hypothèse de travail est que l'usage du terme masque précisément la spécificité et la logique du processus de production médiéval.

${ }^{22}$ On n'insistera jamais assez sur le fait que le recours à ces méthodes numériques ne peut pas être une opération de routine, relevant strictement de la «technique ». Le fantasme de la machine répondant aux interrogations des médiévistes est encore malheureusement assez répandu - et il est d'autant plus fâcheux qu'il entraîne son corollaire : la défiance pour ces méthodes, réputées non-historiennes.

${ }^{23}$ Voir la contribution d'Isabelle Rosé dans le présent volume, qui emploie elle aussi différents ensembles numérisés.

${ }^{24}$ Le corpus contient les textes de Thomas d'Aquin et de ses continuateurs directs.

${ }^{25}$ Dans le cadre des analyses, différents outils de formalisation (Perl, Python), de fouille textuelle (CWB, TXM, NoSketch Engine) et de statistique lexicale (R, en particulier les bibliothèques Cooc et Wordspace, respectivement développées par Alain Guerreau et Stefan Evert) ont été employés. Ils ne sont toutefois utilisables que dans la mesure où les ensembles textuels évoqués ont été lemmatisés, en l'occurrence grâce au lemmatiseur développé dans le cadre de l'ANR Omnia : B. BON, «Omnia - Outils et Méthodes Numériques pour l'Interrogation et l'Analyse des textes médiolatins (I, II et III) », Bulletin du Centre d'études médiévales d'Auxerre (BUCEMA), 13, 2009, p. 291-292; 14, 2010, p. 251-252; 15, 2011 (http://journals.openedition.org/cem/12015). 


\section{PEUT-IL Y AVOIR « TRAVAIL » SANS « TRAVAILlEUR » ?}

\section{I.1. L’influence de la « théorie des trois ordres »}

Avant de traiter à proprement parler des termes liés au processus productif médiéval, il a semblé pertinent de revenir sur la catégorie des « travailleurs », fréquemment employée dans l'historiographie. Il est certes entendu que les documents médiévaux évoquent des personnes s'adonnant à différentes activités, contraintes ou non, pour elles-mêmes, pour le compte d'un tiers ou encore d'une institution ${ }^{26}$. Mais dans quelle mesure peuvent-elles être considérées comme un groupe cohérent, à l'instar des «travailleurs » ou des « ouvriers » contemporains? La question n'est pas anodine : il semble en effet qu'il existe un lien consubstantiel entre le concept de «travail $»$ et celui de $«$ travailleur(s) $»^{27}$.

Or, les médiévistes usent fréquemment de la catégorie historiographique des laboratores. Elle fait partie des termes latins employés pour désigner des concepts historiens, sans que le lien entre ce dernier et les termes médiévaux soit clairement défini ${ }^{28}$. Cette catégorie s'est diffusée largement en histoire du Moyen Âge dans le contexte de la «théorie des trois ordres $»^{29}$. Issue de l'anthropologie, de la linguistique comparée et plus spécifiquement du «principe de la trifonctionnalité » de Georges Dumézil ${ }^{30}$, celle-ci a connu un certain succès auprès de différentes figures de la médiévistique dans les années 1960-1980, mais reste discutée aujourd'hui encore ${ }^{31}$. Pensée lors du séminaire de Georges Duby, auquel se joint alors Jacques

\footnotetext{
${ }^{26}$ Par exemple : M. ARnOUX, « Relation salariale et temps du travail dans l'industrie médiévale », Le Moyen Âge, 115,2009 , p. 557-581. Cette présence d'acteurs de la production n'est toutefois pas systématique : dans sa contribution au présent volume, Nicolas Schroeder rappelle que se sont parfois les tenures qui doivent rendre quelque chose aux dominants, et non ceux qui les cultivent. Ce qui constitue en soi une conséquence structurelle de la fusion des hommes et des terres dans le dominium : voir A. GUERREAU, Le féodalisme. Un horizon théorique, Paris, 1980.

${ }^{27}$ Une recherche dans un corpus de romans du XIX ${ }^{\mathrm{e}}$ siècle montre que le terme « ouvrier(s) » apparaît dans les principaux cooccurrents du lemme «travail». On y trouve aussi «construction», «nécessité », «pénible », « exécuter », « heure » ou encore «salaire ». Voir aussi le très significatif passage d'Hannah Arendt relevé par Michel Lauwers dans son introduction au présent volume, où cette dernière évoque « la glorification théorique du travail » auX XVIII - XIX ${ }^{\mathrm{e}}$ siècle, ayant abouti « à transformer la société toute entière en une société de travailleurs. », dans H. ARENDT, L'Humaine Condition, éd. par Ph. Raynaud, Paris, 2012, p. 62. On retrouve cette association entre travail et travailleurs très fréquemment dans les travaux consacrés à la production contemporaine, par exemple dans P. Bourdieu (avec A. DARBEL, J.-P. RIVET, C. SEIBEL), Travail et travailleurs en Algérie (II), ParisLa Haye, 1963. Enfin, si l'outil Ngram Viewer de Google a souvent été décrié, il permet d'observer que les tendances à la hausse et à la baisse des formes «travail » et «travailleurs » sont strictement parallèles dans le corpus français de Google Books, entre 1800 et 2019.

${ }^{28}$ Le même problème se pose en effet pour une importante série de concepts, qui va de reformatio à memoria, en passant par paternitas (pour évoquer quelques cas que nous avons récemment proposé d'analyser).

${ }^{29}$ G. DUBY, Les trois ordres ou l'imaginaire du féodalisme, Paris, 1978. Les premières enquêtes de Georges Duby sur la question débutent en 1970, ainsi qu'il le relate dans sa préface à l'ouvrage. Sur certaines interprétations et continuations de la proposition de Duby, voir l'analyse d'H.-W. GoETZ, « Les ordines dans la théorie médiévale de la société : un système hiérarchique ? », dans D. IOGNA-PRAT, F. BOUGARD et R. LE JAN (dir.), Hiérarchie et stratification sociale dans l'Occident médiéval 400-1100, Paris, 2008, p. 221-236. Sur ce texte, voir plus généralement P. BOUCHERON et F. BRANDY, «Les Trois Ordres : archéologie textuelle de la complexité », dans P. Boucheron et J. Dalarun (dir.), Georges Duby, portrait de l'historien en ses archives, Paris, 2015, p. $246-273$.

${ }^{30}$ G. DUMEZIL, L'idéologie tripartie des Indo- Européens, Paris, 1958 ; IDEM, Mythe et épopée, tome I : L'idéologie des trois fonctions dans les épopées des peuples indo-européens, Paris, 1968 (nouvelle édition corrigée en 1986) ; sur la réception de cette théorie en médiévistique, voir l'analyse de J. LE GoFF, «Les trois fonctions indoeuropéennes, l'histoire et l'Europe féodale », Annales ESC, 34:6, 1979, p. 1187-1215 ; ainsi que B. GREVIN, «La trifonctionnalité dumézilienne et les médiévistes : une idylle de vingt ans », Fancia, 30:1, 2003, p. 169-189

${ }^{31}$ Outre les travaux déjà mentionnés : J. LE GoFF, « Note sur la société tripartie, idéologie monarchique et renouveau économique dans la chrétienté du IX ${ }^{\mathrm{e}}$ au XII ${ }^{\mathrm{e}}$ siècle », dans T. VON MANTEUFFEL et A. GIEYSZTOR (éd.), L'Europe aux IXe-XI siècles, Varsovie, 1968, p. 63-71 (repris dans Pour un autre Moyen Âge, cit. n. 4, p. 80-90) ; IDEM, «Les trois fonctions indo-européennes. L'historien et l'Europe féodale », Annales ESC, 34, 1979, p. 11871215 ; D. DubUISSON, «L'Irlande et la théorie médiévale des «trois ordres » », Revue de l'histoire des religions,
} 
Le Goff, mais aussi d'autres historiens comme Marcel David, la théorie participe aux réflexions intellectuelles et sociales du $\mathrm{XX}^{\mathrm{e}}$ siècle autour des «classes», des «ouvriers » et des «travailleurs ». En simplifiant, son énoncé est le suivant : la « division du travail médiévale » se serait orientée progressivement vers une construction ternaire, distinguant ceux qui prient, ceux qui luttent et ceux qui travaillent (i.e. les laboratores) ${ }^{32}$. Pour Jacques Le Goff, l'émergence de ce schéma au $\mathrm{X}^{\mathrm{e}}$ siècle correspond à une promotion des «travailleurs », qui accédent alors à un statut propre, tandis que Georges Duby y voit une volonté de l'aristocratie de se distinguer en promouvant une «morale ségrégative $»^{33}$.

Une recherche dans l'ensemble de la $P L$ montre cependant que les occurrences de schémas de division sociale incluant laborator et orator, ou encore laboro et oro, sont extrêmement rares. Souvent déjà relevées par l'historiographie, nous pouvons en dénombrer quelques dizaines tout au plus dans les corpus à notre disposition, et de façon écrasante hors de tout schéma tripartite. Par ailleurs, la majeure partie de ces occurrences associent oro et laboro, et non orator et laborator. Cette dernière combinaison ne se rencontre en effet que deux fois

188, 1975, p. 35-63 ; O.-G. OEXLE, « Die funktionale Dreiteilung der "Gesellschaft" bei Adalbero von Laon. Deutungsschemata der sozialen Wirklichkeit im früheren Mittelalter », Frühmittelalterliche Studien, 12, 1978, p. 1-54 ; IDEM, «Tria genera hominum. Zur Geschichte eines Deutungsschemas der sozialen Wirklichkeit in Antike und Mittelalter », dans L. FENSKE, W. RÖSENER et T. ZOTZ (dir.), Institutionen, Kultur und Gesellschaft im Mittelalter. Festschrift für Josef Fleckenstein zu seinem 65. Geburtstag, Sigmaringen, 1984, p. 483-500 ; IDEM, «Die funktionale Dreiteilung als Deutungsschema der sozialen Wirklichkeit in der ständischen Gesellschaft des Mittelalters », dans H. GABEL et W. SCHUlzE (dir.), Ständische Gesellschaft und soziale Mobilität, München, 1988, p. 15-51 ; M. RouCHE, « De l'Orient à l'Occident. Les origines de la tripartition fonctionnelle et les causes de son adoption par l'Europe chrétienne à la fin du $X^{e}$ siècle », dans Occident et orient au $X^{e}$ siècle, Paris, 1978, p. 31-49 (Actes des congrès de la SHMESP, 9) ; D. IOGNA-PRAT, « Le "baptême" du schéma des trois ordres fonctionnels. L'apport dans l'école d'Auxerre de la seconde moitié du IX ${ }^{\mathrm{e}}$ siècle », Annales, 41, 1986, p. 101-126 (qui pointe précisément l'intrérêt d'un usage ponctuel d'un tel schéma, dans des contextes socio-historiques particuliers); J. MORSEL, L'aristocratie médiévale, $V^{e}-X V^{e}$ siècle, Paris, 2004, p. 167-169 ; D. FRAESDORFF, «Beten für die Gesellschaft. Die oratores-Theorie als Deutungsmodell der sozialen Wirklichkeit im Mittelalter », Historisches Jahrbuch, 125, 2005, p. 3-38.

${ }^{32} \mathrm{La}$ division du travail est un thème central de la transformation systémique des XVII ${ }^{\mathrm{e}}$-XVIII ${ }^{\mathrm{e}}$ siècles. Elle justifie chez Adam Smith la subordination totale des acteurs au nouvel ordre social, qui doivent se plier à cette division, celle-ci permettant en retour de déboucher sur l'augmentation de la production, et donc la création de la valeur: «The greatest improvement in the productive powers of labour, and the greater part of the skill, dexterity, and judgment with which it is anywhere directed, or applied, seem to have been the effects of the division of labour. ", dans A. SMith, An Inquiry into the Nature and Causes of the Wealth of Nations, Londres, George Routledge, 1776 (chap. I: Of the Division of Labour), p. 5. Il est difficile de savoir à quel point G. Duby a été influencé par Durkheim, et encore plus par Smith, puisqu'il ne les cite pas dans son ouvrage. Le syntagme « division du travail » apparaît néanmoins une fois (p. 780 de la réédition en Quarto, Gallimard, 1996), de même que l'expression « divisions sociales » (p. 803, dans le même volume). Quant au terme « division », il est présent une trentaine de fois. Il s'inscrit cependant dans une tendance générale, puisque que le syntagme « division du travail » connaît un pic d'occurrences dans le corpus Google Books entre 1950 et 2000, le maximum semblant atteint vers 1979.

${ }^{33}$ P. BOUCHERON et F. BRANDY, «Les Trois Ordres : archéologie textuelle de la complexité », cit. n. 29. D'autres hypothèses sur ces schémas ont été émises : pour Dominique Iogna-Prat, ceux-ci sont élaborés dans le contexte de concurrence entre les évêques et certains monastères, en particulier autour de Saint-Germain d'Auxerre (cf. D. IOGNA-PRAT, « Le "baptême" du schéma des trois ordres fonctionnels », cit. n. 31, p. 118). Hans-Werner Goetz insiste quant à lui sur la variété des schémas sociaux proposés les auteurs médiévaux (H.-W. GoETZ, «Les ordines », cit. n. 29, p. 223-226), qui sont de fait en écrasante majorité binaires, variables et non ternaires. Dans cette perspective, on renvoie aux analyses plus larges de Joseph Morsel et d'Anita Guerreau-Jalabert sur l'analogisme et les couples binaires dans le système de représentations médiéval : J. MoRSEL, « Dieu, l'homme, la femme et le pouvoir. Les fondements de l'ordre social d'après le 'Jeu d'Adam' », dans M. GoulLET (dir.), Retour aux sources. Textes, études et documents d'histoire médiévale offerts à Michel Parisse, Paris, 2004, p. 537-549; IDEM, « Soziale Kategorisierung oder historische Phantasmagorie? Erkundungen zum historischen Gebrauch von mittelalterlichen sozialen Kategorien », dans H.-P. BAUM, R. LENG, J. SCHNEIDER (dir.), Wirtschaft - Gesellschaft - Mentalitäten im Mittelalter. Festschrift zum 75. Geburtstag von Rolf Sprandel, Stuttgart, 2006, p. 211-237; A. GUERREAU-JALABERT, «Occident médiéval et pensée analogique : le sens de spiritus et caro », dans J.-P. GENET (dir.), La légitimité implicite, Paris-Rome, 2015, p. 457-476. Voir aussi les ouvrages cités note 148. 
dans toute la PL (à une distance de plus ou moins cinq mots). La première mention du couple laborator-orator apparaît dans un schéma quadripartite, au sein d'un opuscule autrefois attribué à Bède ${ }^{34}$. Celui-ci évoque la création du mundus à l'image d'une aula, dans laquelle quatre colonnes correspondent à quatre groupes d'hommes: oratores, defensores, mercatores, laboratores $^{35}$. Cette proposition fait écho, selon l'auteur, aux quatre éléments et aux quatre parties du monde. Dans ce schéma, le rôle des laboratores n'est certes pas faible : le pseudoBède insiste sur le fait que de cette colonne dépend le monde, puisque c'est sur elle que tout repose. La seconde occurrence de l'association entre orator et laborator se rencontre $\mathrm{XI}^{\mathrm{e}}$ siècle, dans le commentaire des Épîtres pauliniennes de Bruno le Chartreux ${ }^{36}$. Celui-ci souligne l'interdépendance des fonctions sociales : ceux qui prient (oratores) assurent le salut des laboratores (salvarentur), tandis que ces derniers sustentent les premiers (sustentarentur).

Une recherche étendue du lemme, au-delà des schémas tripartites/quadripartites que nous venons d'évoquer, confirme que les occurrences de laborator sont extrêmement faibles. On relève tout d'abord qu'il est absent aussi bien des textes antiques païens que de la Vulgate ${ }^{37}$. Le terme apparaît certes par la suite dans la $P L$, mais de façon marginale : environ 35 mentions au total, sur un corpus contenant plus de 100 millions de mots ${ }^{38}$. Le laborator est donc bien une création lexicale des auteurs médiévaux, mais son rôle est tout à fait mineur dans les représentations médiévales, au moins jusqu'au XIII ${ }^{\mathrm{e}}$ siècle $^{39}$. Cette situation est d'autant plus remarquable que les lemmes orator et bellator, qui lui sont associés dans la théorie des trois ordres, sont quant à eux plus fréquents. On dénombre en effet respectivement 1332 et 1229

\footnotetext{
${ }^{34}$ De Quatuor Ordinibus. Ceciderunt columne sustinentes aulam, et ideo obruitur aula. Dominus noster Jesus Christus fecit unam aulam, id est, mundum ; et hanc aulam fecit de quatuor rebus, id est, de quatuor elementis, que sunt ignis, aer, terra, aqua; et in hac aula fecit quatuor angulos, id est, quatuor partes mundi, Orientem, Meridiem, Occidentem et Septentrionem. Ad istam aulam sustinendam constituit Dominus quatuor columnas, que sustinuerunt aulam illam, id est, quatuor ordines hominum : scilicet, oratores, defensores, mercatores, laboratores. [...] Laboratores constituit, ut de labore eorum alii tres ordines pascerentur. Isti uero faciunt bene hoc, ad quod constituti sunt, sicut dicitur in Psalmo: "Labores manuum tuarum, quem qui manducant, beati sunt ». Sed ipsi cum sic possent uiuere iuste, de proprio labore et sudore, et inde populum Dei pascere, et sic sustinere aulam, ne omnino caderet, et sic pervenirent ad regnum Dei [...] (Excerptiones Patrum, dans PL 94, col. 539-560a, ici col. 556c-557b). Ce texte est aussi mentionné par O.-G. OEXLE, «Die funktionale Dreiteilung », cit. n. 31, p. 34 ; H.-W. GoETZ, « Les ordines », cit. n.29, p. 234. L'incertitude concernant la datation du document est forte. Henri de Lubac propose de son côté un terminus post quem au milieu du VIII ${ }^{\mathrm{e}}$ siècle, dans H. DE LUBAC, Exégèse médiévale. Les quatre sens de l'écriture, partie 1, Paris, 1959, p. 265. Mais cette datation est liée au fait qu'aucune source citée n'est postérieure au VIII ${ }^{\mathrm{e}}$ siècle. En 1955, W. Suchier faisait quant à lui l'hypothèse que le texte pourrait être une compilation du XVI ${ }^{\mathrm{e}}$ siècle, le manuscrit de l'édition de la $P L$ étant inconnu : W. SUCHIER, Das mittellateinische Gespräch 'Adrian und Epictitus' nebst verwandten Texten (Joca monachorum), Tübingen, 1955, p. 137-138 (nous remercions vivement Xavier Payet pour cette dernière référence). L'édition de $P L$ semble en effet issue des Opera Venerabilis Bedae, Bâle, 1563, col. 668-669, sans que cette dernière donne des informations sur les manuscrits originaux.

${ }^{35} \mathrm{Cf}$. le texte mentionné dans la note précédente.

${ }^{36}$ Nec ita dico fiat equalitas, ut tantum accipiant imperfecti quantum perfectiores, sed in hoc equalitas, quod singuli singulos nummos accipient, id est perfectam et sufficientem beatitudinem. Ideo non statutum fuit ut alii hominum laborarent, alii orationi vacarent, ut oratores sustentarentur aliorum labore, laboratores vero salvarentur eorum oratione (Expositio in epistolas Pauli, dans PL 153, col. 11-568a, ici col. 256).

${ }^{37}$ Cette situation est doublement intéressante. D'une part, car si l'Europe médiévale reconfigure l'ensemble de la sémantique latine antique, elle hérite d'une bonne partie de son lexique. D'autre part, parce que la Vulgate constitue l'une des bases de la sémantique médiolatine, certes sans cesse réinterprêtée, mais toujours fondamentale. ${ }^{38}$ La forme laboratores apparaît quant à elle seulement 17 fois.

${ }^{39}$ Jacques Rossiaud mentionne la présence de 475 laboratores à Avignon entre 1475 et 1480, mais l'auteur montre bien que le terme renvoie essentiellement à des cultivateurs (J. RoSSIAUD, Lyon 1250-1550. Réalités et imaginaires d'une métropole, Seyssel, 2012, chapitre 9). Voir aussi la note 57 de cette contribution.
} 
mentions de ces lemmes dans la $P L^{40}$. Mais ils n'appartiennent pas, eux non plus, au vocabulaire courant. Un examen plus précis des occurrences de la $P L$ montre que laborator se développe très progressivement aux $\mathrm{VI}^{\mathrm{e}}-\mathrm{VII}{ }^{\mathrm{e}}$ siècles, sans doute d'abord chez Grégoire le Grand ${ }^{41}$, puis chez les auteurs carolingiens - dont Alcuin, Walafrid Strabon et Hincmar de Reims ${ }^{42}$. Quelques-unes des occurrences sont intéressantes, par exemple chez Hincmar, qui oppose les clercs et les laïcs nobiles aux ignobiles atque rustici laboratores ${ }^{43}$. Plus tard, au $\mathrm{X}^{\mathrm{e}}$ siècle, Rathier de Vérone précise que les laboratores peuvent être servi et liberi ${ }^{44}$. Une part non négligeable de ces mentions provient cependant de lettres (Alcuin, Wibald, Alexandre II, Bernard de Clairvaux, Hildegarde de Bingen, etc.). Les laboratores en effet sont quasi-absents de la documentation exégétique et théologique, y compris au XIII ${ }^{\mathrm{e}}$ siècle ${ }^{45}$. Il s'agit d'une

40 Ainsi que 631 et 65 dans les CEMA (où la différence fréquentielle entre orator et bellator est donc plus significative que dans la $P L$ ), et enfin 35 et 99 dans le Corpus Thomisticum (où la proportion des deux termes s'inverse, par rapport à la $P L$ et aux CEMA).

${ }^{41}$ Toutes les occurrences antérieures proviennent d'auctores incerti (pseudo-Jérôme, pseudo-Augustin, etc.), et ne peuvent pas être datées à ce stade de l'enquête. La première mention attestée de façon fiable est donc celle de Grégoire le Grand, Moralia in Job, dans PL 75, col. 509-1162b, ici col. 677b : Unde et non aeque laborantes in vinea (Mt XX:1), aeque cuncti denarium sortiuntur. Et quidem apud Patrem mansiones multae sunt, et tamen eumdem denarium dispares laboratores accipiunt; quia una cunctis erit beatitudo laetitiae, quamvis non una sit omnibus sublimitas vitae. Le passage est d'autant plus intéressant qu'il propose un saut du verbe (lemme laboro, ici laborantes) vers le substantif (laboratores).

${ }^{42}$ Hos tu efficacissimus divini operis laborator tota mentis intentione assequi satage, quatenus Christus ipse per te de tuae puppi carinae populis praedicare dignetur, et sit pius gubernator naviculae, ex qua te retia apostolicae praedicationis in pelagus profundissimae gentilitatis expandere iussit: quatenus illum per suae magnae pietatis miserationem tibi sociisque tuis praecipientem audias: "Afferte de piscibus quos prendidistis nunc " (Jean XXI:10) (Alcuin, Epistolae, dans PL 100, col. 139-512b, ici n XXXVI (Ad Arnonem), col. 193b) ; Christus tria refugia habuit, ut fugeret turbas, in monte, in deserto, in nave super mare; haec tria nobis relinquit: in altitudinem mandatorum, discendere in deserto, deserere vitia, et in unitate Ecclesiae intrare: navis Ecclesiam significat: ut qui habet gubernatorem et navigatores, et aqua qui iactant, hi de nave. Idem Episcopi, et laboratores, et qui ministeria intus faciunt, et tres offendunt naves, periculum in undis, in vento, in cilice, sic Ecclesia periculum, undis, temptationes diaboli, in vento peccatorum, in cilice falsis fratribus, quando ascendebant in montem significabat theorica, id est contemplativa: quando descendit, docet practica, id est, actuale, et cum sedisset, indicat incarnationem eius non apparuisse, quia qui sedit, vestimentum corpus suum defendit (Walafrid Strabon, Expositio In Quatuor Evangelia, dans PL 114, col. 861-916b, ici col. 872c, commentaire de Mat 8:18) ; Nam civitatem, in qua Comes inhabitat, et clerici ac laici nobiles, sed et ignobiles atque rustici laboratores, et etiam Judei ut fertur inhabitant [...] (Hincmar de Reims, Epistolae, dans PL 126, col. 9-280a, ici n XIII (De translationibus episcoporum, contra Actardum Namnetensem), col. 221a-221b).

${ }^{43}$ On retrouve ici le schéma bipartite, plus conforme à la logique de l'analogisme médiéval que la division tripartite, et fondé sur des couples binaires enchaînés.

${ }^{44}$ Omnes autem Ecclesiae filii, inter quos tu etiam numeraris, si tamen non dedignaris, si patrem ut Absalon, arbore vindice multandus, mucrore non persequeris (Reg XVIII:9) ; si vipereo matris viscera ore non rodis, attamen facias, facias tamen, inter eos numeraris, sed vide ne haereditate et cohaereditate illorum a temet frauderis, omnes, inquam, Ecclesiae filii aut de sorte sunt Domini et appellantur clerici et monachi; aut sunt Ecclesiae famuli, episcopi vero confamuli; aut laboratores, servi et liberi, aut milites regni (Rathier de Vérone, Praeloquia, dans PL 136, col. 145-344c, ici col. 236b). Concernant ce texte, voir N. CARRIER, « Travail et servitude paysanne aux $\mathrm{X}^{\mathrm{e}}$ et $\mathrm{XI}^{\mathrm{e}}$ siècles. Autour de Rathier de Vérone et Adalbéron de Laon », Histoire \& Sociétés Rurales, t. 51:1, 2019, p. 7-40.

${ }^{45}$ On trouve en effet seulement deux occurrences du lemme dans le Corpus Thomisticum, qui contient plus de 13 millions de mots : Consequenter cum dicit ego misi vos metere quod non laborastis, adaptat proverbium ad propositum, et primo dicit apostolos esse messores; secundo ostendit esse laboratores, ibi alii laboraverunt, et uos in labores eorum introistis (Thomas d'Aquin, Super Evangelium S. Ioannis lectura, Caput IV, Lectio IV) ; Et jumenta, et oves, et equos, et mancipia, et animas hominum, se dicunt habere, iumenta, domini id est fortes laboratores, qui portant onera aliorum (Hugues de Saint-Cher (?), Expositio super Apocalysim, Caput XVIII). 
situation intéressante, mais pas totalement inatendue : les missivies sont en effet souvent l'occasion pour les auteurs médiévaux d'employer un lexique soigné et parfois même rare ${ }^{46}$.

\section{I.2. À la recherche des laboratores}

Bien au-delà de la question des trois ordres (et donc des représentations), les laboratores sont pourtant omniprésents dans l'historiographie. On parle souvent de leur émergence entre le $\mathrm{X}^{\mathrm{e}}$ et le $\mathrm{XII}^{\mathrm{e}}$ siècle, de leur composition en tant que groupe social, voire de leur vision du monde ${ }^{47}$. Si Marcel David leur consacre deux articles dès $1959^{48}$, Jeffrey Fynn-Paul définit encore en 2018 les laboratores comme « un groupe hybride» entre «campagne et monde urbain $»^{49}$. Quelques années auparavant, Jacques Rossiaud notait qu'au XV $\mathrm{XV}^{\mathrm{e}}$ siècle, certains clercs considéraient les laboratores comme des «gens de basse condition », sans distinction d'activité précise, bien que cela ne soit pas systématiquement le cas ${ }^{50}$. Quant à Jacques Le Goff, il présente les laboratores comme une sorte d'élite paysanne : « la partie supérieure productrice, innovatrice, de la couche paysanne et artisanale, je dirais volontiers les producteurs, qui témoignent aussi d'une certaine promotion du travail dans l'idéologie et la mentalité médiévale autour de l'an Mille ${ }^{51}$. Enfin, en 2012, Mathieu Arnoux emploie aussi la catégorie dans son ouvrage Le temps des laboureurs. Elle évoque pour lui « un groupe social cohérent unifié par la pratique du travail $»^{52}$. Dans d'autres contextes encore, les historiens associent le terme de laboratores aux «laboureurs ». On note ainsi que la catégorie joue un rôle certain chez les médiévistes marqués par l'histoire socio-économique, par les Annales et par les réflexions sociales des années 1960-1970 sur les mouvements ouvriers. L'importance du concept s'étend toutefois au-delà de la médiévistique, puisque l'économiste Thomas Piketty le reprend par exemple dans son ouvrage Capitalisme et idéologie en $2019^{53}$.

Les laboratores seraient-ils beaucoup plus fréquents dans les chartes et les documents dits de la pratique (registres, comptes, règlements, etc.) ? Dans le corpus diplomatique des

\footnotetext{
${ }^{46}$ C'est aussi le cas du lemme paternitas, auquel nous avons consacré des recherches récemment, qui se diffuse en particulier par les lettres : N. PERREAUX, «In nomine patris», dans Histoires, langues et textométrie, éd. L. DUMONT, O. JULIEN et S. LAMASSE, Paris, à paraître.

${ }^{47}$ Les sociologues du travail ont parfois repris la chronologie des médiévistes sur l'émergence d'une « classe de travailleurs », identifiée au laboratores : D. MEDA, Le Travail, une valeur en voie de disparition, cit. n. 3, p. 56.

${ }^{48}$ M. DAVID, «Les laboratores jusqu'au renouveau économique des XI ${ }^{\mathrm{e}}$-XII ${ }^{\mathrm{e}}$ siècles », dans Études d'Histoire du droit privé offertes à Pierre Petot, Paris, 1959, p. 107-119; IDEM, «Les laboratores du renouveau économique, du XII à la fin du XIV siècle », Revue historique de droit français et étranger, 36, 1959, p. 174-195 et 295-325. Voir aussi IDEM, Les Travailleurs et le sens de leur histoire, Paris, 1967. On rappelle que Marcel David était présent aux premiers séminaires de Georges Duby consacrés à la théorie des trois ordres. Ce dernier le citera à différentes reprises par la suite (par exemple dans G. DUBY, «Recherches historiques sur les campagnes médiévales », Études rurales, 13-14, 1964, p. 71-78, ici p. 72), et il en va de même pour Jacques Le Goff.

${ }^{49}$ J. FynN-PAUL, Family, Work and Household in Late Medieval Iberia: A Social History of Manresa at the Time of the Black Death, New York, 2018, chap. 9.2.

${ }^{50}$ J. ROSSIAUD, Lyon 1250-1550, cit. n. 39, chapitre 9.

${ }^{51}$ J. LE Goff, L'Europe est-elle née au Moyen Âge ?, Paris, 2003, p. 24-25. Il rejoint donc ici Marcel David, pour qui le terme désigne certes «l'ensemble de ceux qui n'étaient ni clercs ni nobles, sans avoir pour autant à s'étendre au-delà du monde paysan », mais aussi « ceux des cultivateurs qui pour le travail des champs disposaient d'araires et d'animaux de trait » (M. DAVID, «Les laboratores du renouveau économique », cit. n. 48, p. 174).

${ }_{52}$ M. ARnOUX, Le temps des laboureurs. Travail, ordre social et croissance en Europe (XI -XIVe siècle), Paris, 2012, p. 57. Voir de même IDEM, «Manger ou cultiver : laboratores, oratores et bellatores entre production et consommation (XI ${ }^{\mathrm{e}}$-XIII ${ }^{\mathrm{e}}$ siècle) », dans L'Alimentazione nell'alto Medioevo. Pratiche, simboli, ideologie, Spolète, 2016, p. 939-962 (Settimane di studio della Fondazione Centro Italiano di Studi sull'Alto Medioevo, 63).

${ }^{53}$ T. PIKETTY, Capital et idéologie, Paris, 2019, p. 111 (chapitre 2) : son analyse se fonde précisément sur la théorie des trois ordres, sans doute à partir des travaux de G. Duby. Il est probable que sa lecture passe toutefois par celle de M. Arnoux.
} 
CEMA, nous avons dénombré moins de 200 occurrences du lemme laborator. Il s'agit bien entendu d'un score très faible. La forme la plus fréquente est laboratores, qui correspond au nominatif, au vocatif ou à l'accusatif pluriel, et qui totalise 96 occurrences $(\approx 53 \%)$. Suivent les datifs et ablatifs pluriels, laboratoribus, avec 35 mentions $(\approx 19 \%)$. Il ressort donc que les occurrences au pluriel sont très majoritaires, puisqu'elles correspondent aux presque troisquarts des apparitions du lemme. La chronologie du lemme laborator dans les chartes est cependant intéressante (fig. 1) : après une mention isolée au $\mathrm{IX}^{\mathrm{e}}$ siècle ${ }^{54}$, on note un frémissement du lemme au $\mathrm{X}^{\mathrm{e}}$ siècle (14 occurrences), mais surtout au XI ${ }^{\mathrm{e}}(52)$, puis $\mathrm{XII}^{\mathrm{e}}$ siècle (72), avant une chute bruale au XIII ${ }^{\mathrm{e}}$ siècle ${ }^{55}$. Peut-on pour autant parler d'un groupe social à l'échelle de l'Europe médiévale, émergeant au cours des $\mathrm{X}^{\mathrm{e}}-\mathrm{XII}^{\mathrm{e}}$ siècles ? Il semble pour le moins délicat d'extrapoler à partir d'un si faible nombre de mentions, du moins dans les textes diplomatiques.

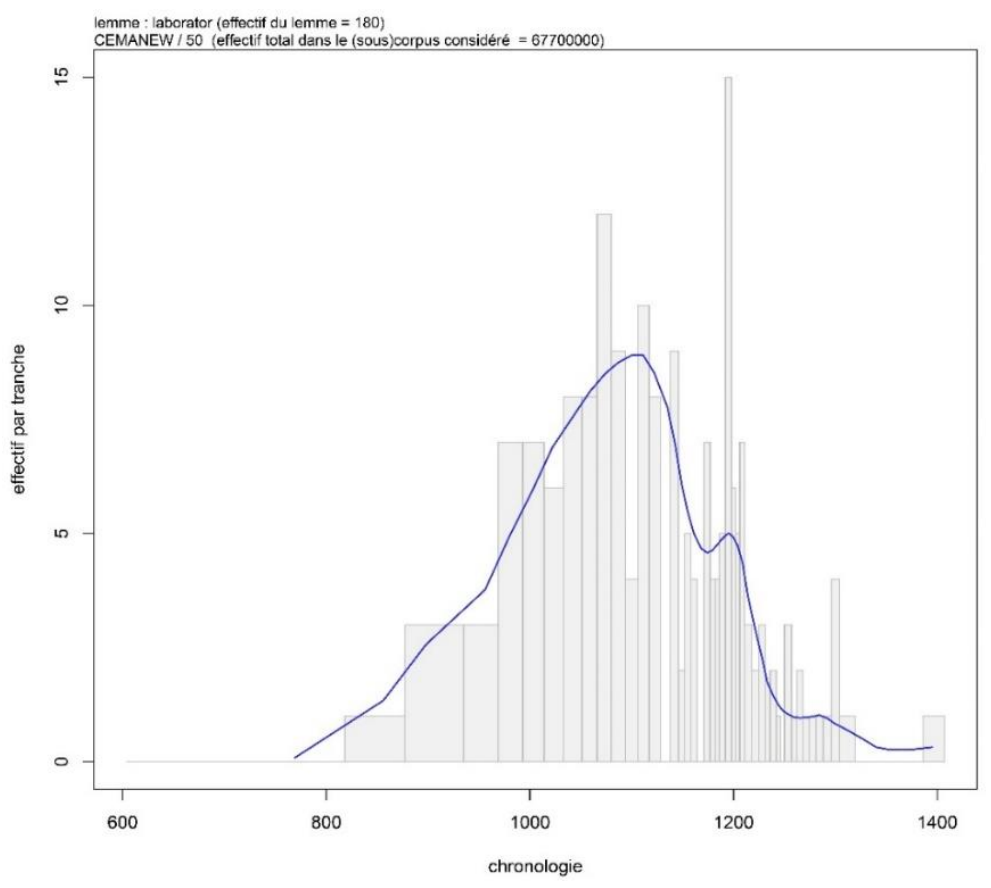

Fig. 1 : Évolution des mentions de laborator dans les chartes (CEMA, VII ${ }^{\mathrm{e}}-\mathrm{XIII}{ }^{\mathrm{e}}$ siècle).

Afin de compléter l'analyse, des enquêtes supplémentaires ont été menées dans les Acta Sanctorum, les OpenMGH, puis dans un corpus de textes théologiques du $\mathrm{XV}^{\mathrm{e}}$ siècle. Au sein de ce dernier ensemble, on relève seulement 11 occurrences de laborator, sur un total d'environ

\footnotetext{
54 [...] et hoc ipso retdito nos laboratores cum nostrum vegamus dispendium una vectura de vino [...] (dans le fonds de Sainte-Giulia de Brescia, en 822 : E. BARBIERI, I. RAPISARDA et G. CoSSANDI (éd.), Le carte del monastero di S. Giulia di Brescia. I 759-1170, Pavia, 2008, $\mathrm{n}^{\circ} 25$ ). Il s'agit en fait d'un acte de l'abbesse Eremperga de San Salvatore detto Nuovo, par lequel elle transfère une terre à un certain Rotperto di Movico, afin qu'il la cultive.

${ }^{55}$ Cette chute est très fréquemment observée, pour des lemmes relevant de différents champs lexicaux, lors du XIII ${ }^{\mathrm{e}}$ siècle et surtout aux $X V^{e}-X v^{e}$ siècles. Elle est principalement liée au fait que les chartes doivent, à l'échelle européenne, être divisée en au moins trois groupes chronologiques : avant le milieu du IX siècle; du milieu du IX siècle au XIII ${ }^{\mathrm{e}}$ siècle ; au-delà du XIII ${ }^{\mathrm{e}}$ siècle. Le groupe central correspond grosso modo à la phase d'encellulement du système européen (bien que ce phénomène soit très variable chronologiquement d'une zone à l'autre). Il n'est donc pas étonnant de voir le terme laborator chuter, comme d'autres, alors que les chartes évoquent de nouvelles questions sociales - et plus nécessairement les transferts de terres, comme lors de la phase centrale.
} 
5,8 millions de mots. Il faut d'ailleurs noter que 6 de ces mentions sont présentes dans le Malleus Maleficarum d'Heinich Kramer (1486-1487). Cette situation est intéressante, car l'ouvrage évoque indirectement la crise sociale qui frappe alors le système de l'Europe médiévale. Plus globalement, tous les résultats se sont avérés très cohérents avec ce qui avait été observé précédemment ${ }^{56}$. Ainsi, les mentions de laborator sont rares, voire très rares dans les corpus examinés, depuis les Pères de l'Église jusqu'au XV $\mathrm{XV}^{\mathrm{e}}$ siècle $^{57}$.

Se pourrait-il alors que les «travailleurs » ou laboratores des historiens soient désignés dans les textes par d'autres termes latins ? Une enquête rapide sur un lemme parfois évoqué dans les mêmes contextes historiographiques, operarius, fait apparaître des tendances proches : les mentions sont moyennement fréquentes, et renvoient régulièrement à la thématique des « ouvriers de la onzième heure » (Mat. 20,1-16) ${ }^{58}$. Tout se passe donc comme s'il n'existait pas de catégorie unifiée pour désigner et penser les «travailleurs » médiévaux en tant que groupe, au moins jusqu'au XIV ${ }^{\mathrm{e}}$ siècle $^{59}$. Cela implique en retour que le concept historien de laboratores ne repose pas sur une catégorie médiévale forte. «Travailleurs » et « travail » étant a priori consubstantiels, ces observations, tant historiographiques que documentaires, fragilisent l'hypothèse même d'un «travail médiéval ». Ces obstacles identifiés, il nous faut revenir à notre question initiale : comment étaient pensées les activités dans l'Europe médiévale?

\section{I.3. Un terme rare et essentiellement méridional}

Avant de clore cette partie, il convient toutefois d'examiner la répartition des occurrences dans les textes diplomatiques, car leur rareté les rend précisément intéressantes ${ }^{60}$. Elles proviennent en effet quasiment toutes de l'espace méditerranéen, en particulier de la Péninsule Ibérique, de l'Italie et de la Provence ${ }^{61}$. Dans les chartes originales de France, les 6 occurrences

\footnotetext{
${ }^{56}$ Avec seulement 5 mentions dans les OpenMGH, dont 4 aux XIV $-X V^{\mathrm{e}}$ siècles. Ou trouve 66 mentions de la forme laborantes dans le corpus, mais il s'agit quasiment toujours du verbe laboro.

${ }^{57}$ Catherine Kikuchi, que nous remercions vivement, a effectué pour nous des recherches dans sa documentation vénitienne des XIV ${ }^{\mathrm{e}}-\mathrm{XVI}^{\mathrm{e}}$ siècles (Archivio di Stato di Venezia, Signori di notte al civil). Elle confirme que le terme y est présent, mais plutôt rare. Mentionnons cependant que Sylvain Parent relève "les noms de centaines de laboratores » dans le registre Introitus et Exitus 61 concernant Spolète (Vatican, Arch. Segr. Vat., Cam. Ap., Intr. et Ex. 61) : S. PARENT, « Le prix de la rébellion. Remarques autour de la reddition de Spolète en 1324 », dans Contester au Moyen Âge : de la désobéissance à la révolte, Paris, 2019, p. 358 (Congrès de la SHEMSP, 49). Il en va de même dans l'article de F. FRANCESCHI, «La mémoire des laboratores à Florence au début du XV siècle », Annales, vol. 45:5, 1990, p. 1143-1167. Pour la situation à Avignon, décrite par Jacques Rossiaud, voir la note 39. Philippe Bernardi relève aussi plusieurs occurrences du terme aux $\mathrm{XIV}^{\mathrm{e}}-\mathrm{XV}^{\mathrm{e}}$ siècles dans les registres notariés d'Aix-en-Provence et d'Avignon : voir P. BERNARDI, Maître, valet et apprenti au Moyen Âge. Essai sur une production bien ordonnée, Toulouse, 2009, Annexes - pièces justificatives $\mathrm{n}^{\circ} 2$, 6-7 et 11 . Les mentions de laborator sont donc probablement plus fréquentes dans les registres, mais il est difficile de dire dans quelles proportions tant que nous ne disposerons pas d'un corpus numérique développé.

${ }^{58}$ Avec environ 500 mentions dans les CEMA, et environ deux mille dans la $P L$ (en incluant à la fois operarius comme substantif et comme qualificatif). Une étude complète devrait toutefois être menée sur le lemme, dont l'importance théologique est nettement plus forte que celle de laborator. Selon François Rivière, que nous remercions vivement, les termes « ouvrier » et «manouvriers » sont relativement fréquents dans les registres au $\mathrm{XIV}^{\mathrm{e}}-\mathrm{XVI} \mathrm{e}^{\mathrm{e}}$ siècles.

${ }^{59}$ On pourrait de même s'interroger sur l'existence d'une catégorie unifiée pour désigner les « outils » (ustensilia est par exemple un terme excessivement rare, au moins jusqu'au XIII ${ }^{\mathrm{e}}$ siècle, avec moins de 50 occurrences dans tous les corpus consultés).

${ }^{60}$ À l'inverse, on pourrait remarquer que ces mentions, faibles au demeurant, pourraient très bien être employées hors d'un cadre quantitatif pour postuler l'existence d'une hypothétique classe de laboratores. C'est donc bien leur intégration dans un cadre global (ici les CEMA) qui permet d'en définir l'importance, toute relative.

${ }^{61}$ Voir les différentes occurrences mentionnés ci-dessous.
} 
de laborator sont contenues dans 5 documents issus des fonds de Montmajour, de l'évêque de Marseille Pons I ${ }^{\mathrm{er}}$, de Saint-Victor de Marseille, puis d'une charte de l'évêque d'Arles Atton pour cette même abbaye, et enfin d'un acte de laïc languedocien ${ }^{62}$. Outre ces mentions, les 180 autres se répartissent ainsi : 116 pour la Péninsule Ibérique, en particulier la Catalogne $(\approx 64 \%)^{63} ; 28$ pour la Provence et le Languedoc, voire plus rarement la Bourgogne $(\approx 15 \%)^{64}$; 24 pour l'Italie, a priori sans distinction entre le nord et le sud $(\approx 13 \%)^{65} ; 6$ pour la France du ${ }^{62}$ La plus ancienne occurrence provient de Montmajour et date de 979 : elle est présente dans Artem $\mathrm{n}^{\circ} 4088$ (cf.
la note suivante). Vient ensuite la mention de Pons $\mathrm{I}^{\mathrm{er}}$, en 1008 : In tale vero conventum ipsi laboratores ipsas
vineas cum bono studio plantare vitis fodere et probagare et fecundare studuerint cum bene avineata fuerit ipsi
laboratores de ipsas vineas una medietatem recipiant a proprium alodem (Artem $\mathrm{n}^{\circ}$ 3980). La mention issue de
Saint-Victor est la suivante, en 1095 : Et illos mansos qui a possessoribus non excolluntur si monachi illos illorum
que terras excolunt quiete possideant donec laboratores cum concilio monachorum adveniant terras que accipiant
et de dono quod homines iteraturi donaverint vel promiserint monachi duas partes recipiant (Artem $\mathrm{n}^{\circ} 4320$ ). La
dernière occurrence provençale dans les originaux émane de l'évêque d'Arles Atton, mais concerne aussi Saint-
Victor, en 1119 : De aliis autem ecclesiis quas clerici tenent et earum parrochiis habeant idem clerici decimas
exceptis ut supradictum est monachorum dominicaturis et si monachi acreverint dominicaturam suam de ipsa
augmentatione habeant decimas et si minuerint et dederint laboratoribus habeant clerici (Artem $\mathrm{n}^{\circ} 4159$ ). L'acte
languedocien est l'Artem $\mathrm{n}^{\circ}$ 531, daté de 1112 .

${ }^{63}$ Quelques exemples parmi les mentions les plus anciennes : Et si ego donator minime fecero et de supra convencione non oc valeat vindicare sed componat in vinculo solidos XX et nos laboratores minime fecerimus [...], dans une donation barcelonaise de 954 (Quan els vescomtes de Barcelona eren. Història, crònica i documents d'una família catalana dels segles X, XI i XII, éd. J. E. RUIZ DoMÉNEC, Lleida, 2006, $\mathrm{n}^{\circ} 1$ ) ; Et si ego laborator ipsam terram non plantavero sicut supra taxatum est componam tibi in uinculo solidos XX et in antea adimpleam quod nostra est convencio, toujours à Barcelone, en 1012 (Diplomatari de l'Arxiu Capitular de la catedral de Barcelona, segle XI, éd. J. BAUCELLS I REIG, Lleida, 2006, vol. 1, $\mathrm{n}^{\circ} 181$ ) ; Manifestum est enim quia donamus vobis kastrum nostrum quem vocant Abiniana qui est destructum et solidum et eremum sine habitatore et absque laboratore et propter metu Ismahelitis inabitabile, à Sant Cugat del Vallès en 1088 (Cartulario de Sant Cugat del Vallès, éd. J. RIUS SERRA, Barcelona, 1945, n 730).

${ }^{64}$ Pour la Provence : Pro tale vero ut dum Deus Rotbaldo et uxori sue vitam concesserit ipsas vineas cum bono studio fodere et propaginare studeant et ipsum fructum quem Deus ibi dederit usque ad Arelatem civitatem salvum venire faciant medietatem unam recipiant canonici et decimum aliam laboratores accipiant, à l'évêché d'Arles en 923 (Gallia christiana novissima. Histoire des archevêchés, évêques et abbayes de France. Provinces d'Albi, Aix, Arles, Avignon et Auch, éd. J.-H. ALBANES, Montbéliard, 1899-1920, vol. 1, n 244, p. 99-100); Aliam laboratores accipiant, en 933 à Arles (Les chartes du pays d'Avignon (439-1040), éd. G. DE MANTEYER, Mâcon, 1914, p. 3637 - dans un acte très proche du précédent) ; Airardo presbitero eredes Romarico condam laboratore [...], à Montmajour vers 966-979 (IDEM, p. 78-79 ; aussi Artem n 4088). Pour le Languedoc, on trouve par exemple cet acte original énumérant les biens détenus en gage par un certain Arnaud Bernard, à proximité de Perpignan : Et de Petrus laborator habet in pignora suam vineam per IIII solidos et dimidium [...], en 1112 (Artem $\mathrm{n}^{\circ} 531$ - sur ce document, voir M. ALART, Inventaire sommaire des Archives départementales antérieures à 1790, PyrénéesOrientales, Archives civiles - Série B. C., tome premier, Paris, 1968, p. 38, B 65); [...] et condirectum ad laborandum integriter et sine enganno ut habeatis teneatis et possideatis eam uos et omnis uestra posteritas per laborationem in perpetuum et de ista hora inantea non possimus uos nec uestros cambiare ullo modo per laborationem per ullos alios laboratores, à Fontfroide en 1128 (Le chartrier de l'abbaye cistercienne de Fontfroide (894-1260), éd. V. DE BECDELIEVRE, Paris, 2009, n 70). Pour la Bourgogne, les occurrences sont aussi très rares: Tunc judicauerunt scaminei ut venissent homines de villis que sunt in circuitu hujus civitatis Matisconensis illi meliores qui sunt laboratores et jurent per antiquis temporibus ut amplius lex non fuisset recipere de duobus carrariis nisi unum denarium, dans un règlement issu d'un plaid comtal vers 928 (Cartulaire de Saint-Vincent de Mâcon : connu sous le nom de Livre enchaîné, éd. M.-C. RAGUT, Mâcon, 1864, p. 292-293, $\left.\mathrm{n}^{\circ} 501\right)$; on trouve une autre mention dans une liste de témoins pour l'abbaye de Molesme, en 1108: Hujus rei testes adsistunt Hugo de Malleio, Arnulfus pistor, Arnaldus famulus cellerarii, Theodericus quoquus, Rotbertus hospitarius, Willelmus filius Ulrici laboratoris (Cartulaire général de l'Yonne, éd. M. QUANTIN, Auxerre, 18541860, vol. 2, $\mathrm{n}^{\circ} \mathrm{XXX)}$.

${ }^{65}$ curam abead ordinandi et disponandi easdem terras et predictum vasum fullonis ita ut per malos laboratores non dispereant set semper meliorentur [...] dans un don pour l'église de Bergame en 1023 (Le pergamene degli archivi di Bergamo aa. 1002-1058, éd. M. CoRTESI et A. PRATESI, avec C. CARBONETTI VendiTtElli, R. COSMA et M. VenditTelli, Bergamo, 1995 puis Pavia, 2005, $\left.\mathrm{n}^{\circ} 75\right)$; et tu et heredes tui licentiam habeatis ibi ponere laboratores absque ordine scripto sine omni nostra contrarietate [...], à la Sainte-Trinité de Cava en 1025 (Codex 
nord $(\approx 4 \%)^{66}$. Parmi ces dernières, on trouve par exemple deux actes de l'évêque d'Arras Fremauld [1174-1183], ainsi que deux autres documents de Vaucelles et un dernier pour Echternach, employant ce lemme ${ }^{67}$. Enfin, 6 mentions $(\approx 4 \%)$ apparaissent aussi dans des diplômes impériaux d'Otton I ${ }^{\mathrm{er}}$, d'Otton III, d'Henri II ou encore de Frédéric II, mais celles-ci concernent exclusivement des abbayes italiennes ${ }^{68}$. Considérant ces éléments, on est bien forcé de constater que la quasi-totalité des mentions provient de Péninsule Ibérique, d'Italie ainsi que du sud de l'actuelle France.

Cette spécificité ne peut sans doute pas s'expliquer par un régionalisme linguistique, car la zone est trop vaste et couvre un large arc méditerranéen. S'agit-il alors d'une tendance sociale, propre à la dynamique de cette zone aux XII $-\mathrm{XVI}^{\mathrm{e}}$ siècles ? L'hypothèse mériterait sans doute d'autres investigations : à défaut de conclure que les laboratores formaient une «classe sociale cohérente », on peut dire que l'apparition du lemme est certes lente et limitée, mais néanmoins réelle. Il s'agirait donc d'examiner l'évolution de ces mentions aux $\mathrm{XV}^{\mathrm{e}}-\mathrm{XVI}^{\mathrm{e}}$ siècles, tout en cherchant à s'affranchir d'une perspective qui pourrait insidieusement devenir téléologique (i.e. «l'émergence des travailleurs »).

\section{UN ENSEMBLE LEXICAL HETEROGENE}

\section{II.1. Question de méthode : faut-il partir d'une liste ?}

Afin de poursuivre l'enquête, il était nécessaire de constituer une première liste de termes relatifs aux activités médiévales, en particulier à partir des dictionnaires numérisés ${ }^{69}$.

diplomaticus Cavensis, éd. M. Schiani, M. Morcaldi, S. De Stefano, G. Vitolo et S. Leone, Naples, 18731984 , vol. $5, \mathrm{n}^{\circ} 763$ ).

${ }^{66}$ Voir les mentions présentées dans les notes suivantes.

${ }^{67}$ presente nostro capitulo, presentibus etiam terre laboratoribus Ursione Revione Iacobo Laiulfi Siluestro fabro, dans un acte de l'évêque Fremauld d'Arras en 1176 (Les chartes des évêques d'Arras (1093-1203), éd. B.-M. TocK, Paris, 1991, $\mathrm{n}^{\circ} 169$ - la formule est reprise quasiment à l'identique dans l'acte $\mathrm{n}^{\circ} 170$, de la même année) ; usque ad finem vite sue sicut fortis laborator se exhibuit, à Echternach en 1179 (Geschichte der Grundherrschaft Echternach im Frühmittelalter. Untersuchungen über die Person des Gründers, über die Klosters- und Wirtschaftsgeschichte auf Grund des Liber aureus Epternacensis (698-1222), éd. C. WAMPACH, vol. I:2, Luxemburg, 1930, $\mathrm{n}^{\circ} 204$ - Diplomata Belgica $\mathrm{n}^{\circ}$ 5702); Concessi etiam quod laboratores eorum in eadem terra sive lignorum emptores in omni pace esse ire et redire faciam et si quis eos impedierit ego eos liberabo, à Vaucelles en 1198 (Les chartes de l'abbaye cistercienne de Vaucelles au XII siècle, éd. B.-M. TocK, Turnhout, 2010, $\left.\mathrm{n}^{\circ} 160\right)$; et dans le même lieu en 1200 : Set et laboratores eorum in eadem terra sive lignorum emptores in omni pace esse ire et redire faciam et si quis eos impedierit ego eos liberabo (Ibid., $\left.\mathrm{n}^{\circ} 169\right)$.

${ }^{68}$ Quia Tuscis consuetudo est ut, accepto ab ecclesia libello, in contumatiam convertantur contra ecclesiam, ita ut vix aut numquam constitutum reddant censum, precipimus modis que omnibus iubemus, ut non episcopus vel canonicus libellum aut aliquod scriptum alicui homini faciant, nisi laboratoribus qui fructum terre ecclesiae et ca[nonicis ipsius loc]i reddant sine molestia vel contradictione aliqua, dans un acte d'Otton Ier pour les chanoines d'Arezzo, en 963 (Die Urkunden Konrad I., Heinrich I. und Otto I. (MGH DD O I), éd. T. SicKEL, Hanovre, 1879$1884, \mathrm{n}^{\circ} 253$ ). Cette occurrence est intéressante, car laborator qualifie précisément ceux qui cultivent la terre d'Église. Un sens identique apparaît dans cet autre acte de 967 pour San Severo in Classe de Ravenne : Et precipientes precipimus [...] ut [...] nulla que maior vel minor persona nullus eiusdem monasterii abbas aut monachus facultatem habeat res ecclesie distribuere per libellos seu per aliqua munimina aut per infiteosin alicui inscribere, nisi laboratoribus qui propriis manibus terram laborant, ne sicut actenus monachi inibi famulantes ea occasione ob inopiam regulariter se non posse viuere dicant (ID., $\left.\mathrm{n}^{\circ} 349\right)$; Messores quoque et quoslibet laboratores ipsorum monasteriorum sub nostra protectione recipimus, dans un diplôme de Frédéric II passé à Messine en 1209 (Die Urkunden Friedrichs II, vol. 1, éd. W. KoCH, K. HöFLINGER, J. SPIEGEL et C. FrIEDL, Hanovre, 2002, $\left.\mathrm{n}^{\circ} 100\right)$.

${ }^{69}$ L'équipe de l'ANR OMNIA a en effet créé une base de données à partir de différents dictionnaires latins, aujourd'hui interrogeable soit à partir des lemmes eux-mêmes, soit à partir des traductions données dans les 
Cette approche quasi-incontournable est toutefois problématique, car elle tend indirectement à présupposer l'existence d'un champ unifié et homogène pour le processus de production médiéval, alors inévitablement considéré comme un décalque de notre propre «travail ${ }^{70}$. Il y a en effet un risque, en se fondant sur de putatives traductions, de reconstruire la pseudocohérence d'un hypothétique champ lexical. Cette mise en garde doit être conservée à l'esprit : en aucun cas, la liste que nous pourrions constituer ne traduit de notre part une hypothèse quant à sa cohérence. Elle ne constitue qu'une étape méthodologique ${ }^{71}$. Son rôle est de nous permettre d'identifier des lemmes sur lesquels nous concentrer, en particulier à partir du critère de leur importance fréquentielle. Pour la constituer, quatre méthodes sont à notre disposition : les dictionnaires, l'historiographie, les analyses sémantiques et la lecture des textes. Une recherche inversée dans les dictionnaires permet d'abord d'obtenir une liste de 86 termes généralement traduits par «travail» ou «labeur» (plus rarement), ainsi que leurs dérivés ${ }^{72}$. La lecture des travaux de Ludolf Kuchenbuch et de Jacques Le Goff permet de compléter et d'amender cet inventaire. Mais seule l'analyse sémantique et la lecture des textes permettra en définitive de dire si ces termes forment des ensembles plus ou moins cohérents et articulés.

Afin de repérer les mots dont la fréquence rend possible une analyse lexico-sémantique quantitative, nous les avons dénombrés dans les différents corpus à notre disposition. Comme souvent, seule une faible partie des lemmes est réellement représentée dans les textes - les autres étant soit totalement absents des corpus, soit présents sous la forme d'hapax. Parmi ces termes rares, un nombre très élevé renvoie à des métiers, en particulier ceux liés à une matière ou à une technique: bombycino, brasserius, equitium, erifice, fabrefactura, lanificium, linificium, machio, metallicus, minagium, temperaculum, tudiatores, etc. ${ }^{73}$. Cette fragmentation n'est certainement pas le fruit du hasard, puisque notre hypothèse est précisément qu'il n'existait pas de catégorie unifiée pour désigner les «travailleurs » (a fortiori le «travail) : nous y reviendrons. Reste une vingtaine de termes bien représentés dans la documentation consultée. Quatre catégories fréquentielles peuvent être distinguées dans les CEMA : 1. Les lemmes représentés par moins de 100 mentions: opusculum, opifex, collaboro, haribannus ${ }^{74}$, operamentum, operatorium, operator, opificus, sudo. 2. Ceux qui comptent entre 100 et 500

ouvrages. Voir B. BON, « OMNIA - Outils et Méthodes Numériques pour l'Interrogation et l'Analyse des textes médiolatins (I, II et III) », cit. n. 25. La version SQLite du dictionnaire a été produite par Alain Guerreau.

${ }^{70}$ Même remarques dans J. LE GoFF, « Travail », cit. n. 8, p. 1137.

${ }^{71}$ Ludolf Kuchenbuch emploie la micro-sémantique pour identifier les termes clés, fondée sur sa connaissance empirique du problème. En définitive, nous verrons que nous aboutissons à des considérations proches, en tout cas complémentaires - et que sa liste initiale est elle-même relativement similaire à la nôtre.

72 Exemple pour les termes liés à «travail» dans les dictionnaires consultés : allaboro, architectonor, bombycinator, bombycino, brasserius, cestrotus, collaboro, combino, delaboro, detorno, dies, dieta, dietarium, equitium, erifice, fabrefactura, fabrica, fabricabilis, fabricatus, haribannus, illaboratus, illaboro, illucubratus, indomitus, inelaboratus, infectus, inoperatus, intractatus, iurnus, labor, laboratio, laboratorium, laborifluus, laboro, ladmon, lana, lanificium, lanificus, lanitium, ligonizo, linaria, linarius, linificium, lucerna, lucubratio, lucubro, machio, manupretiosus, materibatura, metallicus, minagium, negotium, opera, operagium, operamentum, operarius, operatio, operator, operatorium, operatus, opero, operosus, opificina, opificium, opificus, opus, pastinator, perpastino, quindena, rastraria, rusticor, sagnaderius, sarculum, sellularius, sesquiopus, specillatus, subedianus, sudor, temperaculum, toreuma, trauallum, tudiatores, tudito, uehis. «Labeur » n'offre que deux entrées (laboratio, laborerium), ce qui tendrait d'ailleurs à indiquer que le terme est moins problématique que celui de « travail ».

73 Il est probable que l'on trouverait plus de ces termes dans les documents comptables ou normatifs, particulièrement en contextes urbains, aux XIII $-X^{\mathrm{e} V I} \mathrm{I}^{\mathrm{e}}$ siècles. Mais là encore, une enquête chiffrée devrait être menée afin de s'en assurer. Nous renvoyons ici à la thèse de F. RIVIERE, Travail et métiers en Normandie à la fin du Moyen Âge. Institutions professionnelles et régulation économique, Paris, 2017 ; P. BERNARDI, C. MAITTE et F. RIVIERE (dir.), Dans les règles du métier. Les acteurs des normes professionnelles au Moyen Âge et à l'époque moderne, Palermo, 2020 ; ainsi qu'aux analyses lexicales de P. MichAUD-QUANTIN, Universitas [...], op.cit, chap. VII («Du ministerium à la hansa »), bien que ces dernières soient schématiques.

${ }^{74}$ Présent dans la liste, car parfois traduit comme un « service de travail ». 
mentions : laborator, laboratio, operarius, operatio. 3. Entre 500 et 1000 : ars, opero, fabrica. 4. Enfin, plus de 2000 occurrences : labor, negotium, laboro, opus-opera ${ }^{75}$ et officium. Cette liste ne serait toutefois pas satisfaisante si nous n'y ajoutions le lemme servitium, maintes fois retenu par Ludolf Kuchenbuch dans ses analyses ${ }^{76}$.

\begin{tabular}{|c|c|c|c|c|c|c|c|c|c|}
\hline Lemme & Antique & Vulgate AT & Vulgate NT & PL (avant 500) & PL (après 500) & PL (tout) & CEMA & Thomas & Somme \\
\hline servitiun & 171 & 8 & 8 & 458 & 3376 & 3834 & 29241 & 160 & 37242 \\
\hline opus-opera & 6023 & 297 & 102 & 25165 & 91579 & 116744 & 16890 & 11242 & 268042 \\
\hline officinm & 1713 & 32 & 3 & 4798 & 29202 & 34000 & 14681 & 9477 & 93900 \\
\hline negotium & 1002 & 38 & 6 & 2010 & 13042 & 150.52 & 8476 & 506 & 40132 \\
\hline Laboro & 741 & 63 & 24 & 3209 & 11778 & 14987 & 5329 & 960 & 37091 \\
\hline labor & 2307 & 109 & 15 & 5503 & 23489 & 28992 & 4610 & 1442 & 66467 \\
\hline opero & 60 & 96 & 67 & 6799 & 20141 & 26940 & 1644 & 6849 & 62596 \\
\hline fabrica & 49) & 3 & 0 & 311 & 1318 & 1629 & 1568 & 26 & 4904 \\
\hline ars & 2632 & 21 & 4 & 2606 & 8448 & 11054 & 1122 & 2509 & 28396 \\
\hline operatio & 2 & 8 & 12 & 1732 & 9553 & 11285 & 467 & 8945 & 32004 \\
\hline \begin{tabular}{|l} 
operarius \\
\end{tabular} & 17 & 2 & 14 & 268 & 733 & 1001 & 464 & 66 & 2565 \\
\hline Laboratio & 0 & 0 & 0 & 0 & 21 & 21 & 395 & 0 & 437 \\
\hline Laborator & 0 & 0 & 0 & 2 & 33 & 35 & 180 & 2 & 252 \\
\hline opperatorium & 0 & 0 & 0 & 1 & 5 & 6 & 140 & 0 & 152 \\
\hline operamentum & 5 & 12 & 4 & 156 & 739 & 895 & 105 & 105 & 2021 \\
\hline sudor & 237 & 4 & 1 & 303 & 1468 & 1771 & 86 & 87 & 3957 \\
\hline operator & 0 & 3 & 0 & 151 & 339 & 490 & 46 & 30 & 1059 \\
\hline collaboro & 1 & 0 & 2 & 48 & 173 & 221 & 39 & 8 & 492 \\
\hline opificus & 7 & 0 & 0 & 57 & 178 & 233 & 34 & 11 & 522 \\
\hline opusculum & 15 & () & 0 & 616 & 2150 & 2766 & 30 & 5 & 5582 \\
\hline opifex & 53 & 0 & 1 & 225 & 523 & 748 & 25 & 24 & 1599 \\
\hline Somme & 15035 & 690 & 255 & 54418 & 218288 & 272706 & 85572 & 42454 & 689520 \\
\hline
\end{tabular}

Fig. 2 : Nombre d'occurrences des principaux termes médiolatins retenus, au sein d'une série des corpus ${ }^{77}$. Le tri est effectué en fonction du nombre d'occurrences dans les CEMA. En gris, quelques valeurs remarquables.

Ces termes représentent plus de 85600 mentions dans les documents diplomatiques des CEMA. Cette somme est plus élevée dans la $P L$, où les lemmes réunissent environ 272000 occurrences $^{78}$. Définir l'importance de cet ensemble lexical n'est toutefois envisageable qu'en comparaison avec d'autres mots. Face aux 85600 mentions relevées dans les CEMA, coexistent (dans ce même corpus) 2270000 occurrences de terra, 368300 pour sanctus, et enfin 350600 pour dominus. La comparaison avec ces termes clés du système de l'Europe médiévale permet

\footnotetext{
${ }^{75}$ La distinction entre opus et opera n'est pas toujours simple dans l'état actuel des lemmatiseurs, mais il semble en aller de même pour les auteurs médiévaux eux-mêmes. Ces formes apparaissent en effet dans des contextes souvent similaires, sont des substantifs (on rappelle que les lemmatiseurs sont le plus souvent des étiqueteurs morphosyntaxiques, et donc qu'ils fonctionnent à partir des catégories grammaticales) et sont surtout parfois homonymes (ex. les formes opera au nominatif/vocatif/accusatif pluriels pour le lemme opus - que l'on retrouve au nominatif, vocatif et ablatif singuliers pour le lemme opera). Dans un premier temps, nous avons donc préféré regrouper les deux lemmes, avant de les séparer dans les analyses qui suivent. Ce constat est largement partagé par Isabelle Rosé dans ce volume, qui indique que «[1]e nom féminin opera, mal connu, n'est pas toujours clairement distinguable d'opus [...]».

${ }^{76}$ Pour servitium, les traductions proposées sont : « service, charge, obligations, esclavage ». Sur ce terme, nous renvoyons aux travaux de Ludolf Kuchenbuch et Julien Demade, déjà mentionnés.

${ }^{77}$ Le corpus « PL (avant 500) » correspond aux volumes 1 à 62 (inclus) de la $P L$, c'est-à-dire avant Boèce [ $†$ 524]. Il contient environ 22 millions de mots. Celui «PL (après 500) », va donc des volumes 63 à 217 (inclus), soit de Boèce à Innocent III [ $†$ 1213]. Le corpus « Antique » comprend un ensemble de textes assez exhaustif de la latinité païenne (jusqu'au II ${ }^{\mathrm{e}}$ siècle après - soit environ 6,9 millions de mots). Enfin, « Thomas » correspond à l'ensemble du Corpus Thomisticum, soit les textes de Thomas d'Aquin et de ses continuateurs (13 millions de mots). L'ordre des lemmes est donné en fonction de leur importance dans les CEMA.

${ }^{78}$ Dont près de $43 \%$ sont des mentions d'opus-opera.
} 
de mieux situer l'importance de fabrica (1 568), labor (4 610) ou encore ars (1 122) - qui font donc partie du vocabulaire courant, mais certainement pas dominant.

Deux conclusions peuvent, nous semble-t-il, être tirées de ces observations : d'une part, la répartition fréquentielle de ce lexique est extrêmement hétérogène. Des termes comme operarius (un millier d'occurrences pour le substantif dans la $P L$ ) et opus-opera (plus de 116000 mentions) ne peuvent pas être placés sur un même plan structurel, sans compter les nombreux hapax relevés. Cette hypothèse s'explique simplement : des lemmes centraux d'un système de représentation ont nécessairement une portée sémantique, une valence sociale, bien supérieures aux termes rares. En outre, ils possèdent des caractéristiques statistiques différentes, qui incitent à des comparaisons prudentes. D'autre part, certains termes sont nettement plus représentés dans l'une ou l'autre typologie documentaire : c'est par exemple le cas de servitium, qui est 7,6 fois plus présent dans les CEMA que dans la $P L$, alors que dans le même temps opus-opera sont 6,9 fois plus présents dans la $P L$ que dans les CEMA ${ }^{79}$. De telles différences fréquentielles impliquent que ces multiples termes ne jouaient pas le même rôle, ni ne se complétaient, s'opposaient, s'articulaient sur un même plan.

\section{II.2. La promotion chrétienne de l'opus}

Afin de mieux mesurer certaines évolutions liées à ces termes, il est intéressant de comparer les textes médiévaux à ceux de l'Antiquité païenne. Les rapports de production y étaient nécessairement organisés d'une façon bien différente, ne serait-ce qu'au regard de l'esclavage $^{80}$. Une base de données regroupant les principaux textes des auteurs latins anciens, du IV $\mathrm{V}^{\mathrm{e}}$ siècle avant au $\mathrm{II}^{\mathrm{e}} \mathrm{s}$. après J.-C. ${ }^{81}$, a donc été comparée aux documents de la $P L$ pour les $\mathrm{II}^{\mathrm{e}}-\mathrm{V}^{\mathrm{e}}$ siècles (jusqu'à Boèce). Ce rapprochement est d'autant plus intéressant que la somme des termes inclus dans notre liste est proportionnellement équivalente dans l'un et l'autre des ensembles $^{82}$. Toute évolution de la fréquence d'un terme ou d'un groupe de termes au sein de la liste, entre période païenne et chrétienne, est donc d'autant plus significative.

Or, il apparaît qu'opus connaît une évolution fréquentielle majeure. Elle est visible, par exemple, dans l'évolution du ratio entre labor et opus, qui bascule notablement d'une période à l'autre. Tandis que l'on décompte 1,2 occurrences d'opus pour 1 de labor dans l'Antiquité païenne, il existe 4,7 fois plus de mentions d'opus que de labor chez les auteurs chrétiens des premiers siècles ${ }^{83}$. La période chrétienne est donc marquée par une promotion très nette du

\footnotetext{
${ }^{79}$ De même, il y a 160 mentions de servitium dans le Corpus Thomisticum, contre 11242 pour opus-opera.

${ }^{80}$ Voir en dernier lieu N. CARRIER, Les usages de la servitude. Seigneurs et paysans dans le royaume de Bourgogne (VI $-X V^{e}$ siècle), Paris, 2012 ; ainsi qu'A. RIO, Salvery After Rome, 500-1100, Oxford, 2017, qui donne une excellente vue générale de la transition radicale qui s'opère entre le $\mathrm{II}^{\mathrm{e}}$ et le $\mathrm{V}$ siècle après J.-C. (Although many of the practices we looked at in the first three chapters, whether of enslavement or of manumission, had already existed in some version under Rome, many of the uses to which they were put seem new and distinct from those characteristic of Roman slavery [...], p. 246). On trouvera dans ces deux volumes le résumé des discussions ayant agité la médiévistique sur cette question de la transition du système esclavagiste au mode de production médiéval (Bloch, Bonnassie, Freedman, Stella, etc.). Sur l'esclavage antique, en particulier en Grèce, voir la publication récente de P. Ismard, La cité et ses esclaves - Institution, fictions, expériences, Paris, 2019 - qui montre à quel point l'institution esclavagiste façonnait l'ensemble des structures sociales.

${ }^{81}$ Il s'agit du corpus intitulé « Antique » dans la fig. 2.

${ }^{82}$ On décompte ainsi 15035 mentions au total pour le corpus païen, contre 54418 aux II I $^{\mathrm{e}} \mathrm{V}^{\mathrm{e}}$ siècles ; soit 3,6 fois plus d'occurrences, tandis que le corpus se trouve lui multiplié par 3,16. Autrement dit des proportions sensiblement équivalentes.

${ }^{83}$ Le résultat est identique si l'on considère le ratio opus-opera vs. labor. Dans l'Antiquité païenne, ces lemmes sont en effet présents respectivement 6023 et 2307 fois (ratio de 2,61). Or, ils apparaissent respectivement 25165 et 5503 fois chez les auteurs chrétiens des II $^{\mathrm{e}}-\mathrm{V}^{\mathrm{e}}$ siècles (ratio de 4,57).
} 
couple opus-opera (qui représente encore une fois à lui seul $43 \%$ du total des occurrences de la liste lexicale dans la $P L$ ), mais aussi du verbe opero. Alors que les occurrences de labor ne sont multipliées que par 2 entre le corpus antique païen et celui des Pères ( 2307 vs. 5503 mentions), celles d'opero explosent et se multiplient par un facteur de 100 (60 vs. 6799 mentions). D'autres différences peuvent être observées : ars, negotium et sudor sont proportionnellement plus présents dans le système romain païen que chez les Pères de l'Église ${ }^{84}$. À l'inverse, on constate que d'autres termes deviennent nettement plus fréquents lors du passage du système antique au Moyen Âge. Outre opus et ses dérivés (opera, opero), c'est aussi le cas de servitium : dans les chartes, ce terme devient même rapidement le plus employé de la liste, avec plus de 29200 occurrences au total. Ces évolutions ne sont évidemment pas seulement fréquentielles et s'accompagnent de transformations sémantiques complètes, liées pour partie à la promotion de la Vulgate comme système de référence. Elles traduisent probablement une rupture dans la façon d'envisager les rapports de production, qui prennent place au sein d'une architecture articulant les «œuvres », le service divin et seigneurial, une nouvelle conception de la souffrance, le salut chrétien enfin ${ }^{85}$. Notons toutefois qu'il est impossible de détecter une tendance générale dans ces termes généralement traduits par «travail » : tandis que certains augmentent radicalement lors du passage de l'Antiquité païenne au système chrétien, d'autres baissent ou encore stagnent. Autrement dit, il ne semble pas que l'on passe d'un système sémantique à un autre par une simple « reconfiguration », en quelque sorte une «translation » des termes liés à un hypothétique champ : ce qui s'opère ici, c'est un transformation complète.

Dans la Vulgate, opus est nettement plus présent au sein du Nouveau Testament (NT) que dans l'Ancien Testament (AT), avec trois fois plus de mentions dans un ensemble de textes pourtant quatre fois plus petit ${ }^{86}$. Labor enregistre à l'inverse une chute brutale, avec six fois moins de mentions dans le NT que dans l'AT - servitium étant quant à lui quasiment absent du corpus biblique, avec seulement trois occurrences. La tendance est donc à la fois une hausse relative des mentions d'opus et une chute franche des mentions de labor. Visible dans la Vulgate mais aussi chez les Pères, cette double évolution montre selon nous qu'il y a bien eu un changement important dans la sémantique de plusieurs de ces termes lors du passage au système chrétien ${ }^{87}$. Les autres évolutions observées entre corpus païen et Pères de l'Église sont, elles aussi, visibles si l'on compare l'ensemble antique à la Vulgate, mais également l'Ancien Testament au Nouveau Testament : opero augmente fortement, tandis qu'ars ou encore sudor chutent $^{88}$. Cette reconfiguration est cohérente, d'une part avec la mise en place d'un système de

\footnotetext{
${ }^{84} \mathrm{C}$ 'est particulièrement net dans le cas d'ars, dont le nombre de mentions est quasiment équivalent dans le corpus Antique et dans celui des $\mathrm{II}^{\mathrm{e}}-\mathrm{V}^{\mathrm{e}}$ siècles chrétiens (2 632 vs. 2 606). Or, comme nous l'avons déjà indiqué, ce second corpus est presque 3,5 fois plus important que le corpus païen. La non-évolution apparente correspond en fait à une chute brutale des mentions.

${ }^{85}$ Sur l'articulation de ces structures, voir la partie III de la présente contribution. Par ailleurs, s'ils sont beaucoup moins fréquents, on note qu'opusculum et operarius sont eux aussi multipliés lors du passage du système païen au système chrétien. Concernant l'articulation de ces éléments chez les Pères de l'Église, nous revoyons au travail en cours de D. MeHU, La révolution symbolique de l'Occident à la fin du IVe siècle. Ambroise, Augustin, Paulin de Nole, dont nous avons pu consulter certains chapitres préparatoires.

${ }^{86}$ Les deux sous-corpus de la Vulgate font respectivement 580000 et 150500 mots (environ). La comparaison lexicale entre AT et NT est a priori délicate, puisque l'intégralité du texte a été traduit par Jérôme. En pratique toutefois, on constate d'importantes différences lexicales entre les deux ensembles.

${ }^{87}$ Les versets Gn 2:2 (conplevitque Deus die septimo opus suum quod fecerat et requievit die septimo ab universo opere quod patrarat) et Gn 3:17 (ad Adam vero dixit quia audisti vocem uxoris tuae et comedisti de ligno ex quo praeceperam tibi ne comederes maledicta terra in opere tuo in laboribus comedes eam cunctis diebus vitae tuae) eurent en particulier un impact considérable sur l'évolution ultérieure d'opus.

${ }^{88}$ Le cas d'operarius est plus étonnant, car il est assez présent dans la Vulgate et en particulier le Nouveau Testament (14 occurrences - contre 17 au total dans toute l'Antiquité païenne). Malgré cela, il ne sera pas réemployé massivement par les auteurs médiévaux, ainsi que le montre les scores relativement faibles pour le lemme, tant dans la $P L$ que dans les chartes.
} 
représentations proprement chrétien, d'autre part, à plus long terme, avec le passage d'un système esclavagiste à un système fondé sur la fixation des populations et le prélèvement des surplus. Ces transformations idéelles et matérielles ne pouvaient pas ne pas entraîner des modifications sémantiques fortes. Elles sont d'autant plus sensibles que les activités (vivrières, intellectuelles, de construction, etc.) s'insèrent alors progressivement toutes dans l'architecture ecclésiale du salut, et donc de la caritas.

\section{II.3. Des tendances chronologiques contradictoires}

En dépit de ces fortes évolutions, liées à l'élaboration et à la mise en place du système de représentations chrétien, l'examen de la chronologie des mentions d'opus mais aussi de labor, sur l'ensemble de la $P L$, paraît au premier abord assez déconcertant.
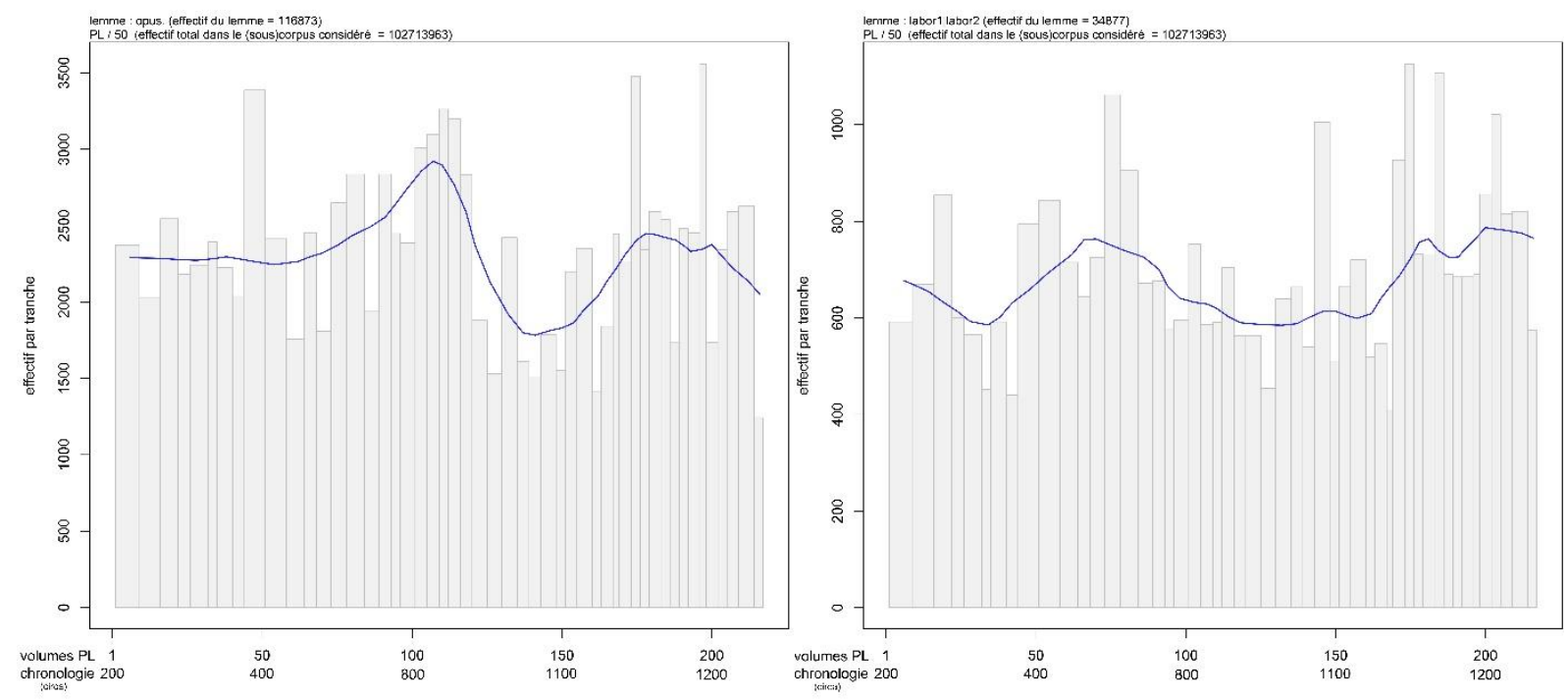

Fig. 3 : Chronologie des mentions d'opus-opera (à gauche) et de labor (à droite) dans la $P L$ (II ${ }^{\mathrm{e}}$-début du XIII ${ }^{\mathrm{e}}$ siècle). Les occurrences sont globalement stables, en dépit d'une légère baisse pour opus entre le milieu du $\mathrm{IX}^{\mathrm{e}}$ siècle et le milieu du XII ${ }^{\mathrm{e}}$ siècle.

Avec environ 116800 occurrences pour opus-opera, et 34800 pour labor, c'est un résultat en creux qui apparaît. Ces lemmes sont en effet globalement stables sur l'ensemble du corpus, même si l'on constate quelques variations sur le temps long (fig. 3) - avec par exemple une légère baisse des mentions entre 850 et 1150 pour opus-opera ${ }^{89}$. Comme chez les Pères, opus est aussi plus fréquent que labor sur l'ensemble de la chronologie couverte. Cette quasistabilité d'opus-opera et de labor dans le corpus n'est pas isolée. Opero, operatio, opifex ou encore opusculum présentent des tendances similaires dans la $P L$. En dehors de quelques oscillations ponctuelles, on serait bien en peine de dégager un quelconque schéma chronologique significatif ${ }^{90}$. Le constat peut même s'étendre à des lemmes dont on attendait a priori une évolution nette, comme fabrica ou operarius. Ars reste aussi plutôt constant entre le $\mathrm{III}^{\mathrm{e}}$ et le milieu du $\mathrm{XI}^{\mathrm{e}}$ siècle environ, moment à partir duquel les occurrences du lemme diminuent. Enfin, si officium et negotium connaissent une hausse, celle-ci est tardive et

\footnotetext{
${ }^{89}$ Soit environ des volumes 120 à 165 de la $P L$. Cette tendance est potentiellement imputable aux évolutions dans la composition du corpus sur cette période.

${ }^{90}$ Nous verrons plus loin que le constat est assez proche dans les CEMA, avec toutefois des variations sur certains termes.
} 
incertaine, limitée pour la $P L$ aux $\mathrm{XII}^{\mathrm{e}}-\mathrm{XIII}^{\mathrm{e}}$ siècles $^{91}$. Tout se passe donc comme si l'évolution fréquentielle et sémantique très forte des lemmes examinés au tournant de l'Antiquité et des premiers siècles du Moyen Âge s'était ensuite figée dans une solution proprement médiévale. Si seule l'analyse sémantique permettra véritablement de poser des hypothèses explicatives, il semble donc que les différents termes retenus aient très tôt trouvé une forme d'équilibre dans les textes théologiques, sans que cet équilibre présuppose une cohérence sémantique globale. Cette stabilité fréquentielle ne plaide pas pour l'identification de ce lexique au «travail », tout au contraire: alors que nous savons par l'historiographie et la documentation que l'Europe médiévale a connu différentes phases dans ses rapports de production entre le $\mathrm{V}^{\mathrm{e}}$ et le XIII ${ }^{\mathrm{e}}$ siècle, rien de tel n'est observable ici à partir des lemmes retenus.
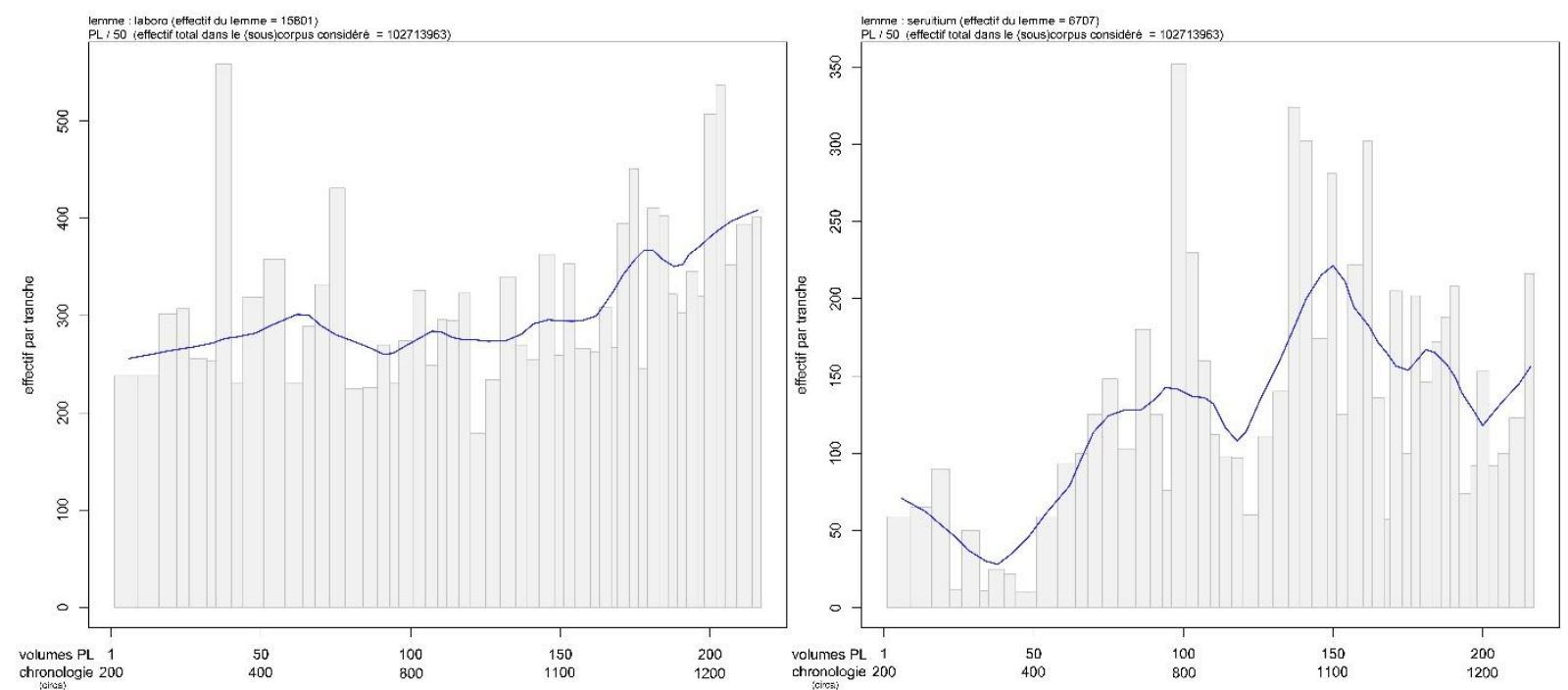

Fig. 4 : Chronologie des mentions de laboro (à gauche) et de servitium (à droite) dans la $P L$ (II ${ }^{\mathrm{e}}$-début du XIII ${ }^{\mathrm{e}}$ siècle). Dans les deux cas, la tendance est à la hausse, même si la dynamique est particulièrement forte pour servitium.

Deux termes offrent cependant des évolutions plus nettes. Il s'agit de laboro et surtout de servitium (fig. 4) ${ }^{92}$. Dans le premier cas, l'augmentation est lente mais tendancielle, puisque les occurrences du lemme sont grosso modo multipliées par 1,5 entre le début et la fin de la $P L$ - avec une accélération à partir de la fin du $\mathrm{XI}^{\mathrm{e}}$ siècle. En ce qui concerne servitium, l'évolution est encore plus franche, puisque ses mentions sont multipliées par 10 environ entre le $\mathrm{IV}^{\mathrm{e}}$ et les $\mathrm{X}^{\mathrm{e}}-\mathrm{XI}^{\mathrm{e}}$ siècles. Si l'on s'en tient strictement au plan quantitatif, cette dynamique est la plus remarquable pour l'ensemble du lexique analysé ${ }^{93}$, et elle tranche fortement avec la stabilité

\footnotetext{
91 « Incertaine » car les derniers tomes de la $P L$ contiennent une typologie documentaire un peu différente, avec en particulier de nombreuses lettres. Les effets enregistrés pourraient donc être liés à cette évolution dans la structure du corpus.

${ }^{92}$ Les analyses du terme servitium sont très rares. L'article d'E. MAGNOU-NORTIER, «Servus-servitium. Une enquête à poursuivre », dans Media in Francia. Recueil de mélanges offert à Karl Ferdinand Werner, Maulévrier, 1989, p. 269-284, obscurcit malheureusement la question en partant de deux hypothèses intenables : le servitium concernerait l'esclavage ; il s'agirait d'une structure héritée de l'Antiquité romaine. Voir cependant A. HARDING, «Servitium debitum », dans Lexikon des Mittelalters, vol. 7, München, 1995, col. 1795-1796 ; L. KUCHENBUCH, «Servitus im mittelalterlichen Okzident. Formen und Trends (7.-13. Jahrhundert)», dans A. DIERKENS, N. Schroeder et A. WILKIN (dir.), Penser la paysannerie médiévale, un défi impossible ?, cit. n. 17, p. 235-274. ${ }^{93}$ On note toutefois une chute importante des mentions du lemme à partir du XII ${ }^{\mathrm{e}}$ siècle. Malheureusement, nous manquons d'un corpus assez dense pour le XIII ${ }^{\mathrm{e}}$ siècle, au-delà d'Innocent III, qui nous permettrait de vérifier si
} 
fréquentielle des autres lemmes. Servitium est en effet relativement rare jusqu'au $\mathrm{V}^{\mathrm{e}}$ siècle. Dans les tomes de la $P L$ qui correspondent aux périodes antérieures, les mentions proviennent, en effet, souvent de textes mal attribués. Ainsi, si un certain nombre d'occurrences se rencontrent en particulier chez Ambroise (81 mentions), le terme reste inhabituel chez des auteurs fondamentaux des $\mathrm{II}^{\mathrm{e}}-\mathrm{IV}^{\mathrm{e}}$ siècles comme Tertullien (10), Jérôme (22) ou encore Augustin (24). L'accélération commence donc aux $\mathrm{V}^{\mathrm{e}}-\mathrm{VI}^{\mathrm{e}}$ siècles, avec par exemple Léon IX, Gélase ${ }^{\mathrm{er}}$, Avit de Vienne, Ennode de Pavie ou encore Grégoire de Tours.
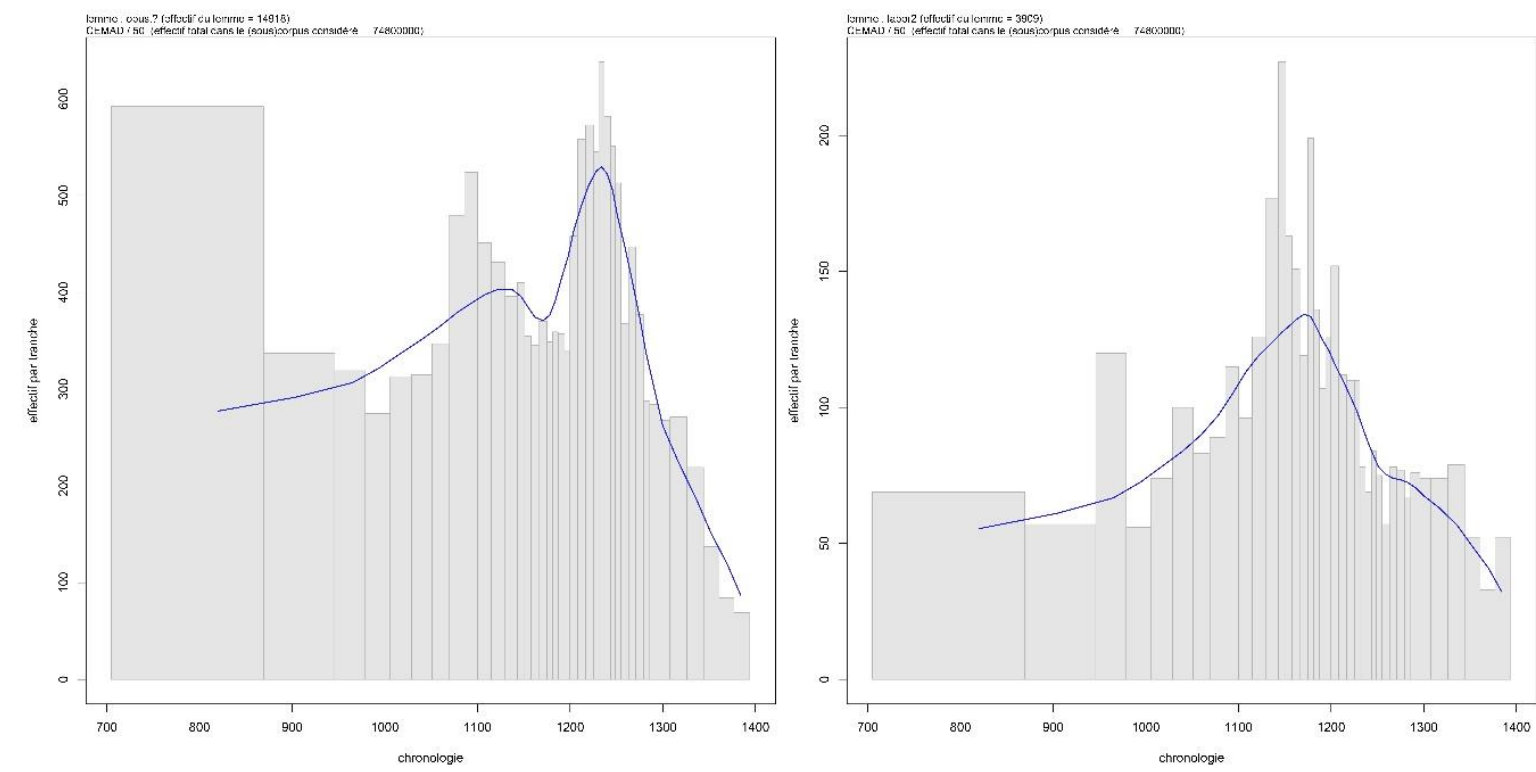

Fig. 5 : Chronologie des mentions d'opus-opera (à gauche) et de labor (à droite) dans le corpus des chartes européennes (CEMA, VIII ${ }^{\mathrm{e}}$-début du XIV ${ }^{\mathrm{e}}$ siècle).

Dans quelle mesure ce constat d'une forte stabilité fréquentielle dans la $P L$ (hors laboro et servitium) est-il extensible aux chartes ? Dans les CEMA, les occurrences d'opus-opera (14 918 mentions datées) et de labor (3909) entre le VIII ${ }^{\mathrm{e}}$ et le début du XIV siècle correspondent à des schémas fréquentiels assez différents. Outre le fait que le second est presque 4 fois moins présent que le premier pendant cette période, leur répartition est non seulement plus dynamique que dans la $P L$, mais aussi plus variée (d'un lemme à l'autre, fig. 5). Opus connaît une évolution en dents de scie, avec trois pics successifs : d'une part dans le très haut Moyen Âge (avant le milieu du IX ${ }^{\mathrm{e}}$ siècle), puis entre 1080 et 1130 , enfin entre 1200 et 1250-1260, le tout suivi d'une chute brutale ${ }^{94}$. La situation de labor est assez différente, avec une augmentation constante entre le VIII ${ }^{\mathrm{e}}$ et le milieu du XII ${ }^{\mathrm{e}}$ siècle, avant une chute.

Contrairement à ce que l'on observe dans les textes théologiques ou narratifs, le lexique retenu fluctue donc assez fortement dans les chartes. C'est aussi le cas d'officium, de negotium, de laboro, d'opero, mais encore de fabrica ou d'operarius, qui connaissent tous un pic

cette chute n'est que temporaire. Les chartes semblent toutefois confirmer que cette chute est réelle, et il en va de même avec le corpus des textes de Thomas d'Aquin - dans lequel on ne trouve que 160 mentions du terme (soit presque 9 fois moins qu'aux $\mathrm{X}^{\mathrm{e}}-\mathrm{XI}^{\mathrm{e}}$ siècles dans la $P L$, pour des ensembles documentaires contenant un nombre de mots comparable).

${ }^{94}$ La chute des mentions de certains lemmes vers 1200-1250 est attendue. Elle est en fait généralisée (on la retrouve pour de nombreux termes) et traduit très probablement une évolution de la typologie diplomatique, voire de la structure sociale. 
d'occurrences entre le $\mathrm{XI}^{\mathrm{e}}$ et le début du XIII ${ }^{\mathrm{e}}$ siècle $^{95}$. C'est toutefois pour servitium que l'évolution est la plus nette : ses occurrences suivent une courbe fortement ascendante entre le début du VII ${ }^{\mathrm{e}}$ siècle et le premier tiers du XIII ${ }^{\mathrm{e}}$ siècle (fig. 6). Ce développement continu doit être considéré d'autant plus sérieusement que le lemme devient le plus fréquent de la liste au sein des CEMA.

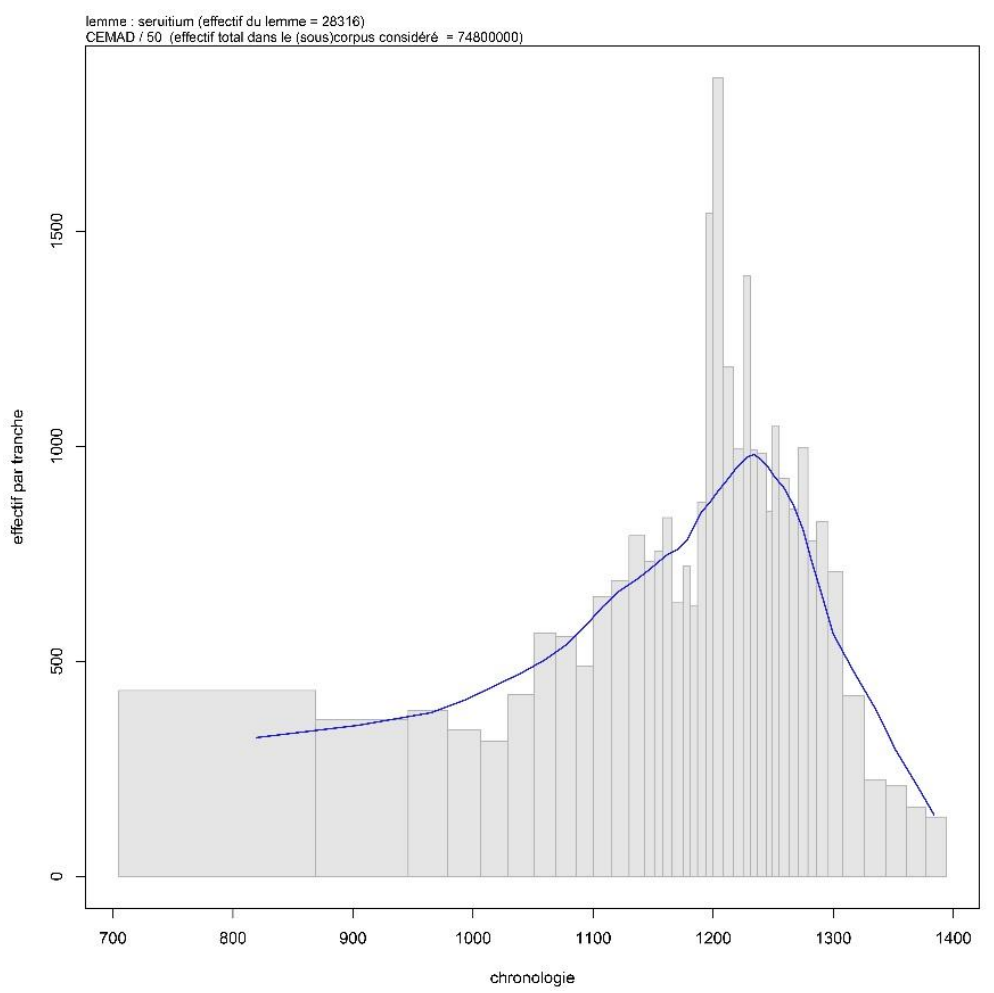

Fig. 6 : Chronologie des mentions de servitium dans le corpus des chartes européennes (CEMA, VII ${ }^{\mathrm{e}}$-XIV ${ }^{\mathrm{e}}$ siècle).

Ces observations numériques sont précieuses, mais elles ne nous renseignent pas véritablement sur le sens des termes retenus, ni sur leur éventuelle cohérence en tant que groupe lexical. Prises comme un tout, elles permettent néanmoins de relever qu'au tournant de l'Antiquité et du très haut Moyen Âge, un basculement a eu lieu pour certains de ces termes. Il se manifeste par la promotion des lemmes opus-opera, au détriment de labor, qui joue manifestement un rôle moindre dans les textes, tout en restant présent ${ }^{96}$. L'ordre fréquentiel entre ces trois termes demeure en outre identique sur l'ensemble de la chronologie examinée : opus-opera étant plus fréquents que labor dans toutes les configurations typologiques ${ }^{97}$. Une des nouveautés est le développement très fort du lemme servitium, qui occupait une place limitée dans l'Antiquité, tout en étant quasiment absent de la Vulgate, et qui ne cesse de gagner en importance sur le millénaire allant du $\mathrm{III}^{\mathrm{e}}$ au XIII ${ }^{\mathrm{e}}$ siècle - et ceci tant dans les textes

\footnotetext{
95 Avec parfois, mais pas systématiquement, un premier pic de mentions avant le IX siècle (toujours potentiellement lié à la forte présence des diplômes).

${ }^{96}$ Même remarque chez Ludolf Kuchenbuch, qui indique dans le présent volume que «[L]abor n'a pas de place prépondérante dans le système de significations de la Regula Benedicti. ».

${ }^{97}$ Une enquête sur l'évolution et la proportion des formes au singulier ou au pluriel serait sans doute instructive, mais elle est en partie empêchée par la confusion des formes communes d'opus et d'opera-confusion encore une fois difficile à démêler pour un lemmatiseur.
} 
théologiques, exégétiques et narratifs, que dans les chartes. C'est toutefois dans ce dernier corpus qu'il prend toute sa place, ce qui indique que son rôle dans les rapports de production était fondamental. Il s'agit donc maintenant d'examiner dans quelle mesure cette série de termes formait un ensemble cohérent (un champ sémantique ?) et quels étaient leurs rapports avec le système de production médiéval en général.

\section{ANALYSES SEMANTIQUES}

\section{III.1. Tentatives d'articulations}

Ces observations fréquentielles doivent évidemment être complétées par une analyse sémantique. Mais est-elle seulement possible ? Nous avons soulevé, tout au long de cette contribution, le problème de la cohérence de ce lexique. Il faut par ailleurs tenir compte d'une difficulté majeure, à la fois abstraite et technique : la reconstruction d'un (ou de plusieurs) schéma(s) sémantique(s) implique de tenir compte à la fois des structures et de leurs dynamiques - qui sont d'autant plus complexes si les termes ne forment pas un ensemble articulé. Afin de procéder le plus méthodiquement possible, il est envisageable de réaliser l'enquête en différentes phases, en procédant d'abord à une analyse synchronique globale (dont les limites sont évidentes, puisqu'elle présuppose là encore une unité sémantique qui n'existe probablement pas), puis en réalisant des analyses diachroniques sur certains termes identifiés comme plus importants ${ }^{98}$.

Pour l'analyse synchronique, nous avons retenu 20 lemmes, dont la liste a été établie à partir des analyses précédentes, mais aussi d'études préalables sur les cooccurrents et l'historiographie ${ }^{99}$. Aux différents termes fréquents déjà repérés (labor, opus, opera, operarius, laboro, opero, operatio, opificus, fabrica, opusculum, ars, officium, opifex, negotium, servitium) s'ajoutent ainsi quelques lemmes complémentaires (fructus, otium, faber, industria). Afin de détecter les éléments sémantiques reliant ces pivots ${ }^{100}$, nous avons établi la liste des 200 cooccurrents les plus importants pour chacun ${ }^{101}$. Ces informations ont été par la suite fusionnées dans un tableau général, dont on a retiré les cooccurrents n'apparaissant que pour

\footnotetext{
${ }^{98}$ L'intérêt intérêt de cette méthode dépend bien entendu de la cohérence du champ lexical examiné : $N$. PERREAUX, «Mesurer un système de représentation? Approche statistique du champ lexical de l'eau dans la Patrologie latine », dans Mesure et histoire médiévale, Paris, 2013, p. 365-374 (Congrès de la SHMESP, 43).

${ }^{99}$ En particulier les articles d'Isabelle Rosé et Ludolf Kuchenbuch dans le présent volume.

${ }^{100}$ Le terme «pivot(s)» est habituellement employé dans ce type d'analyses sémantiques pour distinguer les termes sélectionnés. Une possibilité complémentaire consiste à faire des cooccurrents d'un premier terme les pivots, pour lesquels on calcule ensuite les cooccurrents correspondants (on parle alors de cooccurrents de second ordre).

101 Afin de déterminer cette importance, nous avons employé la fonction CoocA du package Cooc, qui calcule l'indice de Dice. Les listes de cooccurrents employées ont donc été pondérées grâce à cet indice. Ce processus permet de faire ressortir l'intensité de la relation entre deux termes cooccurrents, indépendament de leur fréquence hors de cette relation. Prenons un exemple : ecclesia est omniprésent dans les textes, mais son apparition autour de nombreux termes n'indique pas toujours qu'il s'agit d'une association/cooccurrence significative sémantiquement. L'indice permet précisément de distinguer entre cette « omniprésence fréquentielle » et une coccurrence significative - et celui dit de Dice est en l'occurrence particulièrement efficace.
} 
trois lemmes pivots au minimum ${ }^{102}$. Enfin, le tableau a été binarisé et passé dans une analyse factorielle des correspondances (AFC) ${ }^{103}$.

${ }^{102}$ Ce processus permet de focaliser l'analyse sur ce qui relie les différents pivots, facilitant l'analyse des proximités et des distances entre ces derniers. Une métaphore consisterait à dire que ce processus agit comme un révélateur en chimie. Le seuil de trois lemmes a été fixé après différents essais, mais il fait sens : les cooccurrents qui apparaissent seulement pour un ou deux termes pivots sont peu utiles lorsqu'on cherche à dégager la cohérence d'un ensemble lexical (et donc ce qui relie les termes pivots entre eux). En l'occurrence, le calcul porte tout de même sur 186 cooccurrents, soit plus de 3300 relations sémantiques.

${ }^{103}$ La binarisation consiste à attribuer soit la valeur 1 (si le cooccurrent est présent dans l'entourage du pivot), soit la valeur 0 (s'il est absent) à toutes les cases du tableau. Ce processus a pour objectif de limiter l'analyse à une relation absence/présence. Comme le précédent, il a pour but de renforcer la visibilité des rapports sémantiques examinés. In fine, l'opération permet de réduire la dimensionnalité du tableau. C'est dans cette même perspective que l'analyse factorielle est employée, puisqu'elle permet de transcrire le tableau binarisé en une carte, sur laquelle les pivots possédant des cooccurrents identiques sont visuellement proches. 


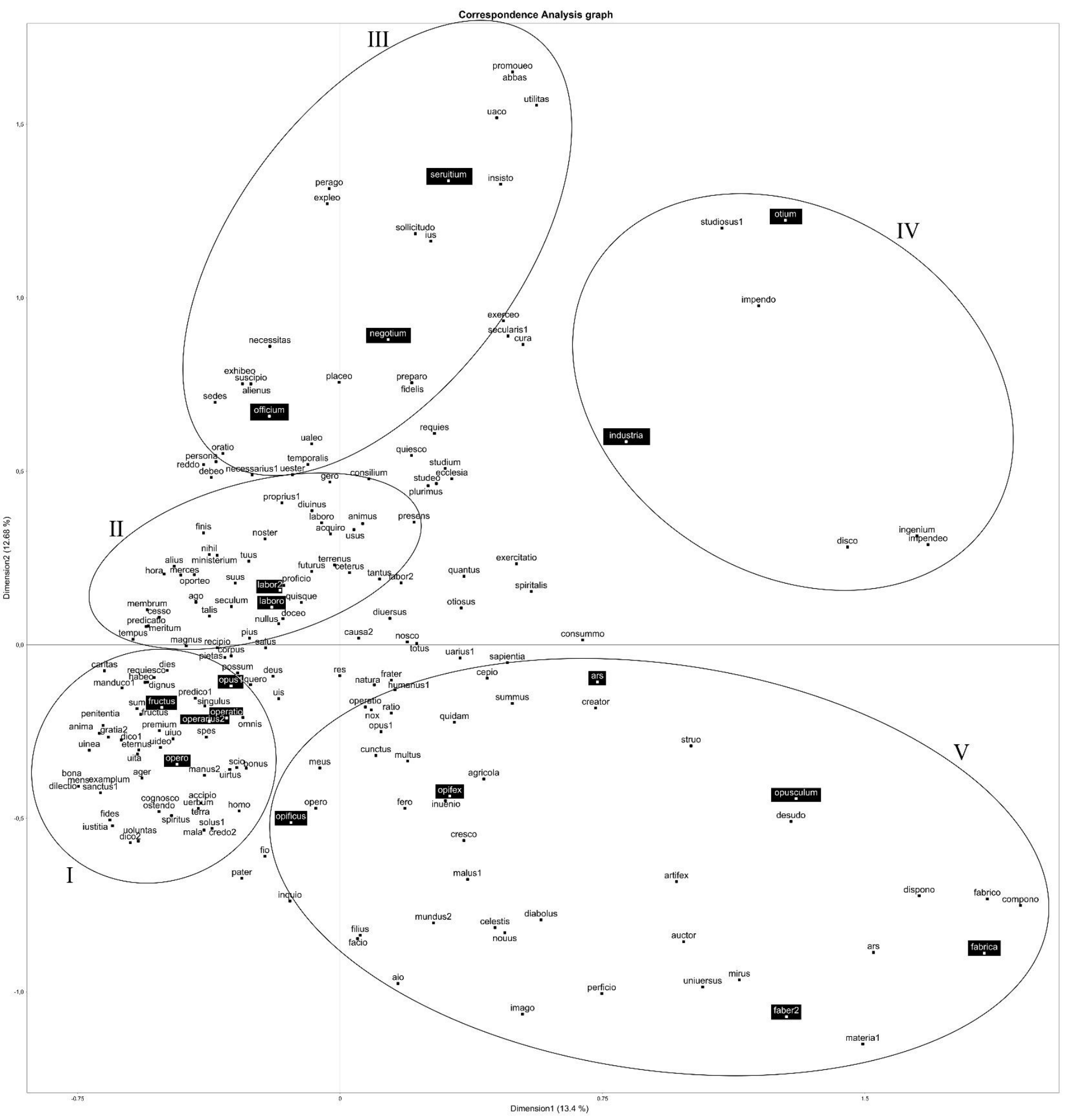

Fig. 7 : Analyse factorielle des termes pivots retenus (en blanc sur fond noir) et de leurs cooccurrents (en noir), dans l'ensemble de la $P L$. 
Il convient une fois encore de rappeler que l'analyse part du présupposé selon lequel ces termes entretiendraient des relations sémantiques fortes. Le biais est évident, et il en résulte une insistance sur ce qui pourrait unir les termes - puisque les pivots ont été présélectionnés - au détriment, d'une part, de ce qui les désunit et, d'autre part, de ce qui pourrait les rapprocher d'autres termes pivots non inclus dans la liste. En dépit de ce présupposé qui pousse à une cohérence factice, l'analyse fait apparaître différentes relations sémantiques ${ }^{104}$.

On relève tout d'abord que des nombreux cooccurrents se concentrent à gauche de l'analyse factorielle des correspondances, autour de quelques pivots: (I) opus, fructus, operatio, operarius, opero, puis (II) labor et laboro. Les autres mots pivots retenus et leurs cooccurrents, à droite de l'AFC, se distribuent de façon peu structurée ${ }^{105}$. On constate, par exemple, que servitium s'isole, même s'il va dans une direction commune avec otium, negotium voire officium (III). Il en est de même pour fabrica, même si, là encore, il existe une tendance commune avec faber, opusculum et ars, ou encore opifex et opificus, cette fois en bas à droite de l'AFC (V). Enfin, en examinant de plus près les cooccurrents autour des pivots situés en haut à droite (IV), on est bien en peine de trouver une structure sémantique globale : que peuvent bien faire ensemble abbas, utilitas, studiosus, sollicitudo, ou encore ius ? La situation n'est pas aussi floue pour les pivots en bas à droite (V : ars, opifex, opusculum, fabrica, faber, voire opificus), qui possèdent des cooccurrents tels qu'artifex, auctor, ars, fabrico, compono, materia, imago, creator, etc., mais encore des verbes d'action tels que compono, fabrico, dispono $^{106}$. L'ensemble paraît donc relever plus ou moins des techniques et de la création, en particulier des techniques constructives ${ }^{107}$. Une analyse complémentaire ${ }^{108}$, portant cette fois sur l'ensemble du tableau (qui renferme plus de 35000 relations sémantiques) montre qu'otium, opusculum, ars, servitium, faber, voire industria, s'isolent très fortement - autrement dit qu'ils ont un grand nombre de cooccurrents propres. La limite de l'analyse est patente : ce n'est qu'en réduisant le tableau aux liens qui peuvent exister entre les termes, que l'on observe une structuration globale.

Outre le groupe relevant des «techniques » $(\mathrm{V})$ et les pivots en haut à droite (IV : otium, industria), le cœur de l'AFC nous paraît donc constitué par deux sous-ensembles : labor et laboro (II), puis opus, fructus, operatio, operarius, opero (I). Ces rapprochements visuels entre labor et laboro, ou encore opus et opero, montrent que l'analyse numérique n'est pas aléatoire. Ainsi, il se dessine des articulations sémantiques au sein des groupes, et parfois même entre les groupes - même si, comme nous le verrons plus loin, elles sont loin d'être simples et directes. Certains cooccurrents contribuent plus fortement à ces regroupements : c'est le cas, en particulier, de manus, bonus-bona, caritas, eternus, vita, sanctus, spiritus, manus, spes, fructus, justicia, vinea, fides pour le groupe I (opus, opero, etc.), mais encore de seculum, tempus, terrenus, finis, futurus, ministerium, etc. pour le groupe II (labor, laboro). Ce qui dessine un

\footnotetext{
${ }^{104}$ Ce n'est pas systématique. De nouveau, nous nous permettons de renvoyer à N. Perreaux, « Mesurer un système de représentation? », cit.

${ }^{105} \mathrm{Si}$ l'on prend une métaphore astronomique, un peu à la manière d'une comète.

${ }^{106}$ Sur la dimension active liée à ces termes, voir L. Kuchenbuch, «Die dreidimensionale Werk-Sprache des Theophilus presbyter. „Arbeits"-semantische Untersuchungen am Traktat De diversis artibus », dans L. KuCHENBUCH, Reflexive Mediävistik. Textus - Opus - Feudalismus, Frankfurt-New York, 2012, p. 341-401.

${ }^{107}$ Nombreuses remarques intéressantes dans A. Guerreau, «Architectus dans les textes latins (fin du IV sièclefin du XIII e siècle)», dans F. Elsig, T. Le Deschault De Monredon, P.-A. MariauX, B. RouX et L. TERRIER (éd.), L'image en question. Pour Jean Wirth, Genève, 2013, p. 14-27.

${ }^{108}$ Non présentée ici.
} 
premier agencement, sur lequel nous reviendrons : l'articulation entre opus et labor se joue en partie autour de l'opposition entre éternité et temporalités.

Deux méthodes peuvent être envisagées pour examiner les liens hypothétiques entre ces lemmes. La première consiste à observer les cooccurrents de chaque terme chez différents auteurs et dans différentes typologies documentaires, afin de voir si les autres termes pivots y apparaissent aussi ${ }^{109}$. Il est bien entendu improbable d'évoquer ici toutes les possibilités (et non-possibilités), tant les combinaisons envisageables entre les termes sont nombreuses. Prenons un exemple : dans le cas de ars, ni opus, ni labor, ni servitium, ni faber n'apparaissent parmi les cooccurrents déterminants. Il en va de même chez les quatorze auteurs examinés pour opifex, qui est seulement présent dans le réseau sémantique direct d'ars chez Augustin ${ }^{110}$. En examinant plus précisément les listes de cooccurrents, il ressort qu'opus et labor apparaissent comme cooccurrents d'ars seulement en $131^{\text {ème }}$ et $153^{\text {ème }}$ positions à l'échelle de la $P L$ toute entière $^{111}$. Il en va de même pour fabrica, qui relève du domaine de la construction et des techniques, et dont les cooccurrents directs contiennent faber ou artifex, mais pas $\operatorname{ars}^{112}$. Ou encore pour servitium, qui dans la $P L$ apparaît par exemple dans des contextes relatifs à l'échange, au devoir et à la domination ${ }^{113}$. On pourrait étendre les exemples à officium, negotium, ou encore otium. Seuls opus, opero, labor et laboro apparaissent conjointement de façon régulière ${ }^{114}$, et encore faut-il nuancer : opus et labor ne sont présents simultanément à 5 mots de distance que 86 fois dans tous les CEMA.

La seconde méthode est plus ambitieuse, puisqu'elle consiste à examiner comment les pivots sélectionnés par l'historiographie et les dictionnaires s'insèrent au sein du réseau sémantique global du système de représentations médiéval. Il faut ici faire appel à la méthode dite des cooccurrences généralisées, qui consiste à établir la liste de tous les cooccurrents d'une grande série de termes, afin de voir comment ceux-ci s'articulent. Plusieurs expériences ont ici été menées dans ce sens, d'abord sur la $P L$ dans son ensemble, puis spécifiquement sur les textes de Raban Maur ${ }^{115}$. Dans les deux cas, une liste des 500 lemmes les plus fréquents a été produite, à laquelle on a ajouté les pivots qui nous intéressent ici ${ }^{116}$. Les cooccurrents significatifs de ces 500 termes ont ensuite été calculés, puis combinés dans un tableau unique,

\footnotetext{
109 Parmi les ensembles examinés : le corpus Antique païen, la Vulgate, la $P L$, les capitulaires, un corpus d'exempla, les CEMA (par siècle), un autre de textes du quinzième siècle, mais aussi plus spécifiquement saint Augustin, Grégoire de Tours, Isidore de Séville, Bède, Raban Maur, Odon de Cluny, Pierre Damien, Bernard de Clairvaux, Hugues de Saint-Victor, Innocent III, Thomas d'Aquin. En retenant au moins dix termes pivots, cela fait plus de 200 listes de cooccurrents et de graphiques correspondants.

${ }^{110}$ Voir la note précédente pour la liste des corpus/auteurs analysés.

${ }^{111}$ Le classement a été réalisé en fonction de l'indice de Dice. À l'inverse, les cooccurrents les plus déterminants sont magicus, liberalis, grammaticus, musica, dialecticus, ingenium, peritia, peritus, artifex, disciplina, medicina, diabolicus, medicus, studium, rhetoricus, imbuo, disco, maleficus, scientia, industria et grammatica.

${ }^{112}$ Ars apparaît en $116^{\text {ème }}$ position dans la liste pour fabrica, dans la PL. On trouve en revanche des liens forts avec la liste suivante : structura, fundamentum, applico, donarius, artifex, superpositus, columna, basis, edificium, erigo, construo, mundanus, consurgo, architectus, mundalis, erogatio, moles, faber, erarius, arca.

${ }^{113}$ Nous reviendrons spécifiquement sur ce terme un peu plus loin.

114 Cela va sans dire : on serait en capacité de trouver tel ou tel texte où certains termes pivots apparaissent conjointement, voire en grand nombre. Notre approche étant structurale, l'objectif n'est pas de relever ce qui tient de l'exception, mais de mieux comprendre l'agencement global du lexique (ou son non-agencement).

${ }^{115}$ Le choix de cet auteur est lié à trois observations articulées : d'une part, Raban est un auteur qui tente de présenter le système de représentations médiéval dans son ensemble; d'autre part, il est généralement très structuré, ce qui permet d'obtenir des modélisations assez lisibles ; enfin, il est plus ou moins situé au milieu de notre chronologie.

${ }^{116}$ Lorsqu'ils ne figuraient pas dans les 500 termes les plus fréquents.
} 
pour enfin être traités dans une analyse factorielle ${ }^{117}$. Les résultats de ces analyses ne sont guère ambigus : si les termes opus, labor (ainsi que leurs dérivés : opero, laboro, etc.) et fructus interviennent parfois dans des contextes communs, l'ensemble des lemmes retenus ne se structure pas en un tout cohérent et homogène, par exemple avec des paires opposées et des correspondances systématiques. Il ne s'agit certes pas de nier les articulations relevées, simplement de dire qu'une stricte cohérence n'existe pas à l'échelle de la liste.

Le cas de fructus est intéressant, car le terme apparait à la fois dans l'entourage d'opus et de labor ${ }^{118}$. À l'inverse, il n'est pas un cooccurrent significatif de servitium. Fructus désigne à la fois la fructification végétale et l'enfantement (en particulier, le Christ enfanté par Marie dans l'Ave Maria : benedictus fructus ventris tui, Jesus), mais plus généralement un résultat (sans que celui-ci implique nécessairement une action) ${ }^{119}$. Le fructus concerne donc à la fois ce que nous appelons aujourd'hui la production et la reproduction. Or, cette fusion des deux aspects n'est pas sans conséquence, dans un système où la « reproduction quasiment à l'identique » participe fortement de l'idéal dominant. Des passerelles existent aussi entre officium et servitium, car les deux termes renvoient aux fonctions de l'officiant lors des rituels ${ }^{120}$. Globalement, toutefois, les tendances exposées à la suite des analyses ponctuelles se confirment: servitium, officium, beneficium, mais encore industria, ars, faber et fabrica relèvent d'espaces sémantiques plutôt disjoints d'opus et de labor (et donc d'opero et de laboro $)^{121}$. Il s'agit donc maintenant d'examiner ce que signifiaient les substantifs les plus fréquents : opus, labor et servitium.

\section{III.2. La fusion de l'action et du résultat (opus)}

La littérature consacrée à opus est abondante mais, dans notre perspective sémantique du moins, peu satisfaisante. Principalement analysé par des historiens de l'art, le terme n'a donné lieu qu'à peu de commentaires structurés ${ }^{122}$. Sa caractéristique principale paraît avoir échappé

\footnotetext{
${ }^{117} \mathrm{Un}$ «nettoyage » du tableau est toutefois nécessaire pour une modélisation plus efficace : il faut en effet que les cooccurrents apparaissent au moins autour d'un nombre minimum de pivots pour qu'ils soient significatifs dans ce cadre. En l'occurrence, nous avons souvent retiré les cooccurrents n'apparaissant qu'une ou deux fois sur les 500 pivots retenus. Enfin, le tableau nettoyé a été binarisé, ce qui permet de focaliser l'analyse sur les relations plutôt que sur les poids de ces dernières.

${ }_{118}$ Mais beaucoup plus rarement autour des verbes opero et laboro.

${ }^{119}$ Ses principaux cooccurrents (pondérés) chez Raban Maur sont : arbor, affero, bonus-bona, opus, lignum, pomum, folium, labor, terra, facio, vinea, mallus, fero, comedo, profero, dulcis, do, gigno, penitentia, semen, etc. Plus généralement, l'idée que des résultats n'induisent pas nécessairement, dans le système de l'Europe médiévale, des actions, pourrait nous parâtre incongru. Pourtant, la Création elle-même n'était pas uniquement liée à des actions, mais bien essentiellement au verbe divin : «Dixitque Deus fiat lux et facta est lux [...] dixit vero Deus congregentur aquae quae sub caelo sunt in locum unum et appareat arida factumque est ita $\mid$ et vocavit Deus aridam terram congregationesque aquarum appellavit maria et vidit Deus quod esset bonum [...] » (Gen 1:3, puis 1:9-10).

${ }^{120}$ Sur ce terme, nous renvoyons à G. AGAMBEN, Homo Sacer. II, 5, Opus Dei, cit. n. 15, chap. 3 « Généalogie de l'officium », qui souligne aussi les passages entre officium, beneficium et servitium/servus/servire.

${ }^{121}$ L'existence de ces « espaces disjoints 》 ou de valences sémantiques différentes n'exclut pas des ponts et des articulations à certains niveaux du système de représentations.

122 Voir cependant P. BONNERUE «Opus et labor dans les règles monastiques anciennes », Studia monastica, vol. 35, 1993, p. 265-291 ; P.C. CLAUSSEN, « Materia und opus: mittelalterliche Kunst auf der Goldwaage », dans V. Von Flemming et S. Schütze (éd.), Ars naturam adiuvans: Festschrift für Matthias Winner, Mainz, 1996, p. 40-49; V. DEBIAIS, «L'inscription funéraire des XI $\mathrm{XI}^{\mathrm{e}} \mathrm{XII}$ e siècles et son rapport au corps. Une épigraphie entre texte et image », Cahiers de civilisation médiévale, vol. 54, 2011, p. 337-362, ici p. 358. Outre les travaux de Ludolf Kuchenbuch et de Michel Lauwers, on trouvera tout de même quelques travaux d'historiens : M. BLANCHARD, De
} 
à de nombreux historiens : le terme désigne à la fois une action et son résultat, la seconde dimension étant sans doute dominante. Il renvoie aussi bien à la Création toute entière (opus $D e i$ ), qu'à la liturgie ${ }^{123}$, aux prières et aux offices (opus Dei, opus divinum), à la construction de bâtiments (en particulier ecclésiaux, mais aussi des ponts), à tout ce qui est nécessaire au fonctionnement d'une institution (le plus souvent ecclésiale : ad opus ecclesie, ad opus monasterii - avec des cooccurrents tels que edifico, necesse, necessarius dans les CEMA) ${ }^{124}$, mais plus globalement aux (bonnes) actions, et en particulier à celles touchant aux dons et à la transformation des choses. Dans ces multiples significations d'opus, la fusion de l'agir et du résultat apparaît à tous les niveaux : le lemme désigne aussi bien l'" action » de Dieu dans la Création que cette dernière, aussi bien le service divin en pratique que la liturgie au sens théorique, aussi bien la construction d'une église que le bâtiment qui en résulte. En règle générale, opus paraît avoir eu une valence globalement positive, et pour tout dire spirituelle. Bonus et bona constituent des cooccurrents centraux du terme ${ }^{125}$, même s'il arrive qu'opus soit plus rarement associé à quelque chose de négatif ou de charnel ${ }^{126}$. C'est en particulier le cas dans les mentions d'opera diaboli, ou encore d'opera carnis, qui se rencontrent assez fréquemment dans la $P L^{127}$. En règle générale, cependant, le terme s'attache à des actions valorisées, spirituelles et ecclésiales, que ce soit l'opus Dei ou les opera manuum cotidiana des règles monastiques ${ }^{128}$. Les mentions ad opus ecclesie sont particulièrement fréquentes dans les corpus : 2115 mentions associent directement opus à ecclesia au sein des CEMA, contre seulement 94 pour castrum (opus castri) par exemple ${ }^{129}$. Si le syntagme opus Dei apparaît dès la Vulgate (4 occurrences), on le retrouve des milliers de fois dans les textes médiévaux. Il désigne toute action divine, mais évoque en particulier la Création de l'Homme et de son âme (anima) : homo est opus Dei per creationem, écrit l'Ambrosiaster dans ses commentaires sur Paul $^{130}$. Outre la Création, la liturgie et la construction des églises, le lemme renvoyait aussi aux activités intellectuelles et à leur matérialisation (studium apparaît comme un cooccurrent important : lecture, rédaction des traités, fabrique des manuscrits, enluminure, etc.), autrement dit des éléments connotés très positivement dans la logique dominante de l’Europe médiévale.

materialibus ad immaterialia, cit. n. 18, p. 104-147 ; V. TONEATTO, Les banquiers du Seigneur. Évêques et moines face à la richesse (IVe-début IX siècle), Rennes, 2012, p. 277-281; ainsi que la contribution d'Isabelle Rosé dans le présent volume.

${ }^{123}$ Outre les références déjà mentionnées, voir P. POURRAT, La théologie sacramentaire. Étude de théologie positive, Paris, 1907 - en particulier sur la distinction ex opere operato / ex opere operantis.

${ }^{124}$ Les occurrences ad opus castri sont très rares : 31 mentions seulement sur l'ensemble des CEMA, contre 655 pour ad opus ecclesie. Nous pensons que cette situation n'est pas seulement imputable à la nature de la documentation.

${ }^{125}$ Par exemple : ut cum venerimus ante tribunal Christi, non nos de neglegentia judicet, set de bonis operibus gratuletur ut pius, en février 767 dans un acte du médecin royal lombard, Gaidoaldus, conservé aux archives de Florence, dans Codice Diplomatico Longobardo, éd. L. SCHIAPARELLI, Rome, 1929-1933, n 203.

${ }^{126}$ Voir les exemples donnés dans «Opus », dans Novum Glossarium Mediae Latinitatis, vol. Opertura-Ordino, Copenhague, 1980, p. 631.

${ }^{127}$ Par exemple chez Ælred de Rievaulx : Dignos fructus poenitentiae facimus, si opera carnis, quibus regnat in homine diabolus, abiicientes, et terram cordis nostri vomere compunctionis scindamus, ut pullulent ex ea fructus spiritus, charitas, gaudium, pax, et caetera quae enumerat Apostolus (Aelredus Rievallensis, Sermones de tempore, dans PL 195, col. 209-360d, col. 292d). Le syntagme opera carnis est en revanche très rare dans les chartes (seulement 4 occurrences dans les CEMA).

${ }^{128}$ M. LAUWERS, «Opus manuum et labor agrorum », cit. n. 17, p. 883-884.

129 À plus ou moins trois mots de distance. Nous sommes toutefois conscients qu'ecclesia, dans ce contexte, pouvait désigner à la fois un bâtiment, une institution ou l'Église toute entière. Un exemple pour castrum : Qualemcumque concordiam bannitus faciat comiti remanebit tamen bannitus donec viris Gandensibus ad opus castri LX solidos dederit, au sein d'une ordonnance comtale de 1177, dans De oorkonden der graven van Vlaanderen (juli 1128-september 1191), II. Uitgave. Band II, éd. T. DE HeMPTINNE, A. VerhulST, L. DE MEY, Brussel, 2001, n 435 (Diplomata Belgica, 4003).

${ }^{130}$ Ambrosiastri qui dicitur Commentarius in Epistulas Paulinas, éd. H.J. VoGELs, Vienne, 1966, p. 447 (14, 20). 
À l'inverse de labor, opus ne semble pas décrire un état transitoire, mais un accomplissement dans lequel le processus se fond. Certes, le lemme désigne, comme nous l'avons dit, une action, une transformation, mais le résultat d'opus est le plus souvent une manifestation durable, stable. Un calcul élémentaire sur les CEMA permet de relever que plus du tiers des mentions d'opus est associé à ad (ad opus) - contre seulement 1,1\% pour labor et $3 \%$ pour servitium ${ }^{131}$. On comprend ainsi que l'opus est très fréquemment effectué pour une destination précise, autrement dit qu'il est polarisé mais surtout polarisant : on œuvrait pour quelque chose. Il ressort de ces quelques remarques un tableau très orienté des actions-résultats, des « œuvres » désignées par ce terme : opus est plutôt positif, indissociablement une action et un résultat (mais avec une insistance sur ce dernier aspect), presque toujours polarisé. Il possédait ainsi de nombreux caractères communs avec le don, lui-même considéré comme une action transformatrice et un résultat polarisé/polarisant ${ }^{132}$. En 1071, à Saint-Benoît-sur-Loire, un très beau préambule évoque, par exemple, les bona opera et maxime per eleemosinarum largitionem $^{133}$. Parmi les cooccurrents fondamentaux d'opus apparaissent caritas, misericordia, pietas, gratia, fides, merces, voire justicia. Associée aux thèmes fondamentaux de la juste circulation sociale ${ }^{134}$, de la «bonne action », la conséquence de l'opus est d'abord au ciel ${ }^{135}$. Quant à la dimension manuelle, elle n'est pas négligée dans le lemme, bien au contraire, mais seulement dans le sens où manus, autre cooccurrent du terme ${ }^{136}$, constitue un autre lemme très fortement lié à l'idée de Création. Les actions des «mains » sont à l'image de la Création divine : elles transforment des matériaux bruts en éléments spirituels, à ceci près qu'elles ne le font pas ex nihilo. On peut noter que les autres membres corporels ne semblent pas spécifiquement mobilisés dans l'opus : il s'agit d'un point important, différent de ce que l'on observera concernant labor. Tout se passe en définitive comme si opus ne relevait pas ou peu de problématiques mondaines, en tout cas charnelles. Ce n'est que parce que le terme est parfois associé à labor que certaines «œuvres» désignées par opus sont pénibles ou encore

\footnotetext{
${ }^{131}$ L'association directe $a d+$ opus renvoie 5685 occurrences dans les CEMA (sur 16890 mentions au total pour opus, soit 33,7\%), tandis qu'ad + labor donne seulement 51 mentions (sur 4610, soit 1,1\%), et enfin ad + servitium 880 (sur 29 241, soit 3\%).

${ }^{132}$ Sur le trésor, nous renvoyons à E. MAGNANI, «Un trésor dans le ciel. De la pastorale de l'aumône aux trésors spirituels (IV ${ }^{\mathrm{e}}-\mathrm{IX}^{\mathrm{e}}$ siècle)», dans Le trésor au Moyen Âge : discours, pratiques et objets, éd. L. BURKART, P. Cordez et P.-A. MariauX, Firenze, 2010, p. 51-68 ; A. Guerreau-JALABERT et B. BON, « Le trésor au Moyen Âge : étude lexicale », dans Ibid., p. 11-32.

133 Omnis homo, quandiu hac fragili carne circumdatus in huius exilii miserrima relegatione a domino peregrinatur, semper debet sibi ante mentis oculos tremendi iudicii discussionem ponere et omni vigilantia satagere ut per bona opera et maxime per eleemosinarum largitionem et dignam ad deum conversionem, mereatur redire ad suum creatorem a quo discessit per primi parentis temerariam offensionem (Recueil des chartes de l'abbaye de Saint-Benoît-sur-Loire, tome 1, éd. M. PrOU et A. VIDIER, Paris, 1907, n LXXX).

${ }^{134}$ Différentes réflexions importantes dans A. GUERREAU-JALABERT, «Caritas y don en la sociedad medieval occidental », Hispania. Revista española de historia, vol. 60, 2000, p. 27-62 ; M. LAUWERS (dir.), Monastères et espace social. Genèse et transformation d'un système de lieux dans l'Occident médiéval, Turnhout, 2014 ; ainsi que les travaux mentionnés note 132.

${ }^{135}$ Il faudrait ici réaliser une étude de grande ampleur sur le verbe opero. Parmi les cooccurrents très significatifs du lemme, on relève en effet miracula et mirabiliter. Les saints, de fait, « opèrent » des miracles. Derrière opero apparaît ainsi une part importante de la pensée des actions médiévales : Dieu a œuvré pour les hommes (qui font partie de l'opus Dei), et c'est à eux désormais d'œuvrer pour se rapprocher de lui, pour atteindre leur Salut. Cette dimension anthropologique, largement délaissée ici, est actuellement analysée par Didier Méhu dans son ouvrage à paraître, La révolution symbolique de l'Occident à la fin du IVe siècle, cit. n. 85.

${ }^{136}$ Par exemple dans le corpus des règles incluses dans la $P L$, où les principaux cooccurrents d'opus sont (par ordre d'importance pondéré ; mots outils exclus) : bonus, opus, bona, labor, manus, opero, exerceo, abrenuntio, iniungo, occupo, cogitatio, facio, fructus, perficio, perfectio, fides, compleo, glorifico. Sur manus, voir les contributions de Michel Lauwers et Ludolf Kuchenbuch déjà mentionnées, ainsi que A. MICHEL, «Le travail des mains dans la littérature latine du Moyen Âge », dans Vie spéculative, vie méditative et travail manuel à Chartres au XII siècle, dir. par R. Faloci, Chartres, 1998, p. 19-29.
} 
douloureuses à réaliser. Opus traduit généralement une certaine joie (gaudium) dans l'action, puisque son résultat est globalement positif et stable.

Que déduire de cette fusion du processus et de la chose dans opus quant à la possibilité d'un «travail médiéval»? Le fait que le terme désignait simultanément des actions et leurs conséquences nous paraît s'opposer, ici encore, au fait qu'il ait pu exister un travail en général dans l'Europe médiévale ${ }^{137}$. Cette fusion bloquait en effet, d'une part, la possibilité de considérer l'action (désignée par opus) comme une «valeur » (et donc comme quelque chose qui implique une rétribution terrestre, pécuniaire) et, d'autre part, la possibilité d'envisager le résultat comme une marchandise (puisque l'opus est effectué en vue d'un résultat et d'une destination bien précise, ce qui empêche de facto toute libre circulation, ou circulation nonpolarisée) ${ }^{138}$. La combinaison du processus et du résultat dans opus (mais aussi partiellement dans servitium) entravait donc le dégagement du résultat en tant qu'entité autonome, puisque ce dernier renvoyait parallèlement à sa création - et donc au motif de cette création, ainsi qu'à la destination de cette dernière. Dans ces conditions, il faut conclure qu'un « marché de l'opus » était structurellement inenvisageable. Or, nous avons montré plus haut que le terme avait connu une promotion considérable lors du passage au système chrétien, dès la Vulgate - et qu'il désignait même une part importante des actions-résultats les plus valorisés. Autrement dit, les actions-résultats les plus valorisées (églises, Création, messes, etc.) n'étaient pas permutables ou échangeables.

Ces éléments ont-ils connus d'importantes variations au cours des siècles ? Si l'on compare l'évolution des cooccurrents dans l'Antiquité païenne, d'une part, et chez les Pères de l'Église, d'autre part ${ }^{139}$, on constate tout d'abord des différences extrêmement importantes. L'opus antique se distingue, en effet, par ses liens avec labor, dominus, bellum, pretium ou encore pecunia. L'idée d'une œuvre (ou d'œuvres) divine(s) y est par ailleurs très rare : seulement 4 occurrences d'opera Deorum ont été relevées dans le corpus antique à notre disposition ${ }^{140}$. Il s'agit de différences très sensibles, puisqu'encore une fois le syntagme désigne, dès les premiers textes chrétiens, aussi bien la liturgie que la Création, et en particulier celle de l'homme et de son âme. Chez les Pères, se met ainsi en place une structure où opus est fortement articulé au couple bien-mal (bonus-bonum / mala-malus / deus-diabolus), au salut (fides, caritas, gratia, virtus, merces, meritum, penitentia), mais aussi aux activités intellectuelles (studium, doctrina). L'opus devient ainsi un élément de la tension entre chair et esprit, de la foi, de la pénitence et de la grâce. On comprend que le lemme s'insère désormais dans l'architecture chrétienne du salut, en lien avec la pratique du don, la construction ecclésiale, la théologie et la connaissance des textes.

\footnotetext{
${ }^{137}$ Du moins jusqu'au XIII ${ }^{\mathrm{e}}$ siècle, terminus ante quem principal de notre étude. Pour les siècles ultérieurs, d'autres documents que ceux mobilisés ici seraient nécessaires pour affiner l'analyse.

${ }^{138}$ Ce qui n'exclut pas, bien entendu, l'idée que les médiévaux étaient capables de hiérarchiser l'intérêt, la préciosité, la qualité des objets. Nous pensons cependant que cette compréhension qualitative ne rendait pas pour autant possible la circulation d'un grand nombre de choses, dont la destination était fixe, polarisée et polarisante. Il s'agit donc de distinguer entre capacité de hiérarchiser et de permutter-échanger-vendre. Sur ce thème, on trouvera différentes réflexions dans L. FELLER et A. RODRIGUEZ (dir.), Objets sous contraintes. Circulation des richesses et valeur des choses au Moyen Âge, Paris, 2013.

${ }^{139}$ Nous avons employé ici la fonction CoocC de la bibliothèque Cooc. Elle compare les listes de cooccurrents dans plusieurs corpus, afin de faire ressortir ceux qui sont spécifiques/propres à chaque ensemble.

${ }^{140}$ Dont trois chez Cicéron et une autre chez Quintilien. Par exemple : Negat opera deorum se uti ad fabricandum mundum, dans Cicéron, Academica, II, dans On the Nature of the Gods. Academics, Cambridge, 1933, p. 622.
} 


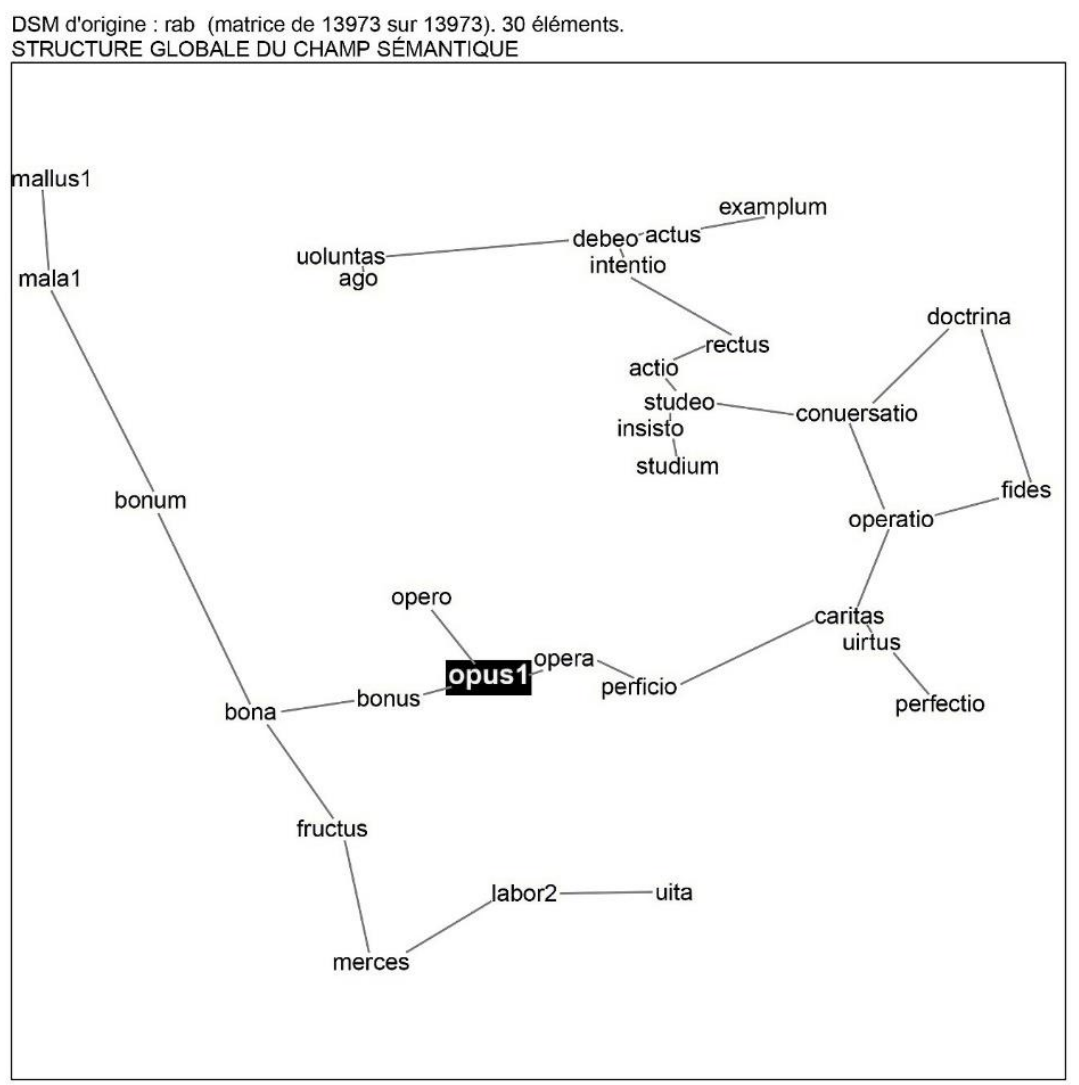

Fig. 8 : Champ sémantique d'opus dans les textes de Raban Maur (PL, méthode WSDSM). Les traits relient les termes les plus proches sur le plan factoriel, sans jamais laisser un terme isolé.

Si nous avançons dans les siècles et retenons un auteur important de la période carolingienne, nous constatons que cette structure est bien visible chez Raban Maur (fig. 8), concernant en particulier les bonnes et les mauvaises actions (à gauche de l'analyse), la caritas, la fides et les qualités qui leurs sont associées, mais aussi l'étude des textes chrétiens (en haut à droite). Ces aspects sont fondamentaux dans tous les corpus consultés, et témoignent d'une assez grande stabilité sémantique ${ }^{141}$. Ils renvoient largement à la logique anthropologique du Salut chrétien : une bonne action consiste à se conformer au projet divin (et donc, sur terre, à la logique ecclésiale), tandis que la mauvaise action est mal orientée, qu'elle désoriente, éloigne de Dieu et de la caritas. Dans les chartes, opus ne renvoie pas nécessairement à une tâche précise, mais plutôt à cette action-résultat orientée - c'est-à-dire à une œuvre, au sens de «bonnes œuvres ». Ces documents mentionnent fréquemment les syntagmes ad opus ecclesie, ad opus fratrum, ad opus sancti, ad opus monachorum, ad opus pauperum, ad opus monasterii, ad opus canonicorum, ad opus domus, ad opus domini, ad opus conventus ${ }^{142}$, et même plus rarement ad opus molendini ou ad opus grangie ${ }^{143}$.

\footnotetext{
${ }^{141}$ Cette stabilité avait déjà été observée en ce qui concerne les fréquences seules (voir la seconde partie de la présente contribution).

${ }^{142}$ Les syntagmes sont classés par ordre d'importance dans les CEMA.

${ }^{143}$ Ces deux expressions ne sont pas si peu fréquentes, avec respectivement 29 et 17 mentions. Dans la totalité des cas, elles se rencontrent entre la toute fin du XI ${ }^{\mathrm{e}}$ et le tout début du XIII ${ }^{\mathrm{e}}$ siècle, en particulier dans les abbayes de l'actuelle France.
} 

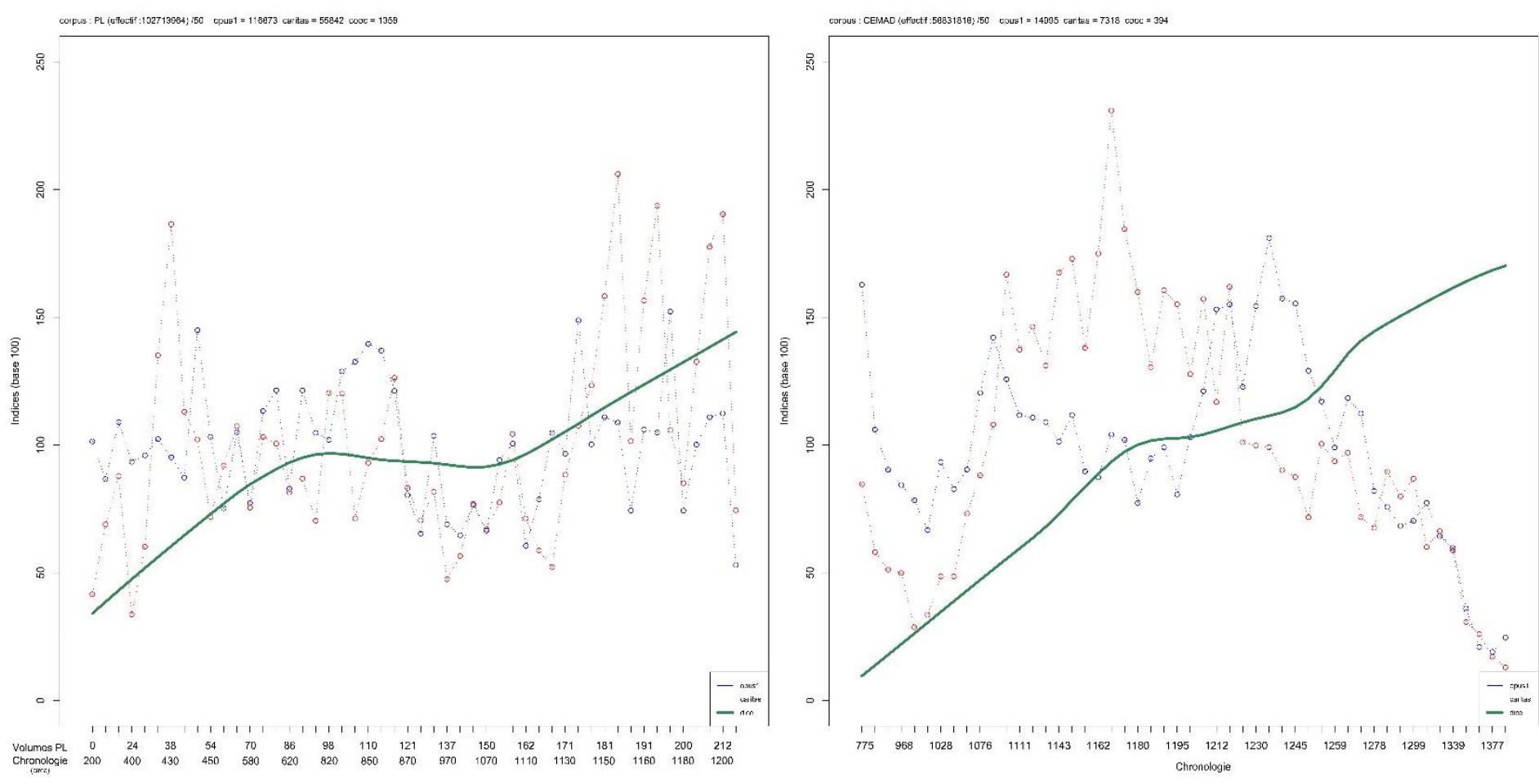

Fig. 9a et b : Évolution des associations (cooccurrences) entre opus et caritas dans la PL (III$\mathrm{XIII}^{\mathrm{e}}$ siècle) et les CEMA ( $\mathrm{VIII}^{\mathrm{e}}-\mathrm{XIV}^{\mathrm{e}}$ siècle).

L'idée qu'opus est articulé à la caritas, nous l'avons déjà dit, est présente dès les Pères (fig. 9a). Mais elle semble se renforcer lors des premiers siècles du Moyen Âge, avec une accentuation des cooccurrences des deux lemmes entre le $\mathrm{III}^{\mathrm{e}}$ et le début du VII ${ }^{\mathrm{e}}$ siècle, puis aux $\mathrm{XI}^{\mathrm{e}}-\mathrm{XII}^{\mathrm{e}}$ siècles. Dans les CEMA (fig. 9b), l'évolution est encore plus visible, avec une augmentation constante de cette association entre le VII ${ }^{\mathrm{e}}$ et le $\mathrm{XIV}^{\mathrm{e}}$ siècle ${ }^{144}$. Il en va de même dans la $P L$ pour d'autres couples sémantiques remarquables, comme opus-eleemosyna ou encore opus-misericordia. Ce que nous avons appelé la promotion chrétienne de l'opus s'accompagne d'un renforcement progressif mais net de la valeur positive, spirituelle, accordée à opus. Parallèlement, le lien entre ce terme et salus s'affirme lors de la période carolingienne, puis au XII ${ }^{\mathrm{e}}$ siècle. Une autre dynamique, très claire, concerne l'association entre opus et ecclesia, qui se renforce continuellement entre le $\mathrm{III}^{\mathrm{e}}$ et le milieu du $\mathrm{IX}^{\mathrm{e}}$ siècle. En contrepartie, nous avons pu observer qu'opus s'éloignait, dans la $P L$, d'autres termes comme terra, mundus ou encore diabolus. La spiritualisation du lemme semble donc être allée croissante au fil des siècles.

\subsection{Un état transitoire et souffrant (labor)}

Bien qu'opus et labor apparaissent parfois conjointement dans les textes, nous allons voir qu'il est délicat de les considérer sur un même plan. Alors que le premier évoque une action-résultat, dirigée vers une finalité (i.e. le résultat), le second désigne plutôt un état

\footnotetext{
${ }^{144}$ Avec 394 cas relevés au total, à une distance de plus ou moins cinq mots. Par exemple : Cum totius boni operis perfectio in sola caritate consistat caritas autem nisi per exhibitionem boni operis perspicua et euidens esse [...], en mai 974 dans un acte d'Otton II pour sa sœur, l'abbesse d'Essen Mathilde (II), dans Die Urkunden Otto des II (MGH DD O II), éd. T. SICKEL, Hanovre, 1888, $\mathrm{n}^{\circ} 77$.
} 
transitoire, non permanent. Ainsi, conformément à la logique globale des représentations médiévales concernant la stabilité et l'instabilité, le temps et l'éternité, opus est plutôt valorisé, tandis que labor est généralement déprécié. Ce dernier terme évoque, en effet, la souffrance et la peine, qui apparaissent comme des états temporaires, liés au siècle et au statut des hommes après la Chute. Commentant les épîtres pauliniennes (Rom 6, 4), Augustin écrit ainsi dans ses lettres : Ambulamus ergo in re laboris, sed in spe quietis : in carne vetustatis, sed in fide novitatis $^{145}$. Alors que l'espérance (spes) est fortement associée à la stabilité (son allégorie iconographique est une ancre de bateau, située analogiquement dans les flots du temps/monde $\left.{ }^{146}\right)$, labor est ici associé par Augustin à un déplacement (ambulo), mais aussi à la chair et à la décrépitude (carne vetustatis). Or, il ne s'agit pas d'un déplacement neutre, puisque, contrairement à via, le verbe ambulo paraît impliquer une forme d'errance, voire même de souffrance $^{147}$. Dix siècles plus tard, dans les textes théologiques et conciliaires du $\mathrm{Xv}^{\mathrm{e}}$ siècle, labor est toujours lié à des termes (certes plus positifs) comme peregrinatio. Le labor est indissociable de la condition humaine dans le monde. Ces éléments d'opposition et d'articulation entre opus et labor ne forment toutefois pas une structure au sens strict, car labor appartient fondamentalement à la logique mondaine, tandis qu'opus n'implique pas toujours le rejet du monde : ils s'insèrent donc à différents niveaux du système de représentations ${ }^{148}$.

On trouvera par ailleurs différents éléments de non-opposition entre opus et labor, à la fois dans l'historiographie et dans les textes ${ }^{149}$. Dans un diplôme de Louis le Pieux, en 822, pour Saint-Pierre, Saint-Jean et Saint-Remy de Sens, le scribe propose une articulation entre laboris studium et pietatis opus ${ }^{150}$. Il est vrai que studium est un cooccurrent fréquent et valorisé de labor, chez des auteurs très éloignés chronologiquement, d'Isidore de Séville à Thomas d'Aquin, en passant Pierre Damien et Hugues de Saint-Victor. Mais cette apparition, comme d'autres, peut aussi se comprendre comme une hiérarchisation : le studium ne serait pénible que dans la mesure où il est ici comparé à une « œuvre pieuse », plus valorisée encore. D'autres combinaisons sont tout aussi intéressantes : Christum, qui est finis laboris, et merces operis, liton chez le pseudo-Rufin ${ }^{151}$. Plus généralement, l'articulation des deux termes joue sur le fait que la réalisation de l'opus peut potentiellement engendrer une pénibilité, une douleur... sans que cette réalisation ne l'implique nécessairement. Ainsi, alors qu'opus renvoie fondamentalement à la Création et à la liturgie, ce n'est jamais le cas de labor : la notion même de labor Dei paraît quasiment antinomique ${ }^{152}$. Opus n'engage parallèlement presque jamais la

\footnotetext{
145 Sancti Aurelii Augustini Hipponensis episcopi opera omnia, tome 2, Petit-Montrouge, 1841, col. 217.

${ }^{146}$ Sur ces associations, nous nous permettons de renvoyer à N. PERREAUX, L'eau, l'écrit et la société. Étude statistique sur les champs sémantiques dans les bases de données, Dijon, 2010, p. 463-464.

${ }^{147}$ Dans la Vulgate, tenebre apparaît 16 fois comme cooccurrent de ambulo.

${ }^{148}$ Contrairement à de nombreux autres lemmes (dominus / homo, dominus / servus, anima / corpus, homo / femina, etc.). Il est donc délicat de dire que les deux termes forment un couple binaire. Sur l'analogisme, outre les textes d'Anita Guerreau-Jalabert, Bruno Bon et Joseph Morsel déjà cités note 33, voir P. DESCOLA, Par-delà nature et culture, Paris, 2005 ; C. Lévi-Strauss, La pensée sauvage, Paris, 1962 ; A. LovEJOY, The Great Chain of Being: A Study of the History of an Idea, Cambridge, 1936 ; M. GRANET, La pensée chinoise, Paris, 1934. La pensée analogique médiévale se distingue de nombreux autres systèmes du même type par son organisation en paires polarisées, renvoyant aux éléments centraux de la pensée chrétienne occidentale.

149 J.-C. BonNE, «Pensée de l'art et pensée théologique dans les écrits de Suger », dans Artistes et Philosophes : Éducateurs?, Paris, 1994, p. 28.

${ }^{150}$ ad laudem obsequium que ipsius toto uite sue cursu noscuntur nostri laboris studium et pietatis opus apud Deum (Die Urkunden Ludwigs des Frommen, éd. THEO KÖLZER et al., Wiesbaden, 2016, n 209). Ou encore en 822 : omnibus laboribus, operibus et oneribus sive difficultatibus, dans un acte de Ceolwulf $\mathrm{I}^{\mathrm{er}}$ pour Christ Church de Canterbury (Sawyer $n^{\circ} 186$ ).

${ }^{151}$ Rufinus Aquileiensis Incertus, Commentarius in LXXV Psalmos, dans PL 21, col. 645-960b, ici col. 789d. Ce qui nous rapproche de la citation d'Augustin déjà mentionnée, note 145.

${ }^{152}$ Seulement 25 occurrences dans la $P L$ associent directement labor et Deus (contre plus de 2500 pour opus et Deus). Les rares mentions de laboro / labor à proximité immédiate de Deus concernent d'ailleurs la négation de
} 
dimension corporelle, en dehors des mains, comme on l'a vu. À l'inverse, labor semble convoquer tout le corps, dans sa dimension la plus charnelle. La sueur (sudor) fait partie de ses cooccurrents principaux, elle-même étant associée à dolor. L'accouchement est fréquemment désigné par le substantif labor (par exemple dans le syntagme labore partus ${ }^{153}$ ), chose beaucoup plus rare avec opus. Dans l'acte d'engendrement, c'est encore une fois la dimension ponctuelle, temporelle, voire fugace qui apparaît : le labor passe, mais l'opus reste, précisément parce que le premier ne désigne pas un résultat. Le terme représente encore une fois un état transitoire, un passage souffrant.

Contrairement à opus, labor s'insère dans différentes séries d'analogies intéressantes. $\mathrm{Au} \mathrm{XIII}^{\mathrm{e}}$ siècle, Étienne de Bourbon, qui cite saint Augustin, oppose le lemme à requies. On retrouve ainsi l'opposition entre un état dynamique, mouvant (labor), et un autre statique, paisible (requies). Mais le dominicain va plus loin et dresse un tableau d'analogies emboîtées : vita s'oppose à mors, salus à dolor, requies à labor, honor à contumelia, divitia à paupertas ${ }^{154}$. En outre, alors que l'on subit ou que l'on affronte le labor (subire labores), on reçoit la requies, qui est donnée (dare requiem). Labor s'associe ici avec mors, dolor, contumelia et paupertas : on ne peut guère faire plus explicite en matière de négativité.

À l'échelle de la $P L$ ou des CEMA, labor penche plutôt du côté charnel du système de représentations ${ }^{155}$. Parmi les lemmes dominants autour de labor, on relève ainsi dolor, difficultas, periculum, molestia, tormentum, afflictio, fatigatio, calamitas, meror, incommodum, periculum, tedium, sudor ou encore tribulatio. L'idée d'un « labeur pénible » est quasiment une tautologie, présente dès les Pères - quand bien même le lien entre labor et péché n'est pas la conséquence strictement logique de ce dernier, mais une simple résultante de l'état mondain. Il existe pourtant un «labeur pieux », celui que l'on mène dans la vigne du Seigneur, et il a d'ailleurs tendance à se renforcer au fil du temps selon nos analyses. Plus qu'opus par ailleurs, labor est lié à merces, soit à l'idée d'une forme de récompense. Le labor est aussi lié à fructus, donc à sa propre conséquence.

\footnotetext{
celui-ci, sous la forme du repos du dimanche après la Création : non enim laboravit Deus, ut quietis indigeret (Augustin, Sermones de tempore, dans PL 38, col. 995-1248, ici col. 1242).

153 Partutio apparaît comme cooccurrent de labor dès la Vulgate.

${ }^{154}$ Venit ad nos celestis negotiator accipere paupertatem, dare divitias, accipere contumelias, dare honores, subire labores, dare requiem, accipere dolores, dare salutem, subire mortem, dare vitam. Item, Augustinus in persona Domini: Habeo venale. Quid? Ait: regnum celorum, paupertate adquiritur regnum, dolore gaudium, labore requies, ignominia gloria, morte vita (Stephanus Borbonensis, Tractatus de diversis materiis predicabilibus. Liber secundus. De dono pietatis, éd. J. BERLIOZ, Turnhout, 2015, Quintus titulus, secunde partis, capitulum XII).

${ }^{155}$ Nous rejoignons donc ici le schéma proposé dans L. KUCHENBUCH, « Die dreidimensionale Werk-Sprache des Theophilus presbyter», cit. n. 106, p. 400 (figure 19), ainsi que certaines observations de M. LAUWERS, «Le «travail » sans la domination?», cit. n. 17.
} 
DSM d'origine : aug (matrice de 13056 sur 13056). 30 éléments. STRUCTURE GLOBALE DU CHAMP SÉMANTIQUE

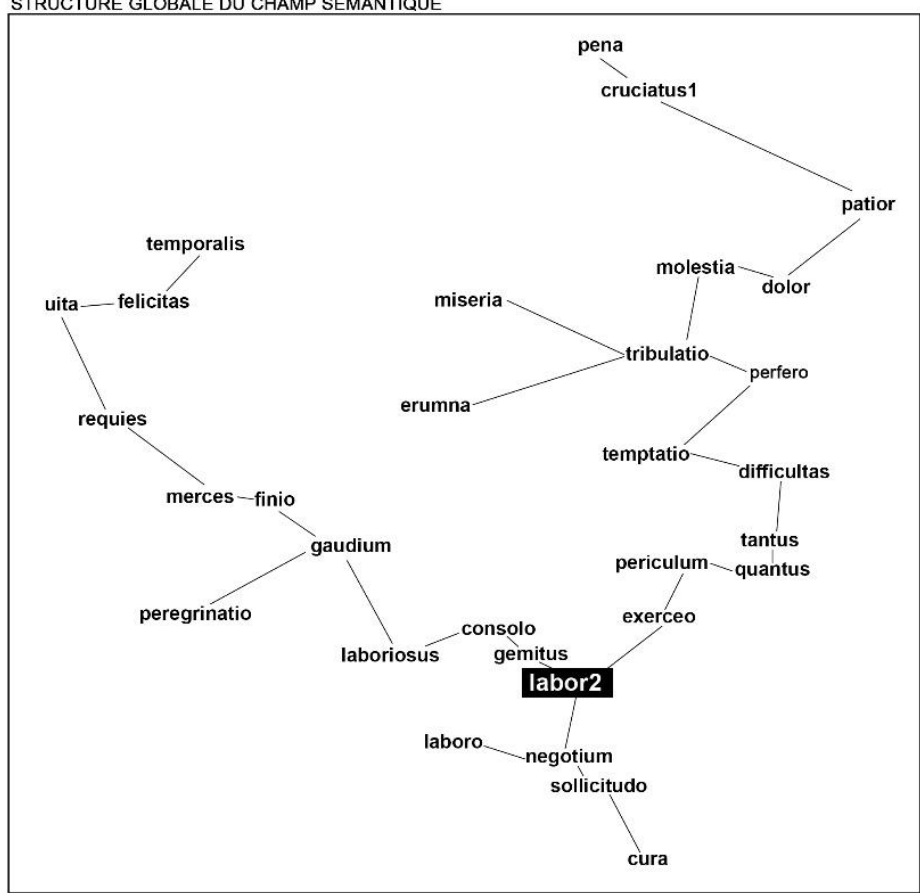

DSM d'origine : rab (matrice de 13973 sur 13973). 30 éléments. STRUCTURE GLOBALE DU CHAMP SEMANTILUE

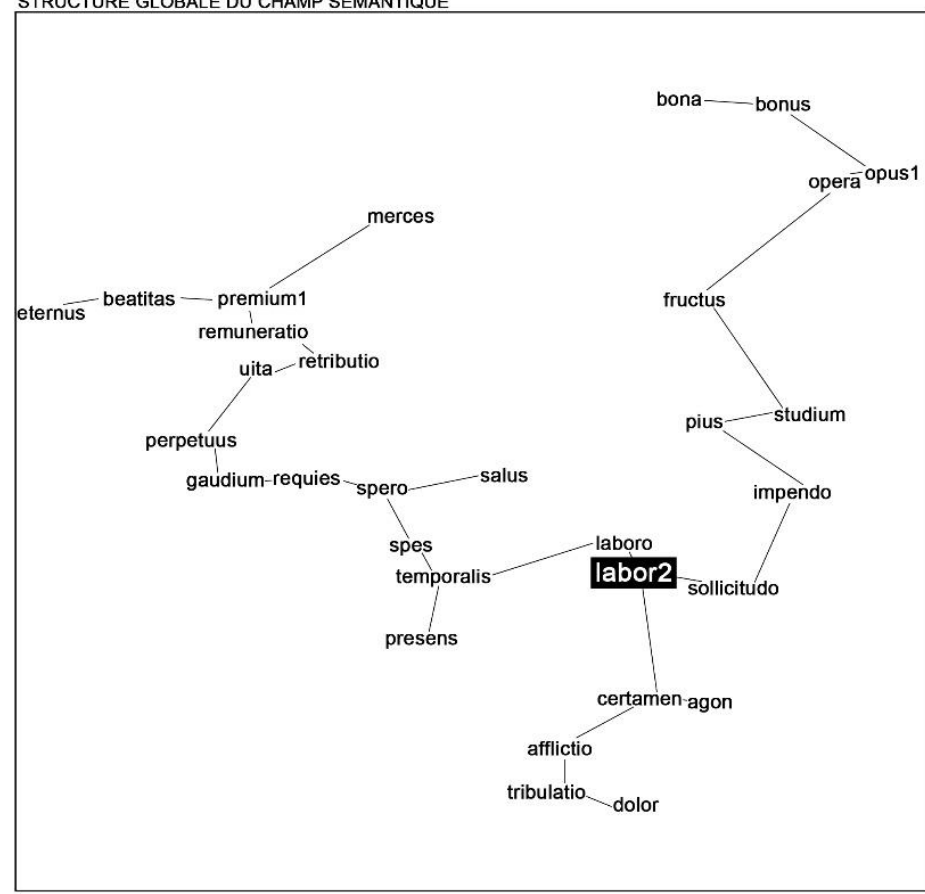

Fig. 10a et b : Champ sémantique de labor chez saint Augustin (à gauche) et Raban Maur (à gauche). $P L$, méthode WSDSM.

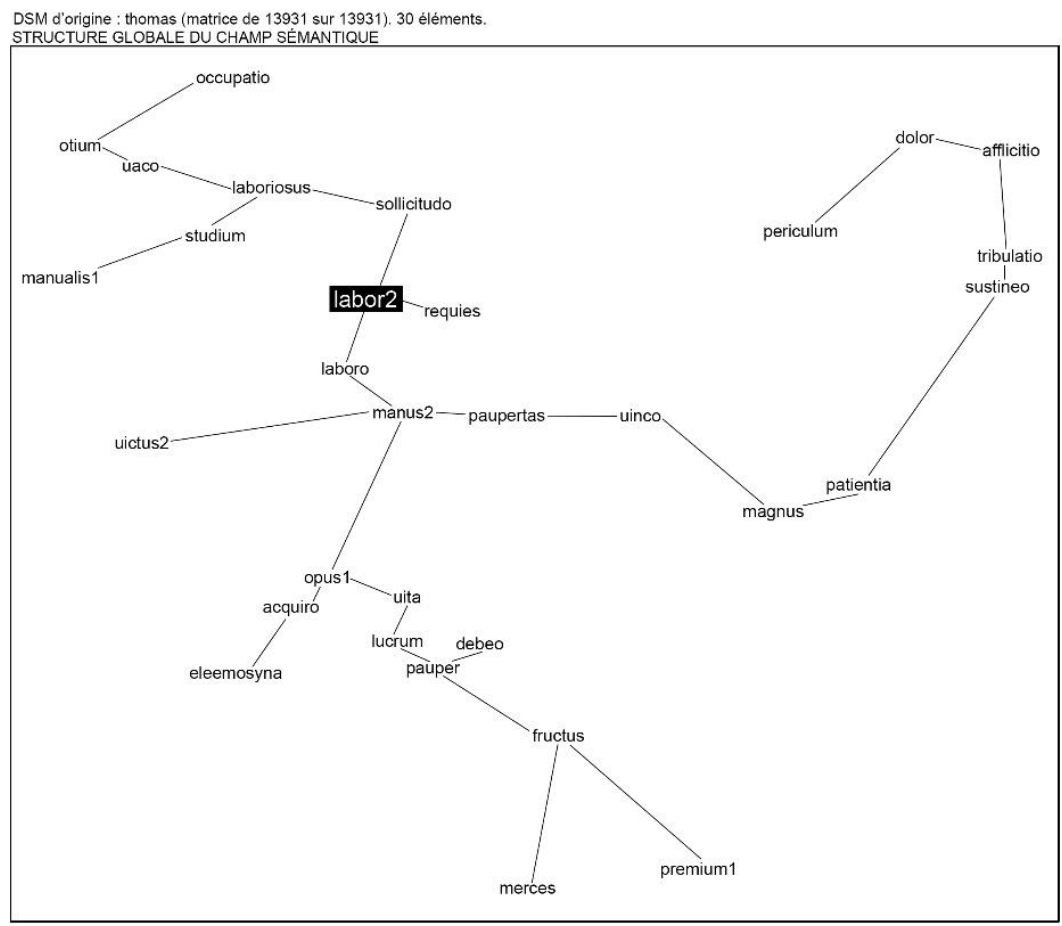

Fig. 11 : Champ sémantique de labor chez Thomas d'Aquin (Corpus Thomisticum, méthode WSDSM).

La comparaison des champs sémantiques autour de labor chez trois penseurs majeurs du système médiéval - Augustin, Raban Maur et Thomas d'Aquin - permet de saisir une partie 
des évolutions autour du lemme ${ }^{156}$. On note en premier lieu que le sens du champ autour de labor paraît plus univoque chez Augustin (fig. 10a), où il se scinde essentiellement en deux ensembles clairement articulés : d'une part (à gauche), la joie / le repos; d'autre part (à droite), la souffrance, qui prédomine. Chez Raban (fig. 10b), on relève l'existence de trois ensembles. La partie à gauche recouvre des éléments positifs : spes, spero, salus, gaudium, perpetuus (d'ailleurs articulé à d'autres éléments temporels : presens, temporalis, eternus), mais aussi retributio, remuneratio, merces, premium. Soit un ensemble relatif au salut, à la récompense éternelle. Il existe donc certaines formes de labor qui peuvent mener au salut, mais cette dimension n'est pas systématique. Il s'agit essentiellement des «pénibilités ecclésiales », liées à l'étude des textes et autres occupations positives (en particulier celles des saints, mais aussi les souffrances consenties pour la construction des édifices). En bas, on note un second ensemble, nettement plus limité que chez Augustin, consacré à la souffrance (dolor, afflictio, tribulatio, agon, etc.). À droite, on constate l'articulation avec opus et studium : bonus, bona, opera, mais aussi fructus, pius, etc. L'évolution est assez nette : si le «labeur » est toujours lié à la souffrance, il ouvre aussi potentiellement la voie au Salut et à la vie éternelle. Elle pourrait bien aussi s'expliquer par la vocation de ses textes : Raban, moine et abbé, pleinement inséré dans la logique monastique, n'écrit évidemment pas dans le même contexte qu'Augustin, ni pour le même public. Enfin, chez Thomas d'Aquin (fig. 11), les structures s'affirment encore : d'une part, en haut à gauche, labor s'articule désormais à la question du repos et de l'inaction : otium, vaco, occupatio, requies. En bas, la conséquence du labeur est aussi plus visible : il s'articule avec la pauvreté (paupertas, pauper), mais aussi les récompenses (fructus, merces, premium). En haut à droite, on remarque que la dimension douloureuse du labeur est plus nette qu'à l'époque carolingienne : une hausse que confirme l'examen global de la $P L$.

\subsection{Servir le Seigneur (servitium)}

Comme nous l'avons indiqué précédemment, servitium est quasiment le seul terme de notre liste initiale à connaître une évolution fréquentielle tranchée ${ }^{157}$. Ses mentions se développent fortement entre le milieu du XI ${ }^{\mathrm{e}}$ et le milieu du XIII ${ }^{\mathrm{e}}$ siècle dans les chartes. Dans la $P L$, elles suivent une tendance globalement ascendante dès le $\mathrm{v}^{\mathrm{e}}$ siècle (fig. 4 et $6{ }^{158}$. Ce développement sur le temps long, particulièrement net au Moyen Âge central, empêche de considérer que le lemme concerne spécifiquement la logique domaniale du haut Moyen Âge : il relève en fait de la logique seigneuriale dans son ensemble ${ }^{159}$. Presque absent de la Vulgate (les trois versets employant servitium ne sont par ailleurs presque jamais repris ou commentés

\footnotetext{
${ }^{156}$ Concernant labor chez Augustin, voir J.-M. SALAMITO, «Labor », dans C. MAYER (éd.), Augustinus-Lexikon, vol. 3, fasc. 5/6 : Institutio, institutum - Liber (libellus), Bâle, 2008, col. 888-892.

${ }^{157}$ Pour être plus clair : les autres termes connaissent des évolutions sémantiques, mais pas fréquentielles.

${ }^{158}$ Ce développement inégal peut s'expliquer soit par la rareté des chartes dans le très haut Moyen Ầge (qui masquerait potentiellement l'apparition et la diffusion progressive du terme dans ce type documentaire), soit par le passage d'un terme d'un type documentaire à l'autre, ici des textes théologiques et narratifs aux textes diplomatiques.

${ }^{159}$ Les travaux sur le servitium sont relativement rares, bien que le terme soit fréquemment mentionné. Voir cependant J. DEMADE, Ponction féodale et société rurale, cit. n. 20, p. 28 et sq. (chapitre 1) ; IDEM, «Les corvées en Haute-Allemagne, du rapport de production au symbole de domination (XI ${ }^{\mathrm{e}}-\mathrm{XIV}^{\mathrm{e}}$ siècles) », dans M. BOURIN et P. MARTineZ SoPena (dir.), Pour une anthropologie du prélèvement seigneurial dans les campagnes médiévales (XI ${ }^{e}$-XIVe siècles). Réalités et représentations paysannes, Paris, 2004, p.337-363; M. MouSNIER, « Jeux de mains, jeux de vilains. Hommage et fidélité servile dans le Languedoc médiéval (XII ${ }^{\mathrm{e}}$-XIII ${ }^{\mathrm{e}}$ siècles) », Histoire et Sociétés Rurales, 14, 2000, p. 11-54. On note du reste que seules les acceptions liées aux redevances rurales sont généralement considérées, alors que le terme possède d'autres sens forts, en particulier ceux liés à l'institution ecclésiale (cf. ci-dessous).
} 
par les auteurs médiévaux $)^{160}$, sa diffusion dans l'Europe médiévale est due à la nature même du rapport auquel il renvoie : le dominium ${ }^{161}$. Servitium désigne, en effet, à la fois le servicedépendance et la redevance ${ }^{162}$. Il est ainsi une conséquence de la relation de domination, et la condition de sa reproduction ${ }^{163}$. En aucun cas, cependant, il ne peut être considéré comme un «travail »: c'est une chose-action que l'on doit au seigneur (terrestre ou céleste), parce que celui-ci crée, engendre, protège comme un père ${ }^{164}$. Il peut prendre des formes très variables, bien connues des médiévistes, de la part en nature à une activité précise (corvées), en passant par des redevances en monnaies ${ }^{165}$. Dans les chartes, il est associé à census, reddo, solvo, debitum, debeo, etc. ${ }^{166}$ Mais la sémantique du lemme est plus vaste que la redevance au sens strict $^{167}$, puisque le servitium Dei désigne un office ecclésial (depuis la messe aux célébrations pour les défunts, en passant par le statut de l'officiant lui-même ${ }^{168}$ ) et plus généralement ce qui est lié au service de l'institution ${ }^{169}$. Le terme est ainsi articulé à ministerium et officium, qui apparaissent souvent dans ses cooccurrents (fig. 12) ${ }^{170}$. D'une certaine façon, on peut dire que servitium servait à désigner ce que nous nommons des fonctions, des « rôles » à accomplir ${ }^{171}$.

${ }^{160}$ veni nobis pacificus dominus et utere servitia nostra sicut placuerit tibi, en Iud 3:6; cumque eiecissent eos a se Aegyptii et cessasset plaga ab eis et iterum eos vellent capere et ad suum servitium revocare, en Iud 5:11; tamen obsecro ut adsumas tibi animalia sive servitia et vadas ad Gabelum in Rages Medorum reddasque ei chirografum suum et recipias ab eo pecuniam et roges eum venire ad nuptias meas, en Tob 9:3. Ces occurrences ne sont donc présentes que dans l'Ancien Testament. La situation est intéressante, car le lemme est peu fréquent chez les Pères mais ne cesse d'augmenter au cours du Moyen Âge. Il était toutefois plus fréquent dans l'Antiquité romaine que chez les Pères. Ce qui semble montrer que le terme a d'abord quasiment disparu, avant de revenir lentement, chargé d'un sens nouveau chez les Pères. Parallèlement, ces versets sont très peu employés ou commentés : dans la $P L$, nous n'avons pu relever que 7 mentions du verset Iud 5:11, 2 de Tob 9:3, et aucune de Iud 3:6. Autant dire que dans le cas spécifique de servitium, la Vulgate n'a joué quasiment aucun rôle sémantique.

${ }^{161}$ Le terme dominium désigne ici le concept proposé par Alain Guerreau en 1980, dans Le féodalisme, cit. n. 26, puis développé dans ses travaux ultérieurs, et non pas le le lemme médiolatin dominium, bien que celui-ci constitue aussi un cooccurrent fréquent de servitium dans les documents eux-même - sans que les deux observations (relation avec une théorie, rapport de cooccurrence) soient strictement équivalentes.

${ }^{162}$ Voir l'article copieux dans Glossarium mediae et infimae latinitatis, éd. DU CANGE et al., Niort, 1883-1887, t. 7, col. 448c ; ainsi que J. DEMADE, Ponction féodale et société rurale, cit. n. 20, p. 58 et sq.

${ }^{163}$ Reproduction qui ne peut advenir que si les dominés consentent (de gré ou de force) à donner ce servitium.

${ }^{164}$ Voir la belle remarque de Jacques Le Goff : « À l'instar de Job, le chrétien du premier Moyen Âge se sauve en s'anéantissant devant Dieu. Il se trouve élevé autant qu'il a paru abaissé. Il n'est pas un esclave, mais un serviteur : le 'serviteur souffrant' » (J. LE GoFF, À la recherche du Moyen Âge, Paris, 2003, p. 136).

${ }^{165}$ C'est toutefois plus rare.

166 On retrouve aussi certains de ces lemmes comme cooccurrents dans la $P L$ (voir la fig. 12).

167 Voir les riches éléments donnés par J. DEMADE, Ponction féodale et société rurale, cit. n. 20, p. $52-58$.

${ }^{168}$ Parmi les cooccurrents significatifs dans les textes théologiques, on note par exemple cultus, devotus, officium, etc. Dans le corpus des règles monastiques présent dans la $P L$, les cooccurrents les plus significatifs de servitium sont deus, divinus et ecclesia. On aurait donc bien tort de penser d'une part que le servitium relève du travail, d'autre part qu'il concerne uniquement des redevances.

${ }^{169}$ Par exemple vers le milieu du $\mathrm{X}^{\mathrm{e}}$ siècle à Savigny, un don de soi à l'institution : Ego, in Dei nomine, Guidrannus sacerdos, tradens me in servitium Dei omnipotentis et beati Martini in cœnobio qui vocatur Saviniacus, omnes res juris mei trado atque cedo ad ipsam casam Dei (Cartulaire de l'abbaye de Savigny suivi du petit cartulaire de l'abbaye d'Ainay, éd. A. BERNARD, Paris, 1853, n 123).

${ }^{170}$ Voir de nouveau G. AgAmBen, Homo Sacer. II, 5, Opus Dei, cit. n. 15, chap. 3 « Généalogie de l'officium ». Isabelle Rosé, dans le présent volume, évoque certains des liens entre ces différents termes. Pierre MichaudQuantin avait déjà repéré que ministerium comme officium concernaient tous deux des « fonctions », en fait des actions à accomplir : « [Ministerium] évoque l'idée d'une activité exercée en dépendance d'un supérieur comme dans un couple fréquent ministerium-auctoritas, qui est presque homologue au rapport de cause instrumentale ou seconde et cause principale [...]. Quant à officium, son acception d'ensemble correspond assez bien à l'un des sens de « office », une fonction, un rôle à remplir [...]. Ils sont l'un et l'autre synonymes dans le cadre des organisations monastiques » (P. MiCHAUD-QUANTIN, Universitas. Expressions du mouvement communautaire dans le Moyen Âge latin, Paris, 1970, p. 171).

${ }^{171}$ Voir à ce sujet les remarques de Julien Demade sur la necessitas du seigneur, dans J. DEMADE, «Les corvées en Haute-Allemagne », cit. n. 159. 


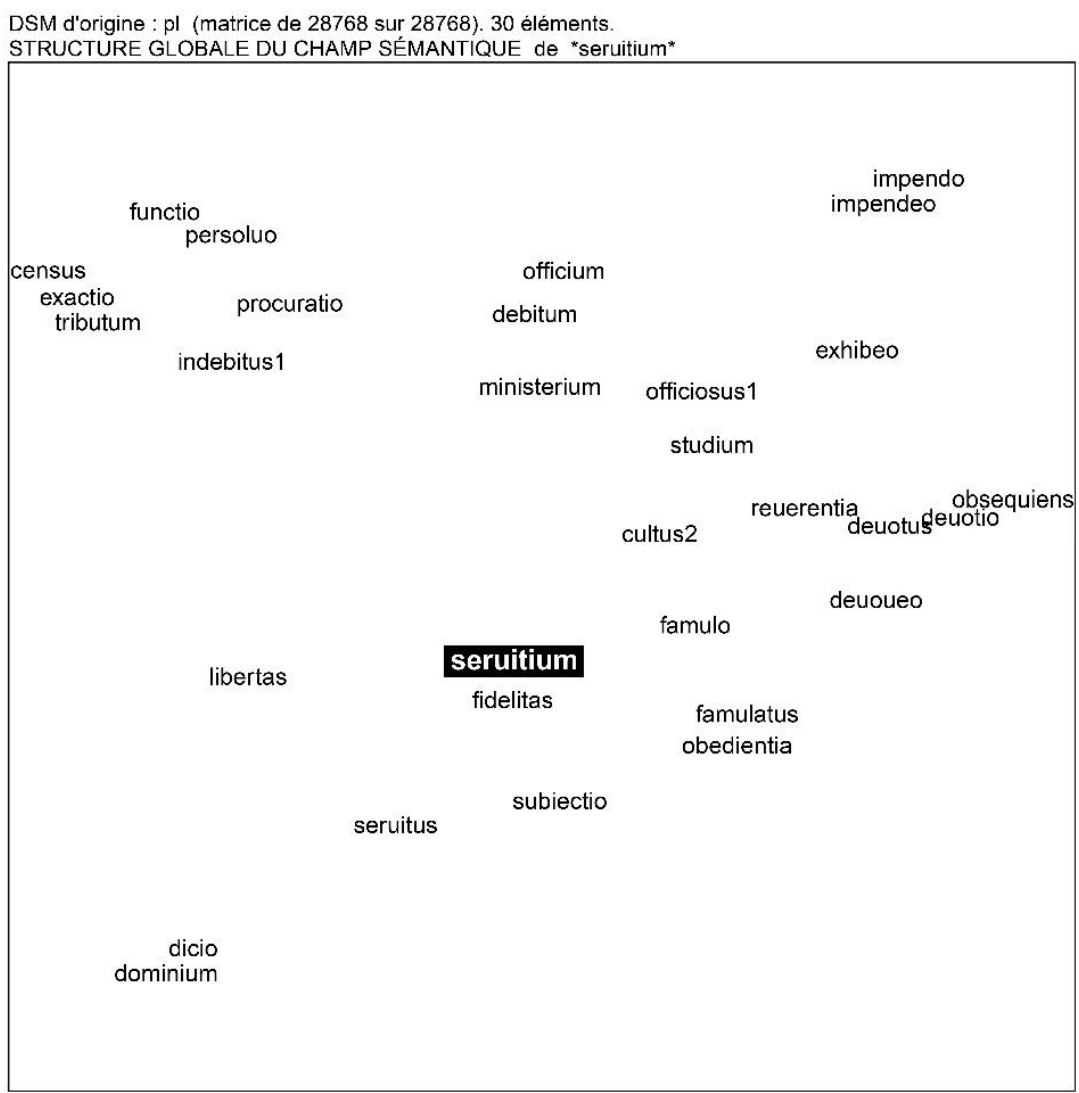

Fig. 12 : Champ sémantique de labor dans l'ensemble de la $P L$ (méthode WSDSM).

En même temps, il apparaît que servitium est un terme fortement lié aux relations sociales au sens large, puisque parmi ses cooccurrents significatifs apparaissent des termes comme hominaticus, fidelitas, hereditas, honor/honorifice, libertas, etc. Il constitue donc un élément de la relation seigneuriale, et plus globalement des règles qui régissent cette dernière. Servitium est ainsi articulé aux «coutumes", consuetudo faisant aussi partie de ses cooccurrents significatifs dans les CEMA ${ }^{172}$. D'une certaine façon, le servitium est la contrainte qu'impliquent ces relations de dépendances seigneuriales. De la même façon que servus forme une paire analogique (fondamentale) avec dominus, en relation étroite avec les couples homoldominus, homo/deus et filius/pater ${ }^{173}$, on pourrait se demander si servitium ne formait pas une paire propre avec dominium ${ }^{174}$.

Comme dans le cas d'opus, servitium désigne donc à la fois des activités et des choses ${ }^{175}$, considérées cette fois sous la forme de redevances : une relation qui ne peut être que polarisée

\footnotetext{
${ }^{172}$ Plus de 2247 cooccurrences à plus ou moins 5 mots. Par exemple : esset omnino libera et quieta et sicut iam dictum est ab omnibus consuetudinibus et serviciis suis heredum que suorum absoluta, en 1074 dans un diplôme de Guillaume I ${ }^{\mathrm{er}} \mathrm{d}$ 'Angleterre pour l'abbaye Saint-Étienne de Fontenay-le-Marmion, dans Regesta Regum AngloNormannorum, the Acta of William I (1066-1087), éd. D. BATES, Oxford, 1998, n 149 . Cette association semble particulièrement fréquente dans les actes anglo-normands.

${ }^{173}$ Sur les liens entre le couple filius/pater et le dominium, nous nous permettons de renvoyer à N. PERREAUX, «In nomine patris », cit. n. 46.

${ }^{174}$ Le terme désigne ici le lemme médiolatin rencontré dans les documents.

${ }^{175}$ Mêmes observations chez J. DEMADE, Ponction féodale et société rurale, cit. n. 20, p. 46 et 50 : « La première remarque à faire, essentielle, est que servitium et servire désignent non pas un type particulier de prélèvement, qui serait « les corvées », mais la relation de prélèvement même, et donc incluent toutes les formes particulières de prélèvement. [...] Néanmoins, les seules caractéristiques du procès productif céréalier ne peuvent suffire à rendre
} 
(on doit quelque chose à quelqu'un, et cette relation manifeste le dominium - au sens abstrait). Le servitium est en effet toujours dû à un ou plusieurs seigneurs. Il ne désigne donc jamais une production-marchandise qui pourrait circuler librement, s'échanger, permuter ${ }^{176}$, et complète l'idée que le servitium ne peut en aucun cas être considéré comme une «valeur interchangeable », du moins du point de vue du dominé. Toutefois, servitium et opus ne paraissent pas intervenir dans des contextes similaires ${ }^{177}$. Contrairement à ce dernier, servitium ne désigne pas principalement la résultante des actions (ce qui est l'idée prédominante dans opus), un putatif «produit», mais suppose l'action/la relation elle-même. Il ne s'agit par d'arriver à une création, mais de fournir, de produire, d'agir. La fragmentation de ce que nous appelons « le travail » est donc là encore très patente : alors qu'opus désigne essentiellement ce qui a été fait (bien que le processus soit inclus dans ce résultat), servitium se focalise sur le processus lui-même : le service, l'action, la relation - et donc la relation de domination, autrement dit le rapport de production lui-même ${ }^{178}$.

Ainsi, à l'instar de labor, servitium est fortement lié aux temporalités et plus spécifiquement aux rythmes ${ }^{179}$. C'est une évidence dans les chartes, où la redevance est articulée à différents éléments du calendrier, et revient selon des cycles plus ou moins complexes (la redevance peut d'ailleurs être temporaire ou «perpétuelle ${ }^{180}$ ). Alors que labor apparait essentiellement comme un état, un moment ponctuel, donc une chose transitoire, le servitium n'est pas isolé : il revient, retourne et s'inscrit ainsi dans le rythme chrétien et seigneurial. C'est aussi un point de divergence avec opus, qui se focalise sur la réalisation et sa stabilité. Servitium est moins marqué par la logique charnelle que labor, puisqu'il n'est pas un état de souffrance au sens strict, mais plutôt un rapport, une relation établie par l'existence de la domination.

\section{En guise de conclusion}

Pouvons-nous en rester là ? On aurait raison de faire remarquer que l'objectif de cette contribution était difficilement tenable, d'abord parce qu'il était triple : a) montrer que le travail au sens contemporain ne pouvait structurellement exister dans l'Europe médiévale, sauf si l'on considère que toute activité humaine organisée constitue un travail ; b) tenter de saisir l'articulation des principaux termes médiolatins habituellement traduits par (ou considérés comme relevant $d u$ ) «travail », en montrant à la fois les passerelles entre ces termes et les nombreuses apories que leur constitution en liste génère ; c) décaler la question, en insistant sur l'impératif que constitue la reconstruction des rapports de production et de domination dans l'Europe médiévale - rapports qui entretenaient des liens complexes et en partie indirects avec les termes médiolatins ${ }^{181}$.

\footnotetext{
compte de la structuration spécifique de la perception, en l'occurrence non pas seulement l'absence de la catégorie distincte du produire, mais la subsomption et du produire et du produit dans la catégorie de servitium ».

${ }^{176}$ Cf. les travaux de Julien Demade, déjà mentionnés.

${ }^{177}$ Le fameux opus servile, souvent mentionné par l'historiographie, est rare voire extrêmement rare dans les documents : le syntagme n'apparaît que 37 fois dans l'ensemble des CEMA (dans $75 \%$ des cas au XII ${ }^{\mathrm{e}}$ siècle, en particulier en Angleterre et Normandie) et 252 fois dans la $P L$.

${ }^{178}$ Entendu à la fois comme rapport de production et/ou de reproduction, puisque le terme désigne aussi bien les redevances que la messe.

179 J.-C. SCHMITT, Les rythmes au Moyen Âge, Paris, 2016, p. 558-563.

${ }^{180}$ Perpetuus, festa tout comme annulatier font partie des cooccurrents centraux de servitium dans les CEMA.

181 Car les décalages entre les rapports de production et le système de représentations (euphémisations, déplacements, déformations, invisibilisations) sont une composante fondamentale de la dynamique des systèmes sociaux : cf. L. ATHUSSER, «Sur le «Contrat social »», Cahiers pour l'Analyse, 8:1, 1967, p. 5-42.
} 
C'est sur le premier point que notre analyse est probablement la plus limitée. Mais fautil vraiment aller plus loin? Nous avons pu montrer que l'Europe médiévale n'avait pas connu, au moins jusqu' au XIII ${ }^{\mathrm{e}}$ siècle et probablement au-delà, une catégorie unifiée de « travailleurs ». $\mathrm{Ni}$ laborator, ni operarius ne sont des termes très répandus dans les presque 200 millions de mots examinés ${ }^{182}$. À l'inverse, nous avons mentionné la multiplicité des noms de métiers, bien connue de l'historiographie, qui invite à penser que les activités étaient considérées individuellement, discrètement, chacune possédant des spécificités propres. Le phénomène apparaît comme relativement cohérent, puisque le système de l'Europe médiévale fonctionnait sur la base de la fixation-polarisation, et que la constitution d'une «classe de travailleurs » aurait permis des circulations et des permutations systématiques déstabilisantes, et pour tout dire ingérables pour la classe dominante ${ }^{183}$. Le travail contemporain est par ailleurs indissociable des notions de «valeur » et de «Marché » ${ }^{184}$. L'apparition dans les années 1880 du syntagme «marché du travail », dont le développement s'accélère à partir des années 1960, constitue d'ailleurs une étape supplémentaire dans la fusion-articulation de ces différents éléments ${ }^{185}$. On pourrait aussi faire observer que d'autres termes fondamentaux pour la conception du travail en général étaient tout aussi absents du système médiéval, du moins dans leurs sens contemporains : production, produit, marchandise, outil, etc. Dans ces conditions, comment maintenir la possibilité de l'existence du travail pour la période qui nous intéresse ?

La seconde partie de l'article a été consacrée aux lemmes historiographiquement considérés comme relevant du «travail ». Or, nous avons vu qu'il était extrêmement difficile, pour ne pas dire impossible, de déceler une structure cohérente en partant de ce présupposé. Tout d'abord fréquentiellement: d'une typologie documentaire à l'autre, certains termes stagnent (en particulier dans la $P L$ ), tandis que d'autres évoluent fortement (en particulier dans les CEMA). Au sein de ce dernier corpus même, les tendances chronologiques des différents termes ne paraissent pas corrélables. Malgré cela, nous avons relevé plusieurs éléments cohérents dans nos observations : la dynamique de servitium, qui passe du statut de terme rare au domaine du vocabulaire courant entre le $\mathrm{V}^{\mathrm{e}}$ et le $\mathrm{XIII}^{\mathrm{e}}$ siècle, tant dans les CEMA que la $P L$ (mais plus spécifiquement aux $\mathrm{XI}^{\mathrm{e}}-\mathrm{XIII}{ }^{\mathrm{e}}$ siècles dans les chartes). Parallèlement, opus et labor possèdent quelques caractères fréquentiels communs, en particulier leur stabilité dans la $P L-$ même si le premier est nettement plus courant que le second. Une autre observation importante est l'évolution d'opus lors du passage au système chrétien, qui nous a semblé constituer le mouvement central au sein de ce lexique plutôt hétérogène. La promotion d'opus dans la

\footnotetext{
${ }^{182}$ Encore une fois, leur rôle dans les registres des XIV e $-\mathrm{XVI}^{\mathrm{e}}$ siècles resterait à examiner systématiquement, à l'aide de méthodes similaires.

${ }^{183}$ Le terme important est ici «systématiques »: on est bien conscient qu'un certain nombre de personnes effectuait différents métiers, simultanément ou au cours de leur existence. Simplement, l'idée d'un « marché du travail » ne pouvait à notre sens exister, ni même celle d'un « code du travail » régulant toutes les professions à la fois. Un des mécanismes de ce blocage structurel résidait à notre sens dans l'existence de règlements propres aux différentes zones/villes du système, multiplicité qui empêchait de facto de nombreuses permutations (et d'abord car la circulation était elle-même encadrée et ritualisée). Sur la diversité (typologique, chronologique, géographique) des « règlements » des mestiers, voir de nouveau F. RIVIERE, Travail et métiers en Normandie à la fin du Moyen Âge, cit. n. 73, p. 568-571 et 574-576, qui insiste à la suite de Jean-Pierre Sosson sur l'impact du contexte local dans la mise par écrit inégale et la variabilité des règlements. Ainsi, on pourrait voir une homologie entre ces règlements fluides mais néanmoins localement contraignants, qui inscrivaient les personnes dans un maillage complexe, et l'organisation spatiale de l'Europe médiévale, à la fois polarisée et enchevrêtée.

${ }^{184}$ A. GUERrEAU, «Avant le marché, les marchés », cit. n. 14 ; C. VERNA, L'industrie au village. Essai de microhistoire (Arles-sur-Tech, XIV et XV siècles), Paris, 2017, troisième partie (où elle observe la multiplicité des marchés).

${ }^{185}$ En 2018, nous avions pu montrer que l'apparition du terme ressource dans son sens contemporain, et surtout le développement des formes aux pluriels (les ressources, qui sont d'abord « naturelles » puis « humaines » au $\mathrm{XX}^{\mathrm{e}}$ siècle, avant la généralisation définitive du concept) était lié au basculement économiste du XVII ${ }^{\mathrm{e}}$-XVIII ${ }^{\mathrm{e}}$ siècle : D. HAUSMANN et N. PERREAUX, « Resources. A Historical and Conceptual History », cit. n. 11.
} 
Vulgate, en particulier dans le Nouveau Testament, et plus généralement chez les Pères, constitue une évolution profonde, probablement corrélée à l'évolution des rapports de production au sens large. La création était définie comme opus Dei : ce syntagme désigna par la suite différentes actions valorisées, en particulier liturgiques. Sémantiquement, il est délicat, mais pas impossible, d'articuler les trois termes (opus, labor, servitium) : ils relèvent en fait de logiques différentes ou, mieux, décalées.

\begin{tabular}{|l|l|l|l|}
\hline \multicolumn{1}{|l|}{ labor } & servitium & opus \\
\hline action-résultat & action & $\begin{array}{l}\text { action (fréquent) - résultat } \\
\text { (plus rare) }\end{array}$ & $\begin{array}{l}\text { fusion action-résulat, avec } \\
\text { insistance sur le résultat }\end{array}$ \\
\hline charnel-spirituel & plutôt charnel & neutre & plutôt spirituel \\
\hline organisation spatiale & non & polarisé & polarisant \\
\hline temporalités & siècle & cycles & éternité \\
\hline
\end{tabular}

Fig. 13 : Labor, servitium, opus : tableau de synthèse sémantique. Nous indiquons les tendances majoritaires, afin de souligner les contrastes-articulations entre les termes.

Labor désigne un état transitoire de souffrance, et pour tout dire, charnel. Certaines actions l'impliquent, mais le labor n'est pas une condition de leur bonne exécution : la souffrance n'est pas nécessaire à la réalisation, elle est une conséquence de certaines activités, conséquence mondaine liée à la Chute. Fortement ancré dans le siècle, le labor est peu polarisant. Quant au servitium, il est cyclique, désignant des redevances, actions, fonctions itératives, qui reviennent sans cesse pour manifester le statut des uns et des autres, et ainsi reproduire la domination ${ }^{186}$. Le servitium n'est pas fixe au sens strict, puisqu'il est rythmé, mais il polarise tout de même, puisqu'il est dirigé vers le S/seigneur. Officium et beneficium nous paraissent aussi s'insérer dans ce cadre. Opus désigne simultanément un processus et une réalisation, dans lequel prédomine cette dernière, qui seule subsiste en bout de chaîne. Sa stabilité et les valences positives associées au terme font qu'opus est un lemme éminemment spirituel. L'« œuvre » est souvent réalisée pour l'Église et pour la spiritualisation du monde. Fondamentalement, opus fixe et polarise : on œuvre pour quelque chose, le plus souvent pour le Salut des âmes, pour l'Église. Ars, opifex et d'autres termes encore relèvent des techniques, des savoir-faire, et renvoient plutôt à l'opus - sans être parfaitement articulés avec ce dernier.

Ainsi, s'il existe des liens entre les trois termes labor, servitium, opus, il faut sans doute les chercher dans leur rapport au couple charnel/spirituel, aux temporalités et aux modes d'organisation socio-spatiale (eux-mêmes liés au couple charnel/spirituel). Mais ces liens ne sont jamais explicitement posés dans les textes et le schéma que l'on propose manifeste un certain degré d'abstraction structurale. L'Europe médiévale dans son entièreté était polarisée ${ }^{187}$, encadrée par l'idéal spirituel de la caritas, dont les relais matériels allaient des églises aux cimetières, en passant par les autels et les reliques. Avec opus, toutes les œuvres avaient une destination précise, et ne pouvaient être affectées selon le bon vouloir des acteurs. Le labor constituait au contraire un état transitoire, un état de souffrance et de peine, qui rappelait l'instabilité du monde, parce que celui-ci était situé dans le temps. Il formait une paire

\footnotetext{
${ }^{186}$ L. KUCHENBUCH, J. MORSEL et D. SCHELER, «La construction processionnelle de l'espace communautaire », dans D. Boisseuil, P. CHASTANG, L. Feller et J. MORSEL (dir.), Écritures de l'espace social : mélanges d'histoire médiévale offerts à Monique Bourin, Paris, 2010, p. 139-182.

${ }^{187}$ A. GUERREAU, «Quelques caractères spécifiques de l'espace féodal européen », dans N. BULST, R. DESCIMON et A. Guerreau (dir.), L'État ou le Roi. Les fondations de la modernité monarchique en France (XIV $-X V I^{e}$ siècles), Paris, 1996, p. 85-101 ; IDEM, « Le champ sémantique de l'espace dans la vita de Saint Maieul (Cluny, début du XI' siècle) », Journal des savants, vol. 2, 1997, p. 363-419.
} 
conceptuelle opposable avec la paix, la stabilité, la tranquillité (qui n'était pas pour autant assimilée à l'inactivité). Le labor pouvait ainsi entraîner un mouvement, un déplacement, dans les différents sens de ces termes, à l'inverse d'opus, qui était conçu comme quelque chose de stable et de durable : une « œuvre » et le plus souvent une «bonne œuvre » (quelques bona opera: Création divine, rites ecclésiaux, mais aussi constructions de bâtiments ecclésiaux, réalisations de manuscrits ou de sculptures, dons, etc.). Certes, opus et labor pouvaient parfois être associés, le second terme désignant alors les aspects négatifs des activités - mais jamais la messe n'aurait pu être qualifiée de labor, car ce mot impliquait souvent une dimension charnelle, par exemple à travers le corps ou la reproduction sexuée. Le servitium s'intégrait quant à lui pleinement à la logique du dominium. Sa racine même renvoyait à la domination : il s'agissait d'accomplir une fonction, de servir un S/seigneur, de rendre une redevance. Mais ce service pouvait se manifester de façon très variable. Chez les clercs, il correspondait tout simplement à la célébration des rites, et donc à la reproduction spirituelle du système (la messe, le baptême, les services pour les morts). Chez les laïcs, il équivalait à des redevances qui pouvaient prendre les formes variées que l'on sait.

Nous pensons donc que cette quasi-absence de liens directs, explicites, est une conséquence logique du rapport de production médiéval : l'articulation des trois notions, leur fusion dans un concept anachronique de «travail », aurait démembré la relation de dominium, fondamentalement liée à la fixation, à la polarisation, et donc aux rapports spatio-temporels proprement médiévaux. Parallèlement, la non-articulation de ces éléments rendait quasiment impossible l'existence et la capacité même à penser ce que nous appelons le «travail ». Dans notre système, cette activité organisée, fortement encadrée, est structurellement reliée à sa résultante-marchandise, mais sans qu'il y ait de confusion entre les deux pôles. C'est cette absence de fusion qui permet la circulation de la marchandise, l'existence d'un surproduit, la création d'une « valeur d'échange » ${ }^{188}$, et in fine d'un « Marché »-ce dernier étant par essence libre, non-polarisé. Dans notre système contemporain, la peine du travailleur se voit associée à une échelle, une «valeur », qui rend possible l'existence d'un «salariat » systématique. Dans l'Europe médiévale, la souffrance du labor paraît le plus souvent exclue de la pensée de la réalisation, tandis qu'opus semble à l'inverse exclure l'idée de la pénibilité. Opus rendait par ailleurs impossible la dissociation entre ce que nous appelons « produire » et «produit », tandis que le labor effaçait complètement le « produit » même. L'opus par excellence était la Création divine, réitérée par la liturgie. Celle-ci n'avait impliqué que peu d'actions (essentiellement des « divisions ») et certainement aucune peine ${ }^{189}$ : elle émanait du Verbe. Il en résultait sans doute une euphémisation de la peine, peine qui n'était pas nécessaire stricto sensu aux réalisations les plus positives du système de l'Europe médiévale (Création, messes, bâtiments, réalisations spirituelles, etc. ${ }^{190}$. Nos analyses ont par ailleurs montré que la valence spirituelle d'opus n'a cessé de croître, valorisant au fil des siècles les créations qui étaient rangées sous ce lemme. En opposition, le labor ne conduisait que rarement à une réalisation précise : corollaire de la condition humaine après la Chute, le labor pouvait certes participer au cheminement vers le Salut. Mais ce cheminement n'était ni direct, ni univoque. L'absence de concept de « travailleur » au moins jusqu'au XIII ${ }^{\mathrm{e}}$ siècle, voire au-delà, ne fait que confirmer l'absence de

\footnotetext{
188 Donc d'une « valeur d'usage ».

${ }^{189}$ Labor n'est pas mentionné dans Gen. 1, où se trouve décrite la création. Le lemme n'apparaît qu'avec la Chute, précisément dans le verset où la conséquence du péché originel est énoncée : ad Adam vero dixit quia audisti vocem uxoris tuae et comedisti de ligno ex quo praeceperam tibi ne comederes maledicta terra in opere tuo in laboribus comedes eam cunctis diebus vitae tuae, Gen. 3:17. Dieu s'arrête (requiesco) certes le septième jour (conplevitque Deus die septimo opus suum quod fecerat et requievit die septimo ab universo opere quod patrarat, Gen. 2:2), mais cet arrêt, ce repos, constitue une pause et non pas l'expression d'une putative fatigue.

${ }^{190}$ Rappelons une dernière fois qu'opus est surreprésenté dans les textes théologiques, où il n'est pas question de «s'activer».
} 
cette structure fondamentale pour notre société : le travail ${ }^{191}$. Nous ne disons pas que cette absence d'articulation était volontaire, simplement qu'elle était conditionnée par le système de pensée et de production de l'Europe médiévale. Ces multiples spécificités rendaient de facto impossible la création d'un surtravail et l'injection de celui-ci au sein d'un improbable «Marché ». Autrement dit, si certains éléments de ce que nous appelons le «travail » étaient bien présents dans les termes que nous avons analysés, ils y étaient 1) désarticulées, mais aussi beaucoup plus variés et hétérogènes ; 2) impossibles à réarticuler sans détruire la logique du dominium ; 3) non-articulées aux organes et concepts centraux du capitalisme ("le Marché », « la valeur », « le surtravail », « les travailleurs », etc.), qui fondent la cohérence de ce dernier.

Les analyses sémantiques proposées plaident ainsi pour une dissociation du lexique médiéval d'avec notre «travail », tout en ouvrant à d'autres réflexions. Nous n'y revenons pas ici. Mais il s'agirait évidemment d'aller plus loin : l'examen des termes retenus, en partie arbitrairement, montre qu'ils s'intercalaient à différents niveaux du système de représentations médiéval, sans nécessairement former un tout. À quel niveau faudrait-il alors se situer pour reconstruire les rapports de production médiévaux? Nous pensons que les deux concepts proposés et articulés par Alain Guerreau, le dominium et l'ecclesia, forment l'ensemble abstrait élémentaire pour comprendre ces relations - d'une part parce que le premier (dominium) constituait le mode de production lui-même, d'où découlait toute la logique des actions médiévales; d'autre part parce que le second concept (l'ecclesia) désignait la principale institution garante et promotrice de ce mode de production ${ }^{192}$. Ainsi, si l'étude des termes retenus (opus, opero, labor, laboro, servitium, ars, opifex, fabrica, ministerium, etc.) doit certainement être poursuivie (nous n'en avons ici dressé qu'une ébauche ${ }^{193}$ ), c'est probablement hors de toute réflexion sur le «travail » au sens contemporain. C'est à ce prix que l'on pourra mettre à jour leurs structures sémantiques, à la fois individuelles et collectives - œuvrer, servir, souffrir, ou plutôt : œuvre, service, souffrance -, et la contribution de celles-ci à la logique d'ensemble du système de l'Europe médiévale.

\footnotetext{
${ }^{191}$ Nous avons cependant noté que les valences de labor évoluaient au fil des siècles : très négatif chez les Pères, il semble que le lemme ait progressivement connu une revalorisation dans certains contextes. Il serait sans doute trop rapide (et certainement téléologique) de faire de cette évolution une des tendances liées à l'évolutions des activités et à la perception des métiers dans l'Europe médiévale, en particulier dans le contexte urbain des XII ${ }^{\mathrm{e}}$ XIII ${ }^{\mathrm{e}}$ siècles. Mais il s'agirait d'une piste à suivre.

192 A. GUERREAU, Le féodalisme, cit. n. 26, et ses travaux ultérieurs sur la question.

${ }^{193}$ L'étude des verbes, en particulier, paraît fondamentale.
} 